NBER WORKING PAPER SERIES

\title{
EDUCATION AND CONSANGUINEOUS MARRIAGE
}

\author{
Ş. Pelin Akyol \\ Naci H. Mocan \\ Working Paper 28212 \\ http://www.nber.org/papers/w28212 \\ NATIONAL BUREAU OF ECONOMIC RESEARCH \\ 1050 Massachusetts Avenue \\ Cambridge, MA 02138 \\ December 2020, Revised June 2021
}

We thank Lena Edlund, Jonathan Schulz, Noam Yuchtman, Murat K rdar, Anastasia Litina, Cagla Okten, Gunes Gokmen, Leyla Mocan, James Fenske, Jared Rubin, Munir Squires, JeanPaul Carvalho, Pauline Grosjean and the participants of the 2020 ASREC 24-Hour Virtual Conference helpful comments. Thao Bui provided excellent research assistance. The views expressed herein are those of the authors and do not necessarily reflect the views of the National Bureau of Economic Research.

NBER working papers are circulated for discussion and comment purposes. They have not been peer-reviewed or been subject to the review by the NBER Board of Directors that accompanies official NBER publications.

(C) 2020 by Ş. Pelin Akyol and Naci H. Mocan. All rights reserved. Short sections of text, not to exceed two paragraphs, may be quoted without explicit permission provided that full credit, including (C) notice, is given to the source. 
Education and Consanguineous Marriage

Ş. Pelin Akyol and Naci H. Mocan

NBER Working Paper No. 28212

December 2020, Revised June 2021

JEL No. I15,I18,I20,J10,Z1

\begin{abstract}
$\underline{\text { ABSTRACT }}$
At least one of every five marriages is consanguineous (between couples who are second cousins or closer) in the Middle East and North Africa, and the rate is higher than 50 percent in some parts of the world. Consanguineous marriage generates serious health problems for the offspring and constitutes an economic problem with its associated medical costs and the impact on human capital. The prevalence of consanguineous marriage and the resultant kinship networks can shape various dimensions of the society ranging from institutional structure to attitudes such as trust, individualism, and nepotism. Using data from Turkey and leveraging an education reform which increased mandatory schooling by three years, we find that the reform made women less likely to find consanguineous marriage as an acceptable practice, and that the reform reduced women's propensity to marry a first cousin or a blood relative. Exposure to the reform altered women's preferences in favor of personal autonomy. Women who are exposed to the reform are more likely to have met their husbands outside of family networks, they are less likely to get forced into marriage against their consent, and they are less likely to agree that only a son can ensure the continuation of the family blood line. These results indicate that educational attainment can alter behaviors and attitudes which may be rooted in culture.
\end{abstract}

\author{
Ş. Pelin Akyol \\ Bilkent University \\ Department of Economics \\ 06800 Ankara / TURKEY \\ pelina@bilkent.edu.tr \\ Naci H. Mocan \\ Department of Economics \\ Louisiana State University \\ 2439 BEC \\ Baton Rouge, LA 70803-6306 \\ and NBER \\ mocan@1su.edu
}




\section{Education and Consanguineous Marriage}

\section{Introduction}

It has been estimated that more than 10 percent of the world's population is related as second cousins or closer (Bittles and Black 2010), and that more than one billion people in North Africa, the Middle East and parts of Asia live in areas where at least 20 percent of marriages are consanguineous, which is defined as a union between couples who are second cousins or closer (Romeo and Bittles 2014). ${ }^{1}$ The rate of consanguineous marriage is as high as 50 percent in some regions of the world (Hamamy et al. 2011, Tadmouri et al. 2009). As we describe in Section II, the underlying cultural and religious factors are likely dominant forces that determine the prevalence of consanguineous marriage in a country, although the change in this prevalence over time and across regions within a country suggests that other factors, including economic ones, are important as well.

Using data from Turkey, where 20 percent of marriages are consanguineous, we investigate the impact of education on individuals' propensity to marry their first cousins and to marry blood relatives, as well as education's influence on people's tendency to approve such marriages. We leverage a Turkish education reform which went into effect in 1997. For political reasons, the reform was implemented very quickly and rather unexpectedly, and it increased the mandatory years of education from 5 to 8 years. Students who had completed the fifth grade in the Summer of 1997 have been exempted from the mandate of the reform, while younger cohorts were required to complete at least eight years of schooling. Using a nationally-representative micro data set, which contains detailed information on marriage characteristics, marital preferences and educational attainment, we confirm the well-documented finding that the reform had a significant impact on educational attainment.

Our results show that the reform made women less likely to find consanguineous marriage as an acceptable practice, and that the reform reduced women's propensity to marry a first cousin or a blood relative. These behavioral changes are related to changes in women's preferences and to a rise in the extent of women's self-determination. For example, we demonstrate that women

\footnotetext{
${ }^{1}$ The word consanguinity is derived from the Latin words of con (common, or the same) and sanguineus (blood).
} 
who were exposed to the education reform are less likely to be in an arranged marriage, and that they are less likely to have met their husbands through networks of their family, relatives or neighbors. Importantly, we provide evidence that the reform reduced women's propensity for being in a marriage to which they were forced by their families. Put differently, the exposure to the reform reduced the tendency of women getting married without their consent.

We show that women, who are treated by the education reform, have not altered their preferences regarding their spouse's religiosity, or regarding desired compatibility with their husband's religious sect. This suggests that a change in religiosity, which could be generated by increased educational attainment, is not the driver of the results. Similarly, the reform has not altered women's propensity to marry outside of their geographical region, indicating that a potential change in the marriage pool due to moving to a new location after getting educated and meeting the spouse in that new location is not the mechanism behind the findings. Rather, our results indicate that increased level of educational attainment had an impact on women's preferences. Additional evidence on the change in preferences is provided as the reform made women significantly less likely to agree with the statement that "only a son can ensure the continuation of the family blood line.” A number of sensitivity tests demonstrate the robustness of these results.

Although the reform increased men's years of schooling as well, it had no significant impact on men's preferences in these dimensions. We show that men's propensity for consanguineous marriage declined because women tend to marry men who are four years older on average, and as a result, some men who missed the reform are nevertheless impacted by it indirectly, through the change in women's behavior.

We make contributions to several areas of investigation. First, we add to a growing body of research on nonpecuniary benefits of educational attainment. While there is a large literature concentrating on private returns to education, nonpecuniary benefits of education and the associated social returns have not been investigated as extensively. ${ }^{2}$ Examples of this line of inquiry include the impact of education on civic participation (Dee 2004; Milligan, Moretti and

\footnotetext{
${ }^{2}$ See Card (2001) and Oreopoulos (2007) as examples research estimating the impact of education on wages.
} 
Oreopoulos 2004), on criminal proclivity (Hjalmarsson, Holmlund and Lindquist 2015; Machin, Marie and Vujić 2011), and on the production of health (Chou et al. 2010; Lleras-Muney 2005).

Within this literature, we contribute to a strand of research which focuses on the evolution of cultural traits, and specifically to research that focuses on the influence of education on the formation of beliefs and preferences. Education impacts beliefs and attitudes in a number of dimensions, ranging from religiosity and superstition (Becker, Nagler and Woessmann 2017; Mocan and Pogorelova 2017; Glaeser and Sacerdote 2008) to immigration (Cavaille and Marshall 2019). Education can also alter preferences and attitudes that directly impact women's well-being. There is evidence that educational attainment makes women more intolerant of practices that are harmful for their well-being, and that education makes individuals more likely to challenge authority (Cannonier and Mocan 2018; Friedman et al. 2016). We add to this literature by investigating the extent to which education impacts preferences for and the practices of consanguineous marriage. In many societies around the world, the practice of consanguineous marriage is part of the fabric of culture. Nevertheless, our results reveal that the propensity to approve this practice and the propensity to be actually in a consanguineous marriage are malleable and that these tendencies are influenced by women's educational attainment.

Second, taken together, our results provide evidence on the empowerment effect of female education. Education can empower women through a number of direct channels, such as the impact on labor market opportunities and wages, and access to leadership positions in society (Duflo 2012). Education can also empower women by altering women's preferences and attitudes regarding issues that impact their well-being, which can ultimately influence their decisionmaking. ${ }^{3}$ Under the assumption that consanguineous marriage is not the optimal marital decision for most women, education empowers them as it becomes a conduit through which women switch away from such marriages.

Edlund (2018) argues that cousin marriage is not a voluntary choice for women. Even if her argument may not be fully applicable in the context of Turkey because of the legal and cultural environment, and even if one is prepared to believe that all Turkish women are allowed to freely choose their husbands from the pool of all available candidates, that education makes women less

\footnotetext{
${ }^{3}$ An example is the impact of education on fertility preference and fertility behavior of women (Keats 2018; Osili and Long 2008).
} 
likely to pick a cousin for a husband is evidence for empowerment. That the reform reduced women's propensity to get married against their free will, and that it changed women's beliefs that only a son can ensure the continuation of the family blood line provide further evidence for a significant degree of empowerment of women, generated by the education reform.

Third, our results are important for research on the determinants of infant health. A large literature in economics has demonstrated that infant health is influenced by in-utero exposure to environmental hazards. ${ }^{4}$ Similar to the deleterious effects of these environmental hazards, medical literature has documented substantial health risks to the offspring of consanguineous marriages, including premature birth, low birth weight, infant mortality, and serious congenital diseases. These effects, however, are larger in consanguineous marriage in comparison to those generated by environmental hazards. We provide the details in the Appendix.

While the negative long-run impact of some undesirable birth outcomes, such as low birth weight, can be counteracted by parental investments in childhood (Heckman 2006; Cunha and Heckman 2008), permanent health problems such as congenital heart failure and cerebral palsy, which are prevalent in children of consanguineous parents, are very difficult and costly to counterbalance using ex-post interventions. This means that the reduction in consanguineous marriage, generated by an increase in education, can be a vehicle through which improvements in child health can be achieved. This is especially true in developing countries where high rates of consanguinity, low education, and public health problems related to high infant and child mortality and morbidity co-exist, but public policy attempts to discourage such marriages are not pursued because consanguineous marriage is considered to be a product of tradition and religion. ${ }^{5}$

\footnotetext{
${ }^{4}$ For example, fetal exposure to air pollution is shown to cause infant mortality (Greenstone and Hanna 2014; Currie and Neidell 2005; Chay and Greenstone 2003). Almond, Edlund and Palme (2009) find that in-utero exposure to radiation lowers school performance of children and reduces future earnings, likely by hindering cognitive development. Along the same lines, Sanders (2012) shows that exposure to ambient pollution in-utero has a detrimental effect on test scores in high school. Low birth weight, which is a significant predictor of future health and educational attainment (Bharadwaj, Lundborg and Rooth 2018; Currie 2009), is impacted by pregnant women's exposure to motor vehicle emissions (Currie and Walker 2011), toxic air emissions from industrial plants (Currie et al. 2015), and by carbon monoxide pollution (Coneus and Spiess 2012).

${ }^{5}$ It is well-established that more educated individuals are better producers of health because education yields to improvement in allocative or productive efficiency (Grossman 2006; Rosenzweig and Schultz 1982; Grossman 1972), and that an increase in maternal education improves child health (Grépin and Bharadwaj 2015; Chou et al. 2010; Makate and Makate 2016). Our results, however, underscore education as a policy lever to improve child health through a different preventative mechanism.
} 
The results are also potentially important for economic development. This is because human capital is an ingredient of development (see Hanushek and Woessmann 2020 for a review of this literature). Improvement in child health, due to reduced incidence of consanguineous marriage, caused by increased educational attainment, is expected to have a positive impact on human capital and economic development. ${ }^{6}$ In addition, family formation and sorting of individuals into families can have an impact on economic development through a number of mechanisms (Fernández 2003; Fernandez and Rogerson 2001). Greif and Tabellini (2017) and Greif (2006) argue that the formation of state as an institution and the evolution of its organizational structure depends, among other things, on loyalty to kinship networks and the extent of kin-based clan organizations. These authors postulate that marriage laws and practices that restricted consanguineous marriage, instituted by the medieval Church in Europe, undermined kinship groups. This move eventually led to the emergence of nuclear families and gave rise to corporation-based institutions and economic growth in Europe. De La Croix et al. (2018) argue that a shift from closed kinship systems towards a system where knowledge is transmitted across individuals helped Europe to progress economically in comparison to regions dominated by extended families or clans. Ghosh, Hwang and Squires (2020) demonstrate the long term economic consequences of legally banning cousin marriages in the U.S.

Along the same lines, Schulz et al. (2019) argue that the movement away from kinshipbased institutions led to independent and isolated nuclear or stem families, which generated personal traits such as individualism, non-conformity, and trust. Schulz (2020) shows that the prohibition of blood marriages has led to the formation of self-governed cities with political structures that were precursors for parliaments. Kinship networks and nepotism, fostered by consanguineous marriages, can lead to a culture of corruption (Akbari et al. 2019). Thus, education-triggered modifications in the way people sort themselves into families can have longterm cultural and macroeconomic implications.

The rest of the paper is organized as follows. Section II provides the historical background of consanguineous marriage and the health risks associated with such marriages. Section III

\footnotetext{
${ }^{6}$ At the macro-level, Diebolt and Perrin (2013) add to the unified growth theory the role played by women and gender equality, arguing that women's empowerment is a key factor of economic development. To the extent that education empowers women, education has this indirect effect on development as well.
} 
describes the Turkish education reform details, and Section IV presents the conceptual framework and empirical implementation. Section V describes the data, Section VI presents the results and the robustness analyses. Section VII provides a summary and discussion.

\section{Consanguineous Marriage}

A consanguineous marriage is defined as a union between two people who are second cousins or closer. ${ }^{7}$ There is substantial variation between countries in the prevalence of such marriages, with rates ranging 0.2 percent in the U.S. to 3.9 percent in Japan, between 10 and 40 percent in many counties in the Middle East, North Africa and West Asia, and reaching 45-50 percent in parts of China, Afghanistan, India, Saudi Arabia and Syria (Hamamy et al. 2011, Global Consanguinity website.)

Although consanguinity is more wide-spread among countries with majority-Muslim populations, it is not confined to Muslim nations, nor is it an exclusive product of Islam. For instance, as detailed in Bittles (1998) and Bittles and Black (2010), the rules of marriage in Islam are similar to those in the Judaic instructions stated in Leviticutes18:7-18, even though there are differences. As an example, uncle-niece marriages are forbidden in Islam, whereas they are allowed in Judaism. Buddhism permits first-cousin marriages, while the rules are more complex in Hinduism where the interplay between religion and local customs has generated substantial heterogeneity in regulations (Bittles and Black 2010). ${ }^{8}$ Close-kin marriages are permissible for Roman Catholics with the proviso that couples receive Diocesan dispensation. The Protestant Reformation accepted the guidelines in Leviticus 18:7-18, which make first cousin marriages permissible for Protestants (Goody 1983). ${ }^{9}$

\footnotetext{
7 This corresponds to an inbreeding coefficient (F), which is equal to 0.0156 or higher. This, in turn, signifies that parental couples share 1/32 of their genes inherited from common ancestors and that their offspring has a probability of 1/64 (or 0.0156) of having identical gene copies of all loci, inherited from both parents. In cases of first cousin marriage $\mathrm{F}$ goes up 0.0625 and in case of uncle-niece marriages practiced in South India, F becomes 0.125 (Hamamy 2012).

${ }^{8}$ As detailed in Bittles (1998), the Aryab Hindus of northern India analyze seven generations on the groom's family and five generations of the bride's side before a consanguineous marriage is permitted. On the other hand, marriages between first cousins are favored and uncle-niece marriages are prevalent among the Dravidian Hindus in south India.

${ }^{9}$ Orthodox churches, on the other hand, do not allow for consanguineous marriage.
} 
Until the early $20^{\text {th }}$ century, the practice of first-cousin marriage was accepted in Europe and it was frequently exercised, especially among the elites. ${ }^{10}$ Sabean, Teuscher and Mathieu (2007) point out that despite differences in religious denominations between European countries, the prevalence of first-cousin marriage has risen markedly everywhere in Europe in the $18^{\text {th }}$ century, and then it has declined rapidly since the 1920s. The rise and decline of consanguinity in Europe over the last three centuries and its current uneven distribution between regions, as well as the variation in the prevalence of consanguinity between locations within countries, underline the importance of regional traditions and socio-economic variables in determining the propensity for consanguineous marriage. ${ }^{11}$ Similarly, that consanguineous marriage has persisted over centuries, and that it is still widespread in many parts of the world (despite its detrimental effects on the offspring and the related costs for both the offspring and the family) suggest that consanguinity is associated with benefits to families. ${ }^{12}$ Thus, the determinants of the formation of consanguineous marriages and endogamy (marriage within the local community) have recently been investigated as a rational decision made by individuals given the economic and institutional constraints (Bahrami-Rad 2019; Mobarak et al. 2013; Do, Iyer and Joshi 2013; Dow, Reed and Woodcock 2016). ${ }^{13}$

\footnotetext{
${ }^{10}$ For example, Queen Victoria of England married Prince Albert, her mother’s brother's son. Kuper (2002) states that "[Her marriage to her cousin] was, and remains a Hanovarian tradition. George I had married his father's brother's daughter, and George IV his father's sister's daughter. George V and Elizabeth II carried on this tradition, both marrying second cousins” (Kuper 2002, p. 166).

11 See Global Consanguinity website (consang.net) for detailed information on the variation in consanguinity rates within counties.

${ }^{12}$ For example, Johow, Willführ and Voland (2019) show that although marriages between cousins were very rare among the landless population in the $18^{\text {th }}$ and $19^{\text {th }}$ centuries in Krummhörn, Germany, the rate of cousin marriage was 5-10 percent among large-scale farmer marriages and that consanguineous marriages were a wealth retention/consolidation strategy, as consanguinity is found to be associated with increased intergenerational transmission of land holdings. The persistence of consanguineous marriage in developing nations, may signal the existence of economic benefits generated by such marriages in the form of wealth accumulation and consolidation, and network creation. If the returns to nepotism and in-group favoritism are non-trivial in the society, this can help preserve in-marriage as a social norm (Akbari et al. 2019).

${ }^{13}$ More generally, economists have investigated, theoretically and empirically, the determinants of marriage practices (Fenske 2015; Gould, Moav and Simhon 2008; Edlund 1999) dowry payments and bride price (Ashraf et al. 2020; Ambrus, Field and Torero 2010; Botticini and Siow 2003), and the decisions surrounding inheritance (La Ferrara 2007; Bernheim and Severinov 2003; Chu 1991).
} 


\section{The 1997 Education Reform}

In August 1997, a newly formed government in Turkey passed a law to increase mandatory education from five to eight years (Law No: 4306). Prior to the enactment of this law, students had to complete five years of elementary school education, but attendance to middle school (grades 68) was voluntary. The reform combined elementary and middle school education and required all students, who were covered by the mandate of the law, to obtain a middle school diploma. Students who had completed the fourth grade or lower in the summer of 1997 had to comply with the new law and had to continue their education until they have completed eight years of schooling, while those who had already completed the fifth grade in Summer 1997 were exempt.

Although most children who were born in 1986 would have been enrolled in the first grade in 1992 and would have completed the fifth grade in Summer 1997 barring grade repetition, some children who were also born in the same year would have completed only the fourth grade in 1997, and therefore would have been impacted by the reform. This is because of the imperfect compliance with a law that regulates school starting age in Turkey (Kırdar, Dayığlu and Koç 2018; Cesur and Mocan 2018; Dinçer, Kaushal and Grossman 2014). ${ }^{14}$ In addition, some families whose children were exempt from the law (those born in 1986 and completed the fifth grade in 1997), may have decided to send their children to school for an additional three years to obtain the middle school diploma, to prevent their kids from being in a disadvantaged position in comparison to the immediately younger cohorts. ${ }^{15}$ Thus, the extent to which the reform impacted the cohort of 1986 is unclear.

The speed with which the law was passed was because of domestic and international politics. In 1997, Turkey was engaged in negotiations for the membership to the European Union

\footnotetext{
${ }^{14}$ The law that regulates the school starting age in Turkey states that a child may start the first grade in the Fall if she is 72 months old at the end of that calendar year. This implies that children born in 1986, especially those born towards the beginning of that year could have started school in 1992. It is wellknown, however, that the age cut-off, is loosely enforced and children could start primary start school in the 69-80 month range (Gun and Baskan 2014). Thus, those who were born in early 1986 could start the first grade in Fall 1991 rather than Fall 1992. Similarly, those born in late 1986 could start school in 1992, rather than in 1991.

15 Therefore, we follow the previous research and exclude those born in 1986 from the benchmark model (Cesur and Mocan 2018; Kırdar, Dayığlu and Koç 2018; Mocan and Pogorelova 2017; Fort, Schneeweis and Winter-Ebmer 2016; Battistin et al. 2009), although as we show that including them does not alter the results.
} 
(EU), and increasing the mandatory years of education was considered the right move to increase the chances of EU membership (Dulger 2004). The law was also an attempt to limit the religious education in the country. ${ }^{16}$ Specifically, before the reform students, who have completed 5 years of mandatory education, had three options: 1) discontinue their education, 2) go on to secondary education at a traditional middle school for 3 years, 3) go on to secondary education at a vocational school, including a religious school which is designed to train religious clerics to be employed at religious organizations, including mosques. By merging the 5-year elementary education and 3year secondary education and making it mandatory to go to school for 8 years, the reform eliminated the stand-alone vocational middle schools. Vocational high schools, including religious schools, could only admit students after the 8th grade. It should be noted, however, that enrollment in religious vocational middle schools was 315,000 students of 2.6 million students of the same grade level (12 percent). Most students in these religious vocational middle schools were boys because these schools were primarily designed as feeders into religious high schools which were primarily designed to train clerics to be employed by mosques and other religious enterprises, but only men can be religious clerics in Islam. It is also important to note that these religious vocational middle schools (Imam-Hatip schools) were not based on a full religious curriculum. Rather, their curriculum consisted of standard middle school curriculum supplemented with religious material. As are result, such students were eligible to qualify to any field of study at a university with the proviso that they did well at the university entrance exam. (Aydemir and Kirdar, 2017).

The reform did not involve any modifications to the curriculum; that is, neither the content nor the composition of courses were affected by the reform (Dulger 2004). ${ }^{17}$ Compulsory education is free in Turkey. Thus, the reform did not involve any change in the cost of education

\footnotetext{
${ }^{16}$ More specifically, a previous government, which had a religious bent, resigned in June 1997 and the new secular government passed the education reform law on August 18, 1997. Details of this point and the political landscape in Turkey in 1997 can be found in Cesur and Mocan (2018) and on pp. 80-83 of Cesur and Mocan (2013).

${ }^{17}$ The Ministry of Education incorporated a number of changes to increase enrollment, including hiring additional teachers, adding new classrooms to existing schools, starting a bus system to transport students from rural localities to urban schools, as well as system of free lunches and books to low income children (Ministry of National Education (MONE) 2001; Dulger 2004). The capacity of boarding schools was also expanded to facilitate the enrollment of rural children in urban areas (Dulger 2004; World Bank 2005).
} 
for families. Although non-compliance is subject to fines, it is not strictly enforced. As a result, although the proportion with at least a middle school diploma rose above 90 percent, full compliance is not achieved. Additional details regarding increased enrollment, employment of new teachers and so on can be found in Kırdar, Dayığlu and Koç $(2018,2015){ }^{18}$

\section{Conceptual Framework and Empirical Implementation}

Following the discussion in the introduction, an individual's propensity for consanguineous marriage ( $M$ ) in Equation (1) is impacted by individual characteristics such as age and gender (X), malleable traits such as religiosity and political views (R), as well as labor market activity and relevant market wages (W). Local cultural traditions (C) also influence the proclivity for consanguineous marriage. Alternatively, $M$ represents various marriage characteristics, such as age at first marriage and the manner in which the individual met his/her spouse. $M$ also characterizes individuals' preferences for several attributes of a spouse and the marriage, such as the desirability of an educated spouse, the importance of shared religious beliefs between husband and wife, and the acceptability of the practice of marrying a blood relative. Individuals' educational attainment (Educ) can directly influence $M$ through a number of channels, including by altering time discounting (Becker and Mulligan 1997; Perez-Arce 2017), by influencing risk aversion via the rise in cognition (Dohmen et al. 2010; Harrison, Lau and Rutström 2007) and by altering attitudes towards matters that are related to women's well-being (Cannonier and Mocan 2018).

$$
M=f_{1}(X, R, W, C, E d u c)
$$

Equation (2) indicates that educational attainment is a function of personal characteristics of the individual (X), religiosity and political views (R), as well as cultural attributes (C). Educational

\footnotetext{
${ }^{18}$ There was another education reform in Turkey in 2012. This reform does not lend itself to an analysis as does the 1997 reform. This is because the 2012 reform generated a multitude of changes simultaneously, the joint impacts of which are unclear theoretically. For example, while the 2012 reform increased the mandatory years of education to 12 years (high school education), it also allowed students to start religious education after the $4^{\text {th }}$ grade. More specifically the 2012 reform created a new system, which is termed $4+4+4$, where the first 4 represents primary education, the second 4 stand for middle school and the last 4 indicates high school. Students can switch schools between these blocks (e.g. switching to a vocational school). Furthermore, the 2012 reform changed the structure and curriculum of some public schools. (see Gun and Baskan 2014 for details). Even if the 2012 reform did not have the ambiguity as to its expected impact, it is not usable in our case, because our data set is based on a survey conducted in 2016. The 2012 reform impacted the $8^{\text {th }}$ graders who were 15 years old in 2012. Thus, the individuals who were exposed to the 2012 reform are 19 years old or younger in our data set, and they do not constitute a useful sample for our purposes.
} 
attainment is also influenced by exposure to the reform (T) because those who are treated by the reform are required to obtain additional years of education.

$$
E d u c=f_{1}(X, R, C, T)
$$

Because an individual's educational attainment is endogenous, estimation of Equation (1) using OLS would produce a biased estimate of the impact of education on consanguineous marriage. ${ }^{19}$ The education reform leveraged in this paper mandated some students to receive three additional years of schooling while it exempted other students from this requirement (based on the grade the students had completed when the law was passed). Thus, exposure to T in equation (2) is exogenous, and therefore the reform can, in principle, be used as an instrument for educational attainment in an effort to estimate Equation (1) (Aydemir et al. 2020; Cesur and Mocan 2018; Dursun, Cesur and Mocan 2018). This instrumental variables procedure, however, is not advisable in this particular context because of likely violation of the exclusion restriction. This is because previous research, using a variety of data sets, has shown that exposure to this reform in Turkey had a significant impact on the educational attainment of both women and men (Mocan 2014; Cesur and Mocan 2018; Kırdar, Dayığlu and Koç 2018, Torun 2018, Akyol and Kırdar 2020). We confirm this finding in our data as well. That the reform influenced the educational attainment of both sexes prevents us from using this instrumental variables strategy because our outcome variables are related to various aspects of marriage. More specifically, an increase in education, triggered by the reform, may have an impact on women's propensity to marry by altering their preferences or by changing costs and benefits of marriage. But, by the same token, the same observed change in the propensity to marry can be the result of the change in the behavior, or the preferences of the opposite sex, because the same education reform increased men's education as well. Thus, exposure to the reform, although exogenous, cannot be convincingly used as an instrument for female (male) educational attainment because the instrument, education reform, can plausibly impact female (male) marriage outcomes indirectly, through its impact on male (female)

\footnotetext{
${ }^{19}$ For example, risk aversion, which is shown to be related to educational attainment (Harrison, Lau and Rutström 2007) can also impact the propensity for consanguineous marriage. Similarly, other difficult-toobserve personal attributes (e.g. cognitive ability) or family attributes (e.g. the family's attitudes towards female education and women's role in the society) can influence both $M$ and Educ in Equations (1) and (2). More specifically, unobservable factors that influence an individual's educational attainment can be correlated with her proclivity for consanguineous marriage.
} 
education. ${ }^{20}$ We, therefore, focus on estimating the reduced-form impact of the reform, depicted by Equation (3) below.

Two additional considerations are important. First, education can have an indirect effect on marriage decisions and marital preferences $(M)$ through its impact on personal attributes such as religiosity and political views (R) (Cesur and Mocan 2018; Becker, Nagler and Woessmann 2017; Mocan and Pogorelova 2017). Second, it has been well-established that education impacts labor force participation and wages. ${ }^{21}$ This means that vectors $\mathrm{R}$ and $\mathrm{W}$ are functions of education, which in turn implies that the reduced form Equation (3) excludes these components.

$$
M=f_{4}(X, C, T)
$$

We focus on Equation (3) to investigate the impact of the reform on consanguineous marriage and related outcomes and preferences. The empirical counterpart of this formulation is presented by Equation (4) which portrays the specific models estimated in the paper.

$$
M_{i}=\alpha_{0}+\alpha_{2} T_{i}+\alpha_{3} T_{i} \times\left(Y o b_{i}-1986\right)+\alpha_{4}\left(1-T_{i}\right) \times\left(Y o b_{i}-1986\right)+\alpha_{5} F E^{\prime}{ }_{i}+\varepsilon_{i}
$$

The dependent variable $M$ in Equation (4) is an indicator to represent whether the individual is married to a first cousin. Alternatively, $M$ stands for other related outcomes such as whether the person is married to a blood relative, age at first marriage, the age difference between husband and wife, whether the person is in an arranged marriage, whether the person was forced into marriage against her own free will, and whether the person believes that spouse's educational attainment, spouse's political views, and compatibility of religious views are important aspects of a marriage. Using the same specification, we also investigate whether education reform had an impact on the extent to which the individual finds consanguineous marriage acceptable. Along the same lines, we analyze if married individuals met their spouses through family and neighbors, or through other avenues such as friend networks, workplace connections, internet and so on, and we investigate if the extent to which the person agrees with the statement that only a son can ensure

\footnotetext{
${ }^{20}$ See Kırdar, Dayığlu and Koç (2018) and Akyol and Kırdar (2020) who make same argument.

${ }^{21}$ See Card (1999) and Meghir and Rivkin (2011) for excellent reviews.
} 
the continuation of the family blood line. Finally, we use the first principal component of these variables as a composite measure and use it as a dependent variable.

$T_{i}$ is a binary variable, equal to one, if the individual has been treated by the reform; i.e., born after 1986. As described in the Section III, the extent to which the cohort of 1986 has been affected by the reform is unclear. Thus, following the approach of Cesur and Mocan (2018), Mocan and Pogorelova (2017), Fort, Schneeweis and Winter-Ebmer (2016), and Battistin et al. (2009), this particular cohort is excluded from the main analysis, although adding it to the sample does not influence the results. Our main analysis sample includes individuals who were born within eight years before or after the pivotal cohort of 1986. This bandwidth for the benchmark models was chosen based on the procedure of Imbens and Kalyanaraman (2012). We show in the robustness section that the results are not sensitive to the increase or decrease in the size of this window.

The variable Yob represents the year of birth. Thus, the model accounts for potentially differential trends in the outcomes of both the treatment and control cohorts. Local cultural characteristics are accounted for by a set of fixed effects (FE). They include region of current residence indicators, region of childhood fixed effects, an indicator of whether the individual spent his/her childhood years (up to age 15) in a village, and the interaction between the indicators of childhood region and growing up in a village. ${ }^{22}$ These variables intend to capture the impact of economic factors and the extent of religiosity and traditional cultural values at the local level, including the prevalence of inbreeding in the geographic region in which the individual resides, and well as exposure to such values while growing up in the childhood region. ${ }^{23}$

Although region of residence and region of childhood dummies account for differences in customs related to marriage practices between regions, variations in personal heritage are also important. For example, minority populations in Turkey that speak Kurdish or Arabic at home have arguably different customs and traditions than those that speak Turkish. The survey does not contain a question about the primary language spoken at home. It, however, contains a question about whether the survey respondent speaks a second language. The ability to speak a second

\footnotetext{
${ }^{22}$ Age 15 is significant because it is the age at which a typical student graduates from the middle school.

${ }^{23}$ The design of the data collection permits identification of 12 regions of current residence, while the region of childhood is identified at a more granular level, which allows assignment to 26 regions.
} 
language may represent different traits, based on the region of residence. For example, in Eastern Turkey, two languages being spoken may imply Turkish and Kurdish, whereas speaking two languages in the Western part of the county may mean Turkish and English. To provide a more granular account for such differences, we included to the models a dummy to indicate whether the individual speaks a second language and its interaction with region of residence dummies. ${ }^{24}$

It can reasonably be argued that the location of current residence and the ability to speak a second language could be endogenous, influenced by education. Thus, we also estimated the models without these variables. Finally, to analyze the sensitivity of the results we dropped from the model all variables other than the trend terms and the treatment indicator. In all these exercises, the inference remained intact.

The model is estimated separately for men and women. The error term $\varepsilon$ captures the impact of individual-specific idiosyncrasies that influence graduation from middle school. Standard errors are calculated in two ways. They are clustered at the childhood region-by birth cohort level, and also at the birth cohort level. ${ }^{25}$ We also report the p-values adjusted for multiple hypothesis testing, using the improved Benforroni correction method of Simes (Simes 1986; Newson 2010; Benjamini and Yekutieli 2001).

We employ the same formulation when we demonstrate the impact of the reform on educational attainment $\left(E d u c_{i}\right)$. In this specification, the dependent variable is a dichotomous indicator which takes the value of one if individual $i$ has at least a middle school diploma (8 years of schooling), and zero otherwise.

\section{Potential Use of the Month of Birth}

Some papers, which analyzed the same Turkish reform, used individuals' birth month to implement a sharper discontinuity design (e.g. Gulesci et al. 2020, Erten and Keskin 2020). We do not prefer this procedure for a number of reasons. First, it is widely-known that the school

\footnotetext{
${ }^{24}$ The ability to speak a second language may be a function of education as much as it is a function of the local culture, which would make this variable endogenous. Dropping the variable from the model, however, had no impact on the results.

${ }^{25}$ Clustering by childhood region-by birth cohort is sensible to the extent that the effectiveness of the reform varied by region, especially in the early years of the reform's implementation. Standard errors, clustered by birth cohort, are bootstrapped.
} 
starting age law is not enforced in Turkey. Although the law which stipulates that a child may start the first grade in the Fall of a given year if she is 72 months old at the end of that calendar year, the age cut-off is not enforced (Dincer et al. 2014, Tosun 2018, Kirdar et al. 2018, Cesur and Mocan 2018). This means that those who were born in 1986, and especially those with birth days in later months of the year (those who would be younger for the cohort of first graders), are likely to start school in 1993 and are exposed to the reform. ${ }^{26}$ Thus, the treatment status of those born in 1986 is unclear, and this is even more questionable for those who are born at the end of 1986.

Second, month of birth provides noisy and incomplete information in all Turkish data sets, primarily because of the attitude and behavior of parents which lead to delays between the birth and its registration to official documents. For example, in our analysis sample 24 percent of all women have missing birth month (1,384 of 5,867 observations). Our ever-married women sample contains 4,695 observations and 1,103 of these (24\%) have not reported their month of birth. The rate of missing birth month is 21 percent in the sample of all men, and 19 percent in the sample of ever-married men. Furthermore, the propensity for a missing birth month is non-random, but it is correlated with the education level and geographic region of the respondents. For example, when we regress the indicator for missing birth month on an indicator of whether the individual lived in a village until the age 15 , the estimated coefficient is 0.035 (se=0.012), indicating that those who grew up in a village are 3.5 percentage points more likely not to know (or not to report) their month of birth. We also find that those who have a middle school diploma and those who have at least a high school diploma are more likely (8.1 percentage points with p-value $=0.00$, and 6 percentage points with p-value $=0.00$, respectively) to report their month of birth in comparison to those with less than middle school education Similarly, those who currently reside in the Western part of the country are more likely to report their month of birth in comparison to those who live in the South; and those who live in the Black Sea region and in the East are less likely to report their month of birth.

Another general problem, which is related to the second issue above, is that about one in five Turkish birth certificates list January as the month of birth. In our particular case, in the

\footnotetext{
${ }^{26}$ Similarly, those with birthdays in early 1987 may have started the school in 1992 and would not be exposed to the reform. Furthermore, there is no social promotion in Turkey, and grade repetition in elementary school was 5 percent in the 1990s. (Dursun, Cesur, and Kelly 2017). This means that about 5 percent of students of the 1986 cohort have been treated by the reform because they were grade-repeaters and were going to school with the 1987 cohort when the law was passed.
} 
sample of all women who did report their month of birth, 17.8 percent list January as their birth month. Similarly, in the sample of ever-married women 18.1 percent indicate that January is their birth month. The rates are 17.1 percent and 16 percent in the sample of all men and ever-married men, respectively. In each sub-sample, a Chi-square test for the equality of the reported birth month distribution to a uniform distribution is rejected with a p-value of $0.00 .^{27}$

Misreporting of birth month as a cultural phenomenon is well-known in Turkey and it is occasionally covered by the media. ${ }^{28}$ The same phenomenon is also observed among the refugees to the U.S. As reported in a piece by NPR, 14 percent of the 80,000 refugees to the U.S. in 2009 has January 1 as their birthday. ${ }^{29}$

In summary, cultural and institutional aspects of the country indicate that it is problematic to rely on month of birth to identify the impact of the reform. This is because in our data set as well as in other Turkish data sets (i) birth month is not reported in a significant proportion of cases, (ii) survey respondents' propensity to report month of birth is correlated with their socio-economic attributes, (iii) reported month of birth is not reliable as there is substantial heaping in January. These issues, coupled with the fact that school starting age in not enforced, imply that it is not the best strategy to try and obtain inference based on those who are born a few months apart (in late1986 vs. those born in early-1987).

\section{$\underline{\text { V. Data and Descriptive Statistics }}$}

We use data from the Turkish Family Structure Survey (TFSS) of 2016, which is a nationally representative survey, conducted by the Turkish Statistical Institute and the Ministry of

\footnotetext{
${ }^{27}$ Our data set in not a special case, but it is the part of this norm. For example, in the 2014 Household Labor Force Survey of Turkey, 12.6 percent of observations have missing month of birth. Of the 344,237 individuals who reported a birth month, 19.2 percent declared January as their month of birth. In the 2013 DHS of Turkey, 12 percent of more than 9,700 women and 12.9 percent of more than 7,200 married women have January birth months. Similarly, the 2008 DHS of Turkey has more than 7,400 ever-married woman, 12 percent of whom have a January birth month. In the Domestic Violence Against Women 2008 data set there are more than 10,800 $(9,800)$ women (ever married women), and 13.3 percent (13.5 percent) of them reported their birth months as January.

${ }^{28}$ Binlerce kișinin 1 Ocak'ta doğması tesadüf değil! (cumhuriyet.com.tr) (The headline reads: "It is not a Coincidence that Tens of Thousands of People have January $1^{\text {st }}$ as their Birthdays"

${ }^{29}$ Why So Many Immigrants Have Birthdays On Jan. 1 : NPR
} 
Family and Social Policies between June 1 and September 26, 2016. The TFSS is administered in 17,239 households. Those who are older than 15 in each household are surveyed, generating information on 35,475 individuals. The household questionnaire of the survey contains information on the dwelling and household conditions, and the individual questionnaire includes information about the basic demographic characteristics such as age, sex, education, and marital status. Because the primary purpose of the survey is to gather information about the family structure, key questions include those on lifestyles and the value judgments concerning the family life, marriage characteristics and preferences. It is important to note that the survey does not include refugees who moved to Turkey from Syria in large numbers since 2011.

Table 1 presents the descriptive statistics of the analysis sample. Columns (1) and (2) display information about all women, and columns (3) and (4) pertain to ever married women. Columns (5)-(6), and (7)-(8) are related to all men, and to ever married men, respectively. The variable Middle School Degree is a dichotomous indicator that takes the value of one if the person has a middle school diploma, which is obtained after eight years of education. Recall that the education reform mandated students to attain at least this particular level of education. The oddnumbered columns of Table 1 display the means and standard deviation of variables for those who are treated by the reform (born after 1986), and the even numbered columns pertain to the control group, consisting of those who escaped the mandate of the reform (those born before 1986). For both men and women the proportion with a middle school degree is substantially greater among those who were exposed to the mandate of the reform in comparison to those who were not. This is true regardless of whether the person is ever married. Figures 1 and 2 display the proportion of women and men, respectively, who have a middle school diploma in each cohort. The number zero on the horizontal axis signifies the pivotal cohort: those born in 1986. The values on the horizontal axis identify the distance of the person's year of birth from 1986. Individuals born in 1987, 1988 and so on (where the horizontal axis takes the values of 1, 2, and so on) constitute the treatment group, and those with negative values on the horizontal axis (born before 1986) are in the control group.

As evident from the figures, the reform increased the propensity to obtain a middle school diploma for both men and women, and the impact was stronger for women. That this Turkish reform had a significant impact on middle school completion for both men and women has been demonstrated by previous work using a variety of data sets (Torun 2018; Cesur and Mocan 2018; 
Dursun et al. 2018; Aydemir and Kirdar 2017; Dursun and Cesur 2016; Kirdar et al. 2015; Mocan 2014). The information displayed in the first row of Table 1 and in Figures 1 and 2 is consistent with those reported by previous research. ${ }^{30}$

Figure 3 presents the proportion of ever married women who have a middle school diploma, and Figure 4 displays the same information for men. A comparison between Figures 12 and 3-4 shows that while there was a steady rise in the proportion of all women and all men with middle school education after the reform (Figures 1 and 2), this proportion leveled off for younger cohorts in the ever-married sample (Figures 3 and 4). This implies that non-compliance with the reform is more prevalent among the ever-married individuals of younger cohorts.

Table 1 shows that about nine percent of the sample is married to a first cousin, and that about 20 percent are married to a blood relative (which consists of cousins and other blood relatives from either the mother's or father's side). These rates are consistent with those reported by earlier surveys (Kaplan et al. 2016, Tunçbilek and Koç 1994). Although there is no significant overall difference in this rate between the treatment and control groups, Figures 5 to 8, coupled with Figures 3 and 4, depict a more complete and accurate picture. Specifically, Figures 5 to 8 reveal an increase in the propensity of first cousin and blood relative marriages among the younger cohorts. ${ }^{31}$ Figures 5 to 8 are, of course, based on ever-married sample, and as mentioned above, non-compliance with the reform is more prevalent among ever-married individuals. This means that some of those who are in the treatment group of the ever-married sample are in fact not treated by the reform and that these individuals are the ones who have higher rates of first cousin and blood marriage. To be exact, one quarter of individuals in the treated group of ever married women do not have a middle school diploma. These women married two years younger in comparison to women who are also in the treatment group but who have received a middle school diploma (19 years of age vs. 21). Non-compliers are almost 2.5 times more likely to have married to a first

\footnotetext{
${ }^{30}$ We also calculated the proportion of individuals with at least a high school diploma. These proportions were the same between the treatment and control groups in the ever married men sample (0.52 vs. 0.53), but the proportion with high school diploma was higher for the treated groups in all other samples ( 0.55 vs. 0.37 for all women, 0.40 vs. 0.35 for ever-married women, 0.63 vs. 0.54 for all men), indicating that the reform had a positive spillover effect on high school education.

${ }^{31}$ Figures 5 to 8 , as well as all other figures related to outcomes, present outcomes net of the control variables (i.e. the set of fixed effects)
} 
cousin (14.2 percent vs. 5.9 percent), or a blood relative (35.4 percent vs. 14.8 percent). ${ }^{32}$ The strong correlation between non-compliance and high propensity to marry a first cousin or blood relative suggests that this pattern (refusal to go to middle school, or dropping out of school, and marrying a blood relative) is likely driven by the individual's or her family's attachment to customs and traditional values. Because we classify these individuals as having been treated by the reform, we would tend to underestimate the reform's impact on consanguinity.

It is also important to note that the sample size is smaller in younger groups, which is particularly the case in the ever-married sample. This is the result of the fact that individuals need to be both younger and be married to be included in this group. For example, in Figure 8 the observation pertaining to men born in 1994 (when the horizontal axis takes the value of 8), is calculated based only on 18 men in this group. Similarly, in Figure 7, there are only 121 evermarried women who were 22 years old during the survey year of 2016 (who were born in 1994). We nevertheless include in the regressions all individuals who are within the 8-year bandwidth and give them equal weight.

Table 1 shows that there are differences in the second language rates between the treatment and control groups, especially in the sample of all women. However, any difference between the control and treatment groups is explained by cohort effects. Specifically, regressions where second language dummy is regressed on cohort trends and the treatment dummy reveal that the coefficient of the treatment dummy is always small (about 0.014) and never different from zero. This is even true in simple models that omit all fixed effects. Appendix Figures A.1 presents this information graphically and reveals no jump in the second language rates attributable to exposure to the reform. As explained in the robustness section, dropping the Second Language variable has no impact on the inference.

Table 1 also presents the descriptive statistics of five marriage characteristics: age at first marriage, the age difference between husband and wife, whether the union was an arranged marriage, whether the person was forced into marriage against her own free will, and whether the

\footnotetext{
32 The non-compliance rate among the treated ever-married men (12.7 percent) is half the rate of evermarried women. The difference between compliers and non-compliers in consanguinity among evermarried men is similar to those found in ever-married women. Ever married men who have not received a middle school diploma are more likely to have married a first cousin (20.9 percent vs. 7.5 percent) or to have married a blood relative (39.5 percent vs. 16.7 percent).
} 
person met his/her spouse through the family, relatives, or neighbors, This information is, of course, provided only by those who are married, and the latter two variables pertain to the individual's current marriage. If the individual was divorced before the current marriage, the latter two questions pertain to the first marriage. Arranged Marriage is an indicator that takes the value of one if the person was married through the initiative of a matchmaker. This variable takes the value of zero, if the person married the spouse (with or without the consent of the family) without an intermediary, or eloped. Forced into Marriage is a dichotomous indicator which equals one if the person was forced by the family to marry his/her spouse, despite the fact that he/she did not want to marry that particular person. Less than five percent of women in the treatment group are in marriages to which they did not consent. The rate is twice as high among women in the control group. The variable Met through Family/Relatives/Neighbors is another indicator which takes the value of one if the person met his/her spouse through family, relatives or neighbors; and it is zero if the future spouse was met through the network of school, work, friends, or through the internet or a dating agency. The propensity to have found a spouse through family, relative and neighbor networks is lower among those who are exposed to the reform. Figures 9-13 pertain to these five variables for women. Appendix Figures A.2 display the same information for men.

The bottom section of Table 1 displays preferences regarding attributes in a spouse. It is OK to Marry a Blood Relative takes the value of one if the individual declared that it is acceptable to marry a close blood relative such as a first cousin. Spouse's Education is Not Important equals one if the person believes that is unimportant or very unimportant for the spouse to be welleducated, and zero if the person believes that this spousal attribute is somewhat important, important or very important. Similarly, Spouse's Religious Sect is Important and Spouse's Political Views are Important are variables that reveal the extent to which these attributes are somewhat important, important, or very important in a spouse. The proportion of ever married women who agreed with these statements are displayed in Figures 14-17 by birth cohort, and Appendix Figures A.3 presents the same information for all women. Only a Son can ensure the Continuation of the Family Blood Line takes the value of one if the survey respondent agreed or strongly agreed with the statement. Appendix Figures A.4 presents the proportion of ever married women and men who agreed with this statement. 


\section{$\underline{\text { VI. Results }}$}

Table 2 presents the estimation results of Equation (4) by gender, and demonstrates that the reform has generated an increase in the propensity of having at least a middle school education by almost 14 percentage points for all women, and about 13 percentage points for all men in our sample (column 1). ${ }^{33}$ Table 2 also shows that the impact of the reform on educational attainment is similar between all women and ever married women; and that the same is true for men. Also evident from Table 2 is that the reform had a positive impact on high school completion as well, but that it had no discernable effect on college education.

Table 3 presents the reduced form (intent-to-treat) estimates obtained from Equation (4). Columns (1) and (2) display the estimated effect of the reform on the probability of marrying a first cousin and marrying a blood relative, respectively, for ever married individuals. Panel A pertains to females, and Panel B displays the results for males. Recall that marriage to a first cousin is a subset of marriages to blood relatives, as the latter includes marriages to individuals who are related by blood but who are not first cousins. Entries in parentheses report the standard errors clustered at the childhood region-by-birth cohort level. Childhood region is relevant because it is where the individual lived until age 15 and was exposed to the education reform. Using the region of residence instead did not alter the standard errors appreciably. P-values, adjusted for multiple hypothesis testing are reported in \{curly brackets\}. Entries in [square brackets] are the wild-bootstrapped p-values of the estimated coefficients, obtained from clustering the standard errors at the birth cohort level. Columns (1) and (2) show that the reform decreased women's propensity to marry a first cousin by 3.6 percentage points (about 42 percent from the baseline), and that it decreased women's propensity to marry a blood relative by 5.6 percentage points (28 percent from the baseline). ${ }^{34}$ On the other hand, the reform had no impact on men's

\footnotetext{
33 These magnitudes are very similar to those reported by Dursun, Cesur and Mocan (2018) who used Turkish Statistical Institute's Health Survey, and the Tobacco Survey of the same Institute. They are slightly smaller than those reported by Mocan (2014), who used a large sample from Turkish Household Labor Force Survey, and those reported by Kırdar, Dayığlu and Koç (2018). Torun (2018), who also used THLS, reported an increase in the propensity to complete at least a middle school by $17 \mathrm{pp}$ for females, and $11 \mathrm{ppt}$ for males.

${ }^{34}$ Analyzing the impact of the same Turkish education reform Asker (2020) concludes that the reform had no impact on women's propensity for first-cousin marriage. He reports a negative, but non-robust impact on the propensity for consanguinity for women raised in urban areas. The author stacks surveys that are conducted in different years (e.g. 2008 Demographic Health Survey, the Domestic Violence Against
} 
proclivity for consanguineous marriage, indicated by small and statistically insignificant point estimates in Panel B. For example, columns (1) and (2) of Panel B reveal that the coefficient of the reform is 0.013 in the model that explains men's propensity to marry a first cousin, and it is 0.003 when the dependent variable is being married to a blood relative and they are highly insignificant.

That the reform had an impact on women's propensity for consanguineous marriage, but that it had no impact on men is surprising. An explanation for this finding can be provided by the fact that, as displayed in Table 1, husbands are on average four years older than the wives, which indicates that the first four cohorts of women who were impacted by the reform are married to four cohorts of men who missed the reform by a few years. More specifically, in Figure 5 the first cohorts of women fully impacted by the reform were born in years 1987-1990. They correspond to time periods 1, 2, 3 and 4 on the horizontal axis. These women are typically married to men who belong to cohorts $-1,-2,-3$ and -4 in Figure 6 , and as evident from the figure, the proportion of men married to first cousins is lower in these particular cohorts. This means that the insignificant effect of the reform on men is likely because about half of the men in the control group (those born between 1982-1985) are indirectly impacted by the reform by the virtue of the fact that the reform reduced the propensity for consanguineous marriage for women these men tend to marry. This in turn implies that the results in columns (1) and (2) of Panel B in Table 3 reflect a downward bias of the reform's impact on men's propensity for consanguineous marriage.

To make this point more clear, we shifted the data points for men in Figure 6 forward by four years and superimposed them on Figure 5 (women). That is, we matched the 1982 cohort of men with the 1986 cohort of women; the 1983 cohort of men with the 1987 cohort of women, and so on. The idea behind this exercise is to match the cohorts of men and women who are likely marry each other given that husbands are four years older than their wives on average. The result, displayed in Figure 18, shows that the proportion of first cousin marriages are not significantly

\footnotetext{
Women Surveys of 2008, and the 2016 Turkish Family Structure Survey), which generates an analysis sample of married women in the age range of 17 to 35 . Specifically, the treated women (those who are exposed to the reform) are17 to 21 years old when they were surveyed in 2008 . This creates a potentially severe sample selection issue because young married women (17 to 21 year old) who are "treated" by the reform are likely different from 17-to-21 year old single women who are also treated by the reform but who are not in the analysis sample because they are not married. To the extent that marrying at a young age is positively correlated with the strength of traditional cultural values, this selection would bias the impact of the reform.
} 
different between men and women within most of these cohorts that are matched by the husbandwife age difference. It is also noticeable that there is a drop in Figure 18 when the horizontal axis is positive. This region includes women who were treated by the reform and the corresponding cohorts of men who were in these women's marriage pool. ${ }^{35}$ This procedure is meaningful to the extent that the reform influenced women's attitudes and behavior regarding consanguineous marriage and that the consanguineous marriage of men is influenced as a result. This conjecture is supported by the data because, as we demonstrate below, the reform influenced women in a number of domains related to marriage preferences, but the reform had no impact on men's attitudes or behavior in any outcome analyzed.

Figure 19 displays the same information as in Figure 18, but it pertains to blood relative marriages. That is, to obtain Figure 19 we moved the cohorts of men in Figure 8 up by four years and superimposed them on Figure 7. Once again, the assumption here is that the cohorts of men born between 1982 and 1985 are de facto impacted by the reform because these men's marriage pool (younger women who are exposed to the reform) has altered its behavior towards consanguine marriage. Figure 19 is similar to Figure 18, and running a pooled regression using the cohortmatched sample of Figure 19 indicated that the reform reduced the propensity to marry a blood relative. ${ }^{36}$

Column (3) of Table 3 reveals that the reform increased the age at first marriage for women by about half a year. This could be the result of preferences changing in favor of delaying marriage; it could also be a mechanical result of “incapacitation” because of staying in school longer. To the extent that those who are still in school are less likely to get married, exposure to the reform may have delayed age at marriage mechanically. As Table 2 demonstrates, the reform not only increased the propensity to receive a middle school diploma, it also had a positive impact on high

\footnotetext{
${ }^{35}$ When we ran the regression for the propensity for marrying a first cousin in this pooled sample shown in Figure 18, we found that the coefficient of the reform was $-0.020(\mathrm{p}=0.084, \mathrm{~N}=9,068)$, and that the impact of the reform was not different between men and women (the interaction term of the reform indicator and gender indicator was very small and highly insignificant). This regression included the cohort of 1986 as displayed in Figure 18. Dropping this cohort produced the impact of the reform on first cousin marriage as $-0.024(\mathrm{p}=0.069, \mathrm{~N}=8,562)$.

${ }^{36}$ When we ran the model in this pooled sample shown in Figure 19, we found that the coefficient of the reform was -0.026 ( $\mathrm{p}=0.097, \mathrm{~N}=9,068)$, and that the impact of the reform was not different between men and women (the interaction term of the reform indicator and gender indicator was very small and highly insignificant). This regression included the cohort of 1986 as displayed in Figure 19. Dropping this cohort produced the impact of the reform on first cousin marriage as $-0.025(\mathrm{p}=0.170, \mathrm{~N}=8,562)$.
} 
school graduation. Recall that the reform increased educational attainment of men also, but panel B of Table 3 shows that the reform had no statistically significant impact of men's age at first marriage. Column (4) in Panel A of Table 3 shows that the reform reduced the age gap between husbands and wives by 0.44 years for ever married women (although the coefficient is significant only at the 12-percent level when standard errors are clustered by birth cohort). Given that the reform had no impact on men's behavior, (see Panel B where none of the estimated coefficients is different from zero), this finding suggests that the narrowing of the husband-wife age difference is driven by women delaying their age at first marriage.

As shown in Table 1, about 52 percent of ever married women and 43 percent of ever married men got married through an arranged marriage, where an informal match-maker (a relative, a family friend, or a friend) introduced the future bride and groom to each other, typically with the consent of the families. Column (5) of Table 3 shows that women who were exposed to the reform are about seven percentage points (about 13 percent) less likely to have an arranged marriage orchestrated by a match-maker. ${ }^{37}$ On the other hand, the reform has no impact on men's propensity to get married through a match-maker.

Column (6) of Table 3 shows that the reform reduced women's likelihood of being married to someone who they did not want to marry by 2 percentage points (29 percent). ${ }^{38}$ In other words, the reform reduced women's propensity for having been forced by their families to marry a particular person. This is a strong impact given that the prevalence of this outcome among married women is only seven percent. Finally, the last column of Table 3 reveals that the reform altered women's propensity to meet their future husbands via their families, neighbors or relatives. The left-out category of this dependent variable includes meeting the spouse through friends, school, the workplace, or on the internet. Thus, this result, consistent with those of columns 5 and 6, indicates that the reform increased women's propensity to make their marriage decisions independently.

\footnotetext{
${ }^{37}$ The p-value of the estimated effect rises to 0.107 when the standard errors are clustered at the birth cohort, but as we show in Appendix Table A.3, the impact is statistically significant with p-values less than 0.05 with the same clustering in models using other bandwidth sizes.

${ }^{38}$ While the estimated coefficient is not statistically significant when the standard errors are clustered at the childhood region-by-birth year, they are significant with a p-value of 0.028 when the standard errors are clustered by birth year. Later in the paper we show the robustness of this result.
} 
Table 4 presents the results of the analyses where we investigate the impact of the reform on women's marriage preferences. Panel A displays the results for ever married women, and Panel $B$ reports the results for all women. The results for men, displayed in Appendix Table A.1, reveal that the reform had no impact on the outcomes displayed in Table 4 for men. ${ }^{39}$

In Panel A of Table 4, column (1) presents the estimates of the education reform on the extent to which ever married women find a union between two blood relatives acceptable. The reform reduced the acceptability of such marriages by 3.8 percentage points for ever married women although the p-value obtained from bootstrapped standard errors clustered by birth cohort are larger than conventional levels. This translates into a 25.3 percent decline in women's approval of marriages to blood relatives. It could be the case that cognitive dissonance might alter women's responses to this question. More specifically, women might indicate their approval of marriages to blood relatives because they themselves are (or were in the past) married to a blood relative. Therefore, we also estimate the model using all women, including those who were never married. The results reported in column (1) of Panel B show that neither the coefficient nor the standard error changes appreciably suggesting that the impact is not confounded by marital status.

Column (2) of Table 4 reveals that the reform changed ever married women's preferences in favor of more educated husbands. On the other hand, the point estimates in columns (3) and (4) are small and not different from zero. This indicates that the reform did not alter the extent to which women believe that it is important for a married couple to belong to the same religious sect (column 3) or the extent to which they think that a wife and her husband should share the same political views (column 4).

In summary, the results reveal that the reform reduced acceptability of consanguineous marriage to women and that it lowered women's likelihood of marrying a first cousin or a blood relative. The reform increased women's age at first marriage, reduced the age difference between husband and wife, and made women less likely to declare that education is an unimportant attribute

39 It has been shown that an increase in education, when the baseline education is low, exerts little-to-no impact on men's behavior and preferences in developing countries, although it impacts women. For example, Cesur and Mocan (2018) find that the same Turkish education reform has an impact on women's religiosity and the propensity to vote for religious parties, but had no impact on men on these dimensions. Similarly, Cannonier and Mocan (2018) find that an education reform, which targeted primary school age children in Sierra Leone, altered women's attitudes on matters that impact women's health, on the number of desired children, and on attitudes regarding violence against women. The same reform, however, had no impact on men along these dimensions. 
of a husband. The reform also caused women to make their marriage decisions more independently from the influence of their families. Specifically, the reform reduced women's propensity to get involved in an arranged marriage, reduced their propensity for marrying somebody against their will (having been forced into marriage by their family), and it made women more likely to meet their spouse through school, friends, workplace, the internet or other avenues, as opposed to meeting their spouse via family, relatives or neighbors. These results are not sensitive to control variables and the impact of the reform is confirmed when we use aggregate measures as dependent variables, rather than specific indicators.

\section{Robustness Checks and Placebo Tests}

The models contain a variable to indicate if the person speaks a second language and its interaction with region of residence dummies to account for cultural differences. It can be argued that being able to speak a second language is not a function of the existing local culture but a function of the education reform. Exposure to the education reform would not impact the ability to speak Kurdish or Arabic as a second language, but it may have impacted the ability to speak English because the middle school curriculum (grades 6 to 8) includes English classes. To guard against the possibility of endogeneity of this variable, we dropped it from the model. As shown in column (1) of Table 5, the results did not change. ${ }^{40}$ In addition to this exclusion, dropping from the models the region of residence fixed effects did not alter the results (column 2) either. Finally, as displayed in column (3) of Table 5, omitting all variables from the model and running the dependent variables only on the treatment indicator and the trends provided the same inference.

In Table 6 we report regressions in which we use aggregate indicators as dependent variables by combining the outcomes used in Tables 3 and 4 . Specifically, we employ all variables listed in Table 3 with the exception of age at first marriage, and the age difference, and use the first principal component of the five variables. The reason why we exclude these two variables is because it is unclear whether an increase in them has the same interpretation as an increase in the other five variables (e.g. an increase in the propensity to marry a cousin, an increase in the probability to be in a forced marriage, and so on). The result, displayed in column (1), confirms

\footnotetext{
${ }^{40}$ The raw means of this variable is different between the control and treatment groups for some groups (see Table 1). However, this difference is explained by age trends, which are included in all models. Specifically, controlling for age trends eliminates the impact of the reform on speaking a second language.
} 
the significant impact of the reform, and dropping all control variables (other than the trend terms) has no impact on the inference (column 2). Similarly, we use the four variables of Table 4 to create their principal component, which is employed as a dependent variable. The estimated coefficients of the reform, displayed in columns (3) and (4), are not statistically significant. This is not surprising because the two variables embedded in this aggregate measure (the importance of spouse's religious sect, and the importance of similar political views) are not impacted by the reform (see columns 3 and 4 of Table 4). We create a third summary indicator, which is the principal component using the variables It is OK to Marry a Blood Relative and Spouse's Education is Not Important (variables listed in columns 1 and 2 of Table 4). The reform has a significant impact on this summary indicator regardless of whether the model includes or excludes control variables (columns (5) and (6) of Table 6, respectively).

To further investigate the sensitivity of the results, we implemented a number of exercises. First, we estimated the models by including linear and quadratic terms in age, rather than differential age trends in the treatment and control groups, which did not alter the conclusions. Second, recall that those born in 1986 are not included in the analyses because, as detailed in the data section, it is unclear whether they are treated by the reform. As a sensitivity check, we added this cohort to the analysis sample and considered it as part of the treated group. Alternatively, we assigned the value of 0.5 to this cohort. As displayed in Appendix Table A.2, although the statistical significance is lost in a couple of cases, the results remained robust.

The empirical specifications effectively compare individuals who differ in age by eight years. There was no sudden change in the country, other than the education reform, that could have impacted a cohort of individuals differently from another cohort. However, by design, those who are treated by the reform are younger than those who are not treated. It can be argued that the results may be driven by this age effect because younger individuals may be more rebellious against social norms, and that people may conform to cultural norms and traditions as they get older. That the models control for time trends that vary between pre- and post-treatment periods and vary between women and men (because we estimate the models separately by sex), and that we find a significant effect for women, but not for men, argues against this conjecture and indicates that the results are unlikely to be driven by an across-the-board age effect. Nevertheless, as a third exercise, we estimated the models of Table 3 using different bandwidths, which are displayed in Appendix Table A.3. The table presents the results obtained from models which are based on 
bandwidths of 6, 7, 9, and 10 years. It also displays the results of the same exercise for the two outcomes of Table 4 that are significantly impacted by the reform (It is OK to Marry a Blood Relative and Spouse's Education is Important).

The sample size gets smaller as the bandwidth becomes narrower, which is expected to negatively impact the precision of the estimates. On the other hand, control and the treatment groups become arguably more dissimilar as the bandwidth gets larger. Nevertheless, the estimated coefficients are rather stable across different bandwidths, indicating that while narrowing or widening the age intervals of the treatment and comparison groups changes the sample composition, it has no meaningful impact on the results.

\section{Selection into the Analysis Sample}

Because the bulk of the analysis is focused on ever-married women, younger women who marry later than average are less likely to be included in the analysis sample. For example, 22 year old married women are in the regression sample of Tables 3 and 4, but 22 year of single women are not. The probability of getting married (and thus being included in our analysis sample) goes up with age. This is problematic to the extent that young women who are not yet married and therefore not included in the analysis sample may be systematically different from other young women who are in the sample because they are married. Therefore, we re-estimate the models by shortening the bandwidth for the treatment group, while keeping the bandwidth of the control group at 8 .

In the data we find that 38 percent women who are 22 years old are married, divorced or widowed at age 22. The rate is 43.5 percent for women who are 23 years old, and 50 percent at age 24. Thus, we re-estimated the models with bandwidths of 7 and 6 for those who are exposed to the reform. The bandwidth for the control group is kept intact. The results are reported in Appendix Table A.4. The first column is the benchmark specification as displayed in Tables 3 and 4 (with bandwidth of 8 for both the control and the treatment groups). The second and third columns display the results obtained from specifications where the 22 year old women, and 22-23 year old women in the treated group are excluded, respectively. The table shows that the results are insensitive to dropping these younger women from the sample.

We also implemented placebo tests by imposing incorrect reform years on the data. The first cohort that was fully impacted by the reform is the cohort of 1987 . We ran regression on the 
same sample, but assumed that the first affected cohort was 1988, 1990 or 1991. Similarly, we moved the reform year back in time, taking the cut-off year as 1985, 1984, or 1983. In the six regressions we ran (based on these six false reform years) where the dependent variable was middle school completion, the point estimate of the reform was negative in three regressions (one being statistically significant), and positive in the other three (one being significant). Thus, the use of placebo reform years eliminates the true effect of the reform on educational attainment.

We re-estimated regressions by employing the same sample of ever married women, and by using as dependent variables the seven marriage attributes that are significantly impacted by the reform (Panel A of Table 3) and the two marital preferences where reform had a statistically significant impact in Table 4 (It is OK to Marry a Blood Relative and Spouse's Education is Important). We estimated these models six times using six placebo reform years. Of the 54 coefficients generated from this exercise, seven coefficients flipped signs (in comparison to the results reported in Panel A of Table 3, and columns 1 and 2 of Table 4), and only 1 was statistically significant.

In an alternative exercise, we moved the reform years back and forth as described above, but each time we kept the eight year window on both sides of the false reform dates. This procedure changed the sample composition in comparison to the sample used in Tables 3 and 4 . Of the 54 coefficients estimated, only 14 were significant, and 13 coefficients had the opposite signs than those reported in Tables 3 and 4.

\section{Heterogeneous Impact of the Reform}

Did the reform impact women's propensity for consanguineous marriage differently in different regions of the country? The western region of Turkey is economically more developed and more urban, including big cities such as Istanbul and Izmir. The Eastern part of the country is more conservative and has a higher proportion of residents with Kurdish and Arabic heritage. As column (1) of Appendix Table A.5 reveals, the rate of middle school completion is lower in the eastern part of the country, but the reform had a significant impact on the propensity to complete middle school. The rates of cousin marriage and blood marriage are 12.4 percent and 28.0 percent, respectively in the East, while the corresponding rates are 6.5 percent and 15.6 percent in the West. As displayed in column (2) of the top panel of Appendix Table A.5, when we estimate the models in the sample of Eastern residents, we find that the coefficient of the reform in cousin marriage 
regression is -0.054 (se=0.031), and it is -0.123 (se=0.040) in the blood marriage regression. ${ }^{41}$ The corresponding coefficients in the Western sample are smaller $(-0.029$, se $=0.020$ for cousin marriage and -0.022 , $\mathrm{se}=0.027$ for the marriage to a blood relative). The impact of the reform on the propensity of marrying a blood relative is 44 percent in the East, while it is 14 percent in the West.

The middle panel and the bottom panel of Appendix Table A.5 show that the same inference is obtained when we divide the sample into East vs. West by the childhood region, or by urban vs. rural residence in childhood. The latter classification is based on the information in the data which allows us to determine whether the individual lived in a village, in a town or in a city until age 15.

The summary of Appendix Table A.5 is that the prevalence of first-cousin marriage is twice as high in the eastern region of the country, but that the impact of the reform is also bigger in magnitude and statistically significant in the East. The same is true in the sample of individuals who grew up in villages in comparison to those who grew up in towns or cities. The rate of blood relative marriage is also twice as high in the East and in the rural sample, and the reform has a significant impact on these marriages. The impact on blood marriage is weaker in the West. Thus, although the results are similar between regions, they indicate a more robust reaction in the Eastern region of the country which is economically less developed and more conservative in comparison to the Western region.

We also investigated whether the impact of the reform depends on the extent of consanguinity when the reform was implemented. To that end, we obtained the rate of blood marriage in 1993, which is available only at a course regional level. ${ }^{42}$ Adding these baseline rates and their interactions with reform exposure showed that if a region's rate of consanguineous marriage was one percent higher in 1993, women's propensity for marrying a cousin or a blood relative is one percentage point higher today in that region. These results are reported in Appendix

\footnotetext{
${ }^{41}$ The western part consists of the region of Marmara (which includes Istanbul), the Aegean region (which includes the city of Izmir), the region of Western Black Sea, the region of the Mediterranean, and the capital city of Ankara.

42 This information is reported by Koc and Eryurt (2017) for five regions of the country: East, West, North, South, and Central. These five regions are based on Demographic Health Survey classifications used by the authors.
} 
Table A.6, where models with and without control variables are estimated with different bandwidths. The results also revealed that the impact of the reform is stronger on women who reside in regions which had higher baseline consanguinity rates. In the western region of Turkey with the consanguinity rate of 13.6 percent in 1993, the reform reduced women's propensity for marrying a blood relative by 1.5 percentage point, whereas the reform led to a 10 percentage point decline in the East where the blood marriage rate was 34.3 percent before the implementation of the reform. ${ }^{43}$

\section{Potential Channels}

\section{Economic Factors}

Previous research has shown that the reform had no significant effect on women's labor force participation behavior, but that it had a substantial effect on women's wages (Torun 2018, Mocan 2014). The rise in women's wages may have increased women's bargaining power (with their parents) regarding their free choice of a spouse. It should be noted, however, that in Turkey consanguineous marriage has its roots in cultural traditions more than economic considerations. Evidence supporting this conjecture is obtained from the same household survey used in this paper. The survey includes a question about the reasons why the respondents find consanguineous marriage acceptable. Specifically, those who agreed with the statement that It is OK to Marry a Blood Relative, were asked a follow-up question as to their reasons for finding such unions acceptable. The options are i) not to divide up the wealth, ii) to preserve the family roots iii) because husband and wife get along better if they are blood relatives iv) because the elders of the family get more respect in blood marriages v) to preserve custom and traditions vi) other reasons.

Table 7 present the distribution of the responses. At least 46 percent of the respondents in each category indicate that the main reason for the acceptability of consanguineous marriage is the preservation of the family roots. Almost 30 percent of women and about 20 percent of men state that they approve the practice of consanguineous marriage because husbands and wives get along better in such marriages. Only less than 0.5 percent of women and about one percent of men state preserving wealth as the main justification for consanguineous marriage, and the rate

\footnotetext{
${ }^{43}$ Note that in Table A.5 "East" and "West" refer to the eastern and western halves (approximately) of the county (see footnote 41). In the analysis reported in Table A.6, the consanguinity rates of 1993 are reported in 5 regions of the country; and here "West" ("East") refers to the regions which constitute a subset of the western (eastern) half of the country.
} 
is less than two percent among those who are married to a cousin (columns 5 and 6). Thus, Table 7 depicts that in Turkey the protection of the family wealth is not a reason for the endorsement of consanguineous marriage. The main reason for its acceptance is the concerns about the preservation of customs and traditions.

\section{Improved Health Knowledge}

Education expands individuals' health knowledge which can lead to a change in their health behavior. ${ }^{44}$ Health complications of consanguineous marriage cannot be learned in school in Turkey because neither the middle school curriculum nor the high school curriculum includes health education. ${ }^{45}$ On the other hand, the more educated will have better cognitive skills, and educational attainment may allow more efficient access to health information. The data set does not contain any information on health knowledge. Thus, we cannot test whether those who are exposed to the reform have better knowledge about the health effects of an action or behavior (consanguineous marriage, smoking, vaccination, etc.) However, that exposure to three additional years of education alters women's preferences but that it has no impact on men suggests that either (i) increased cognitive skills, due to additional schooling, is not an important driver of the results, or (ii) the increase in schooling at this low margin is sufficient enough to register a change in women's preferences and behaviors, although it is not powerful enough to generate an impact for men.

\section{Decline in Religiosity}

It has been shown that an increase in educational attainment has a negative impact on religiosity (Becker, Nagler and Woessmann 2017; Mocan and Pogorelova 2017, Hungerman 2014). Using the same Turkish education reform analyzed in this paper, Cesur and Mocan (2018) show that increased education, due to the reform, decreased women's propensity to identify themselves as religious, reduced their propensity to wear a head cover (head scarf, turban or burka) and increased their tendency to identify themselves as modern as opposed to traditional or

\footnotetext{
${ }^{44}$ See Grossman $(2008,1972)$ for the theoretical framework regarding how education can impact health and the references cited in Altindag and Mocan (2014) for empirical applications.

${ }^{45}$ Although the department of education introduces it sporadically as an elective class.
} 
religious conservative. The reform, however, had no impact on men's religiosity. The results of Cesur and Mocan (2018) therefore suggest that the impact of the reform on the decline in women's religiosity could be an avenue through which women's propensity for consanguineous marriage is weakened. However, we provide evidence indicating that the potential change in religiosity is not the driver of the results. First, recall that the reform had no impact on women's beliefs regarding the importance of their husband's religious sect (see Table 4). In addition, we extracted a new variable from the data set, which gauges the extent to which the respondents agree with the statement that "It is important to have a religious spouse." Using this indicator as an outcome, we find that the reform had no impact on people's beliefs that religiosity is an important attribute of a spouse. As Appendix Table A.7 reveals, the estimated coefficients are small and never statistically different from zero for either men or women, regardless of the bandwidth. These results indicate that although the reform likely had a negative impact on religiosity, it did not alter women's preferences regarding the appeal of a religious husband. Thus, it is unlikely that a change in religiosity is driving the reduced propensity for consanguinity.

\section{Geographic Mobility and Exposure to "Others"}

It is possible that increased education and the associated wage effect on women identified by previous work (Torun 2018, Mocan 2014) may have motivated women to leave their home towns and to move to different locations to pursue better labor market opportunities. If such behavior is prevalent, geographically mobile women would be in a different marriage market and their propensity to marry a cousin or a blood relative would be lower not because of a change in preferences but because of the change in the marriage pool. To investigate the validity of this hypothesis, we created an indicator which equals one if both the wife and husband grew up in the same province (81 provinces). If the mobility hypothesis is true, the reform should lower the probability of having been married to somebody who is also from the same province. Alternatively, we created another indicator variable which takes the value of one if the husband and wife grew up in the same province and they also grew up in a similar settlement of that province (a village vs. a town/city). For example, if a woman grew up in the city of Ankara but her husband grew up in a village around Ankara, this variable takes the value of zero because even though both of them are from the province of Ankara, one of them grew up in an urban area of the province whereas the other grew up in a village of that province. 
Appendix Table A.8 displays the results, and shows that exposure to the reform had no impact on the probability of a couple having been grown up in the same province (Panel A), or in the same province and same type of settlement (Panel B). Thus, the impact of the reform on consanguinity is unlikely to be driven by geographic mobility.

Another explanation may involve being "outside of the home" during the adolescent years. Exposure to the mandate of the reform compelled individuals to attend school when they were between the ages of 12 to 15 . This might help women create new friendship networks which could not have been possible otherwise. ${ }^{46}$ Attending school and being able to spend time outside of the home during the adolescent years could have allowed females to get exposure to new ideas and experiences other than those provided by their family and relatives. ${ }^{47}$

\section{Do the Results Reflect Women's Empowerment, or the Decisions of their Families on Behalf of Women?}

It can be argued that even though women who are exposed to the education reform reduce their propensity to marry a cousin or a blood relative, this outcome does not reflect women's own decisions. Instead, their parents may have decided that increased educational attainment of their daughter made it now optimal for her to marry somebody else, rather than her cousin. In this scenario, consanguinity declines due to the reaction of women's families, and not because of women's improved autonomy regarding their own marital decisions. Although we cannot dismiss the influence of the family, it is unlikely that this is the primary driver of the results. We posit that the reform improved women's independence regarding their marital decisions, and that it changed women's preferences regarding marital decisions. The net result is the empowerment of women.

\footnotetext{
${ }^{46}$ As shown elsewhere (Kırdar, Dayığlu and Koç 2018, Mocan 2014) and in Table 2 of this paper, the reform also had a spillover effect as it increased high school education as well. This means that some females, who are treated by the reform, were exposed to these influenced for additional years beyond the three years mandated by the reform.

${ }^{47}$ When the reform law was passed in 1997, the labor force participation rate of women ages 15-24 was $32 \%$, while the labor force participation rate for men was $63 \%$. This difference indicates that girls and young women had a much higher propensity to have more limited exposure to social life outside of the home, compared to boys and young men.
} 
This is reflected by a number of observations. First, as discussed earlier, the reform made women less likely to go along with the wishes of the family and marry somebody they don't want to marry. That is, the reform made women more resilient in terms of resisting the pressure of the family regarding the marriage decision. Second, the reform made women less likely to marry somebody who they met through the network of family, relative or neighbors. Instead, exposure to the reform made women are more likely to meet their husbands through their network of friends, workplace colleagues, school, the internet or a dating agency. As Appendix Table A.8 shows, this is not an artifact of the change in the marriage pool due to geographic mobility. Third, the reform made women less likely to be in a marriage arranged by a match-maker. Fourth, the reform altered women's preferences in favor of an educated husband.

Fifth, we analyzed the responses to a survey question gauging the extent to which women agree with the statement that "Only a son can ensure the continuation of the family blood line." As displayed at the bottom of Table 1, the proportion of women (ever-married women) who agree with this statement is $0.226(0.242)$. Appendix Figure A.4 displays this information, net of exogenous covariates, by cohorts of ever married women and ever married men, respectively. Table 8 displays the impact of the reform on the propensity to agree with this statement. The results for the benchmark model with the bandwidth of eight years are displayed in the table along with the results obtained from using other bandwidths (as was done in the robustness analyses of Table A.3 in the Appendix.). As shown in Panel A of Table 8, the reform reduced married women's propensity to agree with the statement that only a son can ensure the continuation of the family blood line by about 7 percentage points in the benchmark model. This impact, which represents a 29 percent decline in the sentiment, is statistically significant and robust to the variations in bandwidth. Panel B shows that the impact is smaller in magnitude in the sample of all women (4 percentage points), but it still translates to an 18 percent decline in the propensity to agree with the statement. ${ }^{48}$ These results, taken together suggest that the reform may have positively influenced women's self-confidence and independence.

\footnotetext{
${ }^{48}$ Panels C and D reveal that consistent with the results reported earlier, the reform does not influence men's beliefs regarding the continuation of the family blood line as a function of the sex of the progeny.
} 


\section{Summary and Discussion}

Consanguineous marriage is a remarkably common phenomenon, especially in developing nations. In most countries of the Middle East and North Africa, the rate of consanguineous marriage is more than 25 percent, and it is as high as 50 percent in some parts of the world. As detailed in Section II, although such inbreeding is more prevalent in Muslim societies, it is not strictly a function of religion. The variation in consanguinity between countries which adhere to the same religion, and the change in the prevalence of consanguineous marriage over time indicate that the intensity of this practice is the result of the interplay between religion, cultural norms, institutions and economic conditions.

In this paper, we use data from Turkey, where 20 percent of marriages is consanguineous. The nationally-representative data set contains detailed information on individuals' marriage attributes and marital preferences, along with their personal characteristics. We leverage an education reform, which increased the mandatory schooling by three years for students who completed the $4^{\text {th }}$ grade or who were in lower grades in Summer 1997, but exempted older students (those who completed the $5^{\text {th }}$ grade) from the mandate of the reform. We confirm the result of previous research that this reform generated an increase in the probability of having at least a middle school education (which requires completion of eight years of schooling).

We find that the reform made women less likely to find consanguineous marriage as an acceptable practice, and that the reform lowered women's propensity to marry a first cousin or a blood relative. It has been argued that consanguineous marriage is not a voluntary choice for women in traditional Muslim societies (Edlund 2018). Women may be denied the right to decide their own marriage, and they may be forced into these arrangements by their fathers, or more generally, by their families. To the extent that women's decisions to marry a cousin or a blood relative are under the influence of dominant males of the patriarchal family as suggested by Edlund (2018), our results indicate that education increases women's autonomy in marriage decisions.

It can be conjectured that although the reform led to a decrease in women's propensity for consanguineous marriage, this may reflect the modifications in the decisions that the families make on behalf of their daughters, rather than women's improved autonomy to make their own marital decisions. However, we provide evidence indicating that higher educational attainment, generated by the reform, led to more independence for women. First, women who were treated by the reform are less likely to be in an arranged marriage, and they are more likely to have met their husbands 
through networks outside of their family, relatives or neighbors. Second, a unique feature of our data set is the ability to determine whether the individuals got married to their spouses voluntarily (by their consent) or whether they were forced into it by their family. We find that exposure to the reform reduced women's probability of having been married against their will. ${ }^{49}$ These findings indicate that the reform increased women's autonomy, as exposure to the reform enhanced their ability to make marriage decisions independent of their families.

We also find that the reform made women less likely to agree with the idea that only a son can ensure the continuation of the family blood line, which implies that the reform altered women's beliefs and attitudes in favor of females. Taken together, these results indicate that exposure to the education reform increased women's inclination to make marriage decisions that are consistent with their own preferences, instead of going along with the wishes of the family, or the customs of the society. Put differently, the reform had an empowerment effect on women. ${ }^{50}$ We show that these results do not emerge because of a change in religiosity or geographic mobility.

The results show that exposure to the reform made women delay their first marriage, and that it changed women's preferences in favor of an educated husband. The reform had no significant impact on men's preferences even though it increased men's education as well. The propensity for consanguineous marriage for men went down because women tend to marry men who are four year older on average, and therefore some men who missed the reform are nevertheless impacted by it indirectly, through the change in women's behavior.

These results are potentially important for a number of reasons. First, they contribute to our understanding of non-pecuniary effects of educational attainment. They demonstrate that education alters women's preferences, and that it impacts behavior in a setting where such behavior (marrying a first cousin or a blood relative) is part of the culture of the society.

The results also have implications for child health. The practice of consanguineous marriage is associated with increased mortality and morbidity and serious health consequences for

\footnotetext{
${ }^{49}$ Although this point estimate is non-significant at conventional levels, arguably because of limited variation of the variable in the sample, the effect is robust to variations in bandwidth and other variations in model specifications.

${ }^{50}$ Although in a different context, these findings resemble the results of Jensen and Oster (2009), who find that exposure to the Cable TV in India reduced women's preference for sons, and increased women's autonomy (their ability to go out without permission, ability to participate in household decision making.)
} 
the offspring. As summarized in Section II, it has been shown that the probability of a premature birth is higher for babies of consanguineous parents. Prenatal and neonatal mortality are also significantly higher for the newborns of such couples, and the same is true for post-neonatal mortality, infant mortality and under-5 mortality rates for the progeny of first cousin marriages. Infants born to consanguineous parents are lighter at birth and they suffer from a number of health problems as children, including being stunted and having learning disabilities. The detrimental impact of low birth weight on future outcomes (Currie 2009) can, in principle, be counterbalanced by investment into these children after birth (Heckman 2006; Cunha and Heckman 2008). There are, however, a number of other serious permanent health problems and disorders generated by consanguinity, including deafness, blindness, childhood glaucoma, congenital heart defects and cerebral palsy.

Although the harmful health effects of consanguineous marriage are well-documented in the medical literature, public policy attempts to discourage these marriages are not pursued because such attempts are presumed to create a backlash in the target populations. ${ }^{51}$ Along the same lines, as summarized by Modell and Darr (2002), several experts in the medical and social sciences argue that consanguineous marriage is engraved in the fabric of the society in many countries, and therefore it would be inappropriate to discourage it at the population level. Thus, a typical policy recommendation is to identify at-risk families and provide them with genetic counseling. ${ }^{52}$ Given this hands-off approach, policies that increase female education can be a vehicle through which the prevalence of consanguineous unions and the related health risks can be diminished. For example, a back-of-the-envelope calculation reveals that in Turkey about 200,000 children are born each year to parents who are blood relatives, and about half of these children are progeny of first cousins. In the absence of the education reform, there would have

\footnotetext{
${ }^{51}$ An example of such a situation is the incident in the U.K. in February 2008, where the environment minister Phil Woolas told the Sunday Times about the increased risk of genetic problems and birth defects among the children of first cousin marriages. He underlined that such marriages are a cultural, not a religious, issue. Nevertheless, these statements prompted the Muslim Public Affairs Committee to call on the Prime Minister Gordon Brown to fire Mr. Woolas as they were interpreted as being Islamophobic. (http://news.bbc.co.uk/2/hi/uk_news/7237663.stm)

52 These recommendations emerged following the two meetings of experts, organized by the Regional Office of the Eastern Mediterranean of the World Health Organization in 1994 and 1996. Modell and Darr (2002) summarizes the discussion at these meetings and the recommendations that emerged from them.
} 
been 56,000 additional children born the parents who are blood relatives and 36,000 of these children would be to first cousin marriages. ${ }^{53}$ Without the reform there would have been at least 580 additional infant deaths per year. ${ }^{54}$ Furthermore, there would be permanent birth defects and serious congenital malformations among the more than 55,000 surviving children of consanguineous parents each year.

High rate of consanguinity, coupled with high fertility rate in some developing countries, produces large cohorts of children born to consanguineous couples. For example, using 14 countries in the Middle East and North Africa, where data on the number of births and the rate consanguinity are available, ${ }^{55}$ we estimate that there are 3 million children born in these nations each year to consanguineous marriages. ${ }^{56}$ If female educational attainment impacts marriage preferences and decisions in most countries in the same way as it does in Turkey, education can be a potent policy tool to improve child health.

Finally, given the importance of human capital in economic development (Hanushek and Woessmann 2020), the associated improvements in physical health and cognition can have nontrivial effects on economic development. To the extent that consanguineous marriage promotes and preserves kinship clan networks and strong bonds to extended family, it impacts institutional structure, corruption, trust, and economic growth (Greif and Tabellini 2017, Akbari 2019, Schulz et al. 2019). Thus, the decline in consanguinity is also expected to impact long-run economic growth and cultural change.

\footnotetext{
${ }^{53}$ Consanguineous marriages may be associated with higher fertility rates (some of which may be due to replacement fertility because of the infant mortality-enhancing effect of consanguineous marriage). The reduction in fertility due to the decline in consanguinity is not accounted for in this number.

${ }^{54}$ This calculation makes use of the information that 20 percent of marriages are consanguineous in the country, the infant mortality rate is 9 deaths per 1,000 live births, and that infant mortality rate is 2.5 times higher among the offspring of consanguineous marriages.

55 The data can be downloaded from https://population.un.org/wpp/Download/Standard/Fertility/

${ }^{56}$ These countries are Turkey, Algeria, Egypt, Libya, Morocco, Tunisia, Iraq, Jordan, Kuwait, Lebanon, Omar, Qatar, Sudan, and Saudi Arabia.
} 


\section{Figures}

Figure 1: Proportion of All Women with at least a Middle School Degree by Birth Cohort

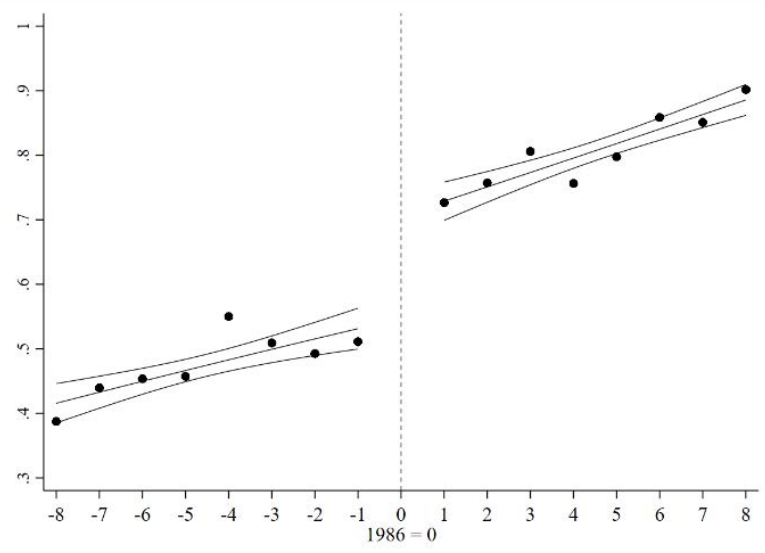

Figure 3: Proportion of Ever Married Women with at least a Middle School

Degree by Birth Cohort

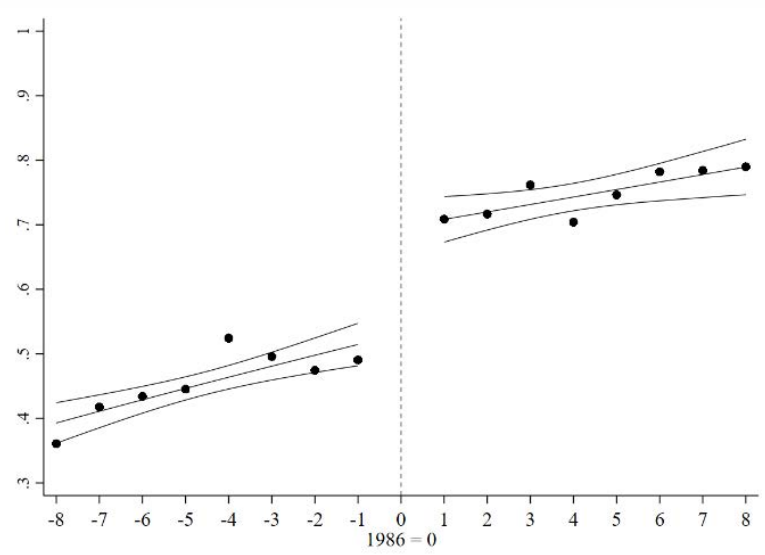

Figure 2: Proportion of All Men with at least a Middle School Degree by Birth Cohort

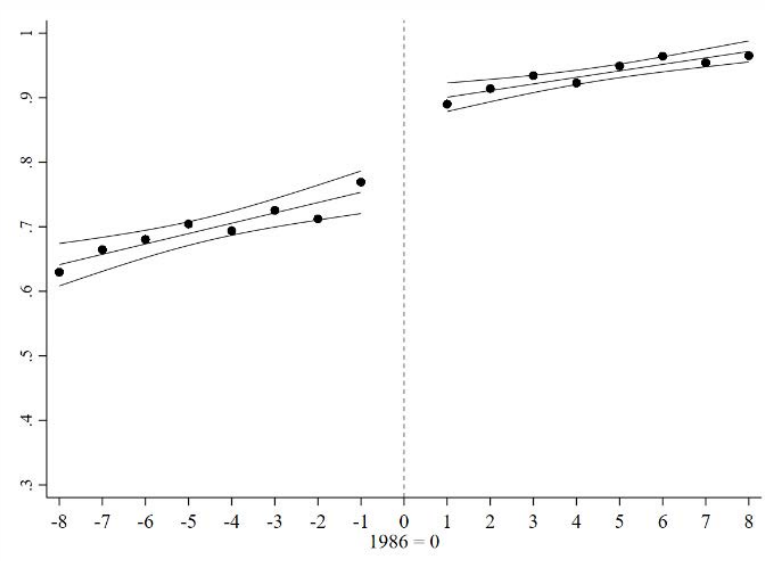

Figure 4: Proportion of Ever Married Men with at least a Middle School Degree by Birth Cohort

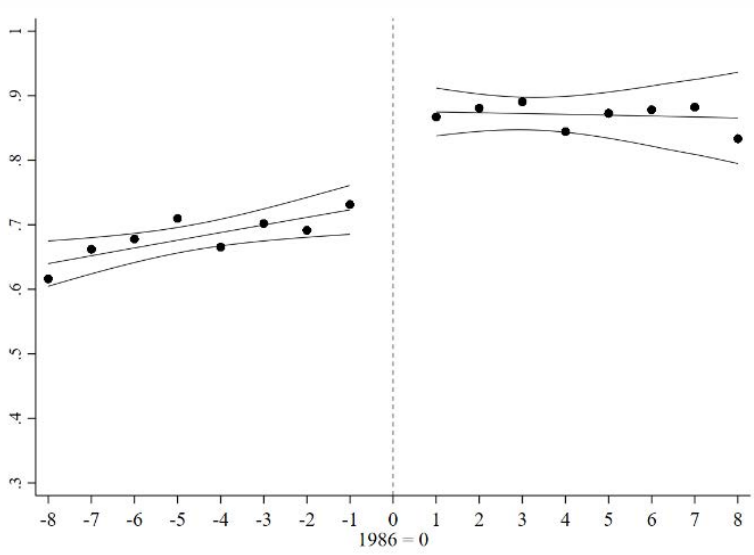


Figure 5: Proportion of Women Married to a First Cousin by Birth Cohort

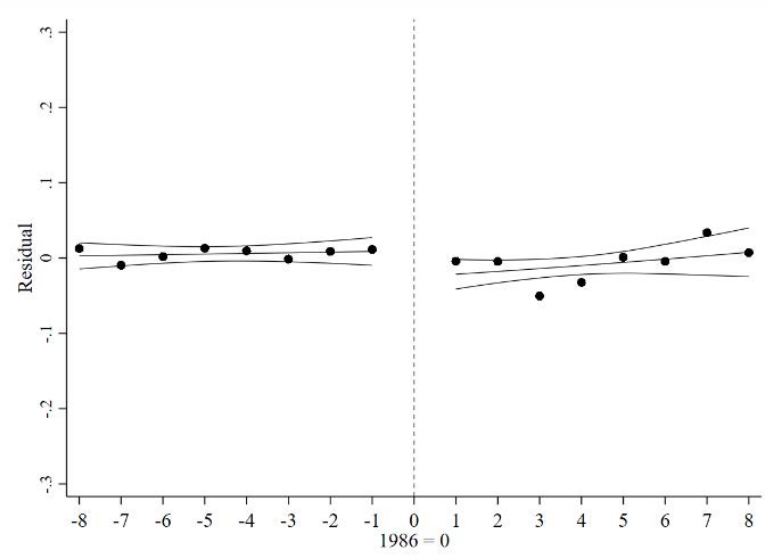

Figure 7: Proportion of Women Married to a Blood Relative by Birth Cohort

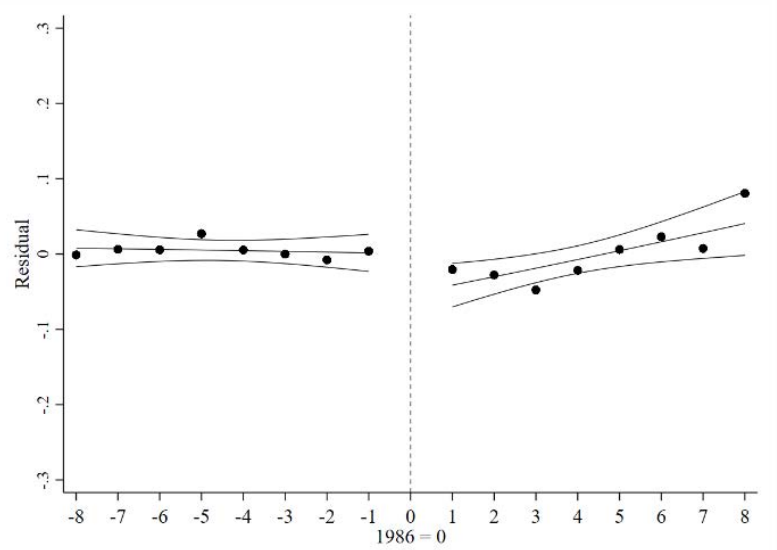

Figure 6: Proportion of Men Married to a First Cousin by Birth Cohort

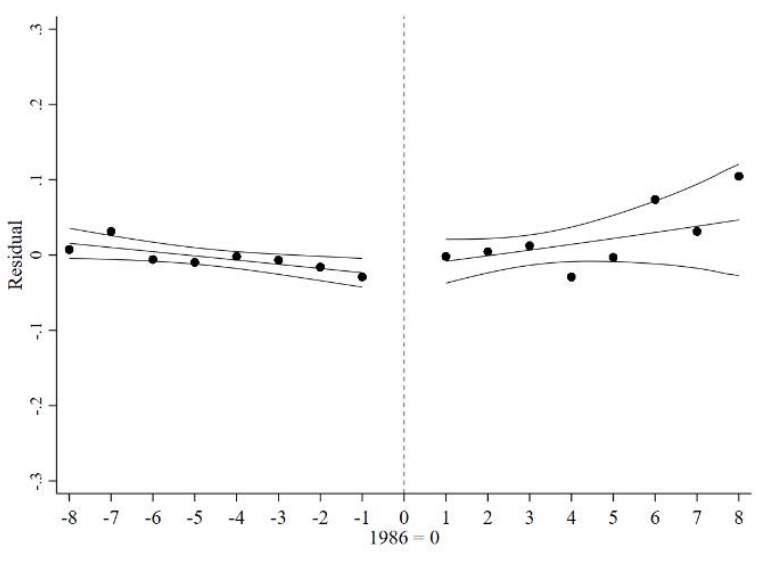

Figure 8: Proportion of Men Married to a Blood Relative by Birth Cohort

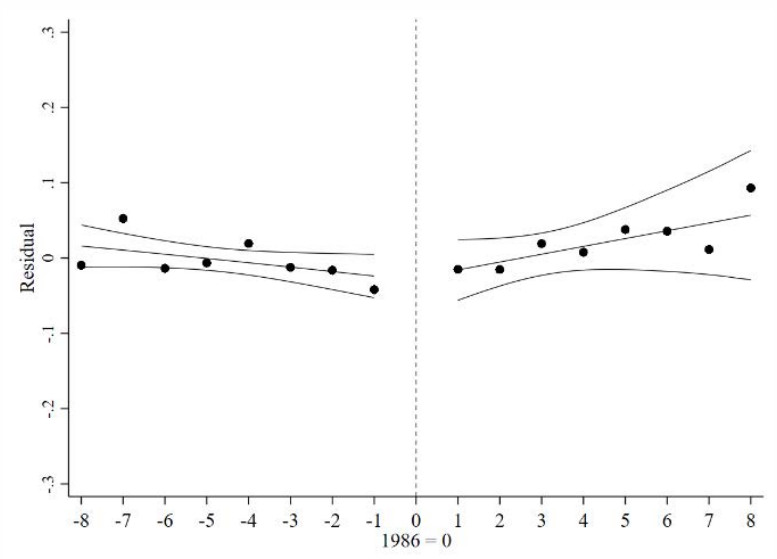


Figure 9: Age at First Marriage for Women by Birth Cohort

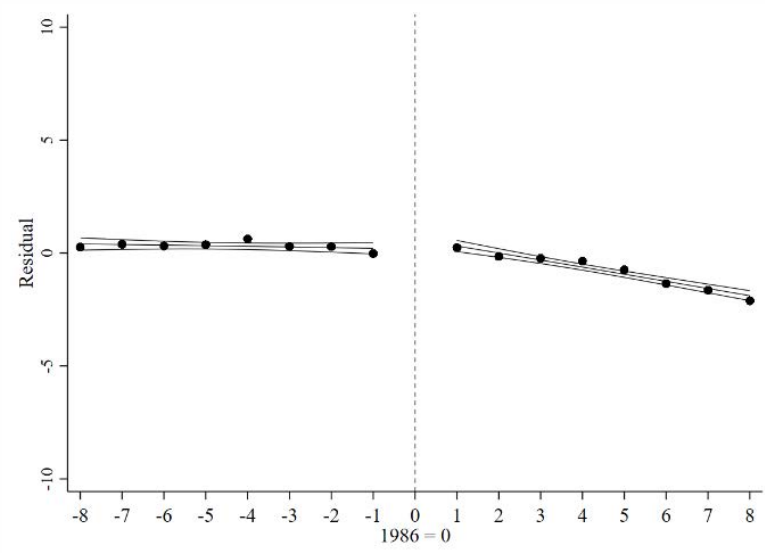

Figure 11: Proportion of Women by Birth Cohort who are in an Arranged Marriage

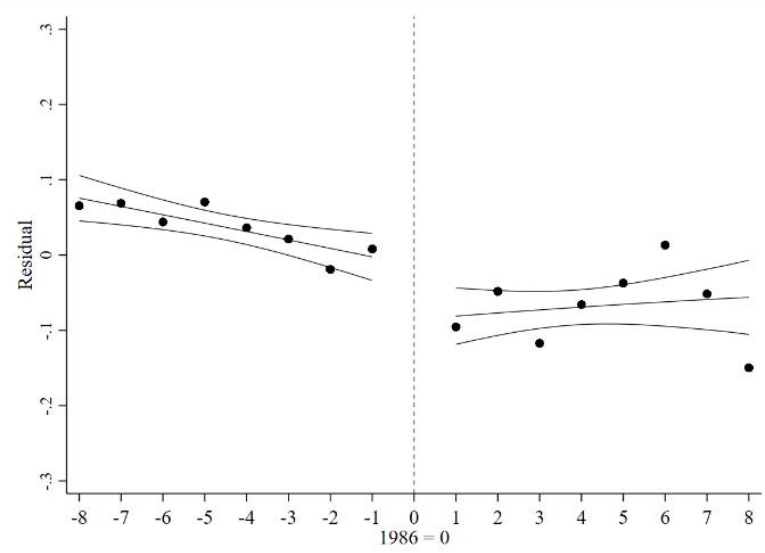

Figure 10: Age Difference for Women between Husbands and Wives by Birth Cohort

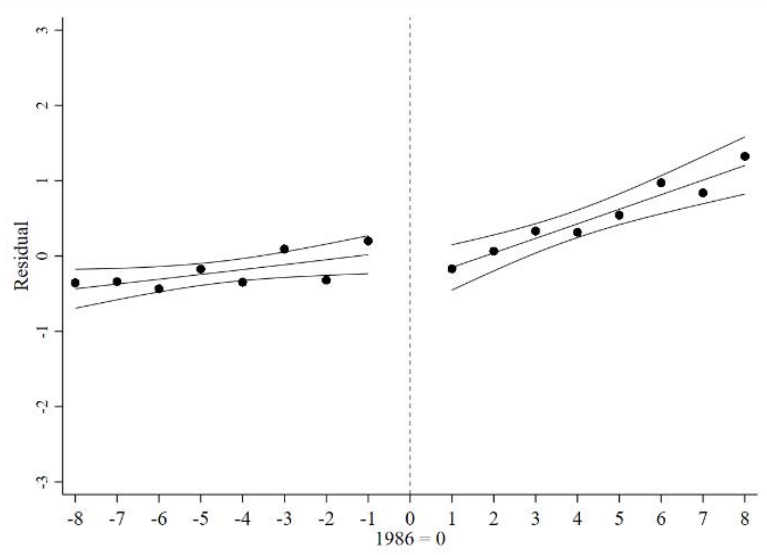

Figure 12: Proportion of Women by Birth Cohort who are Forced into Marriage

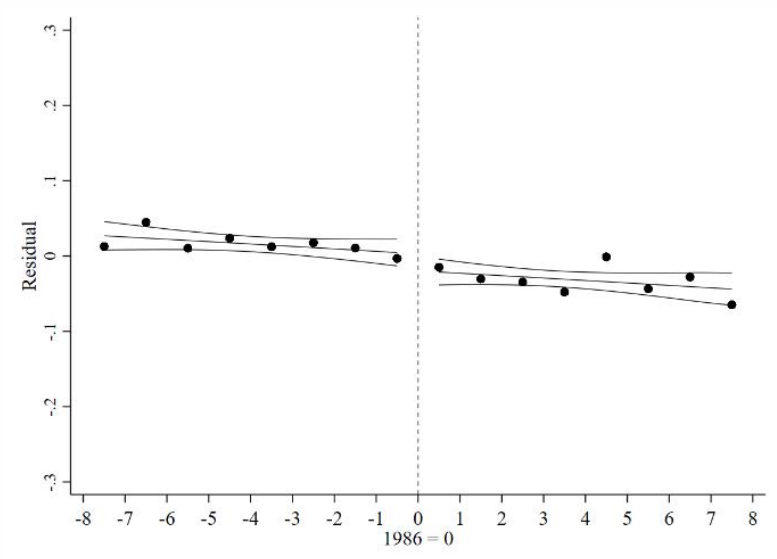


Figure 13: The Proportion of Women by Birth Cohort who met their Spouses through Family/Relatives/Neighbors

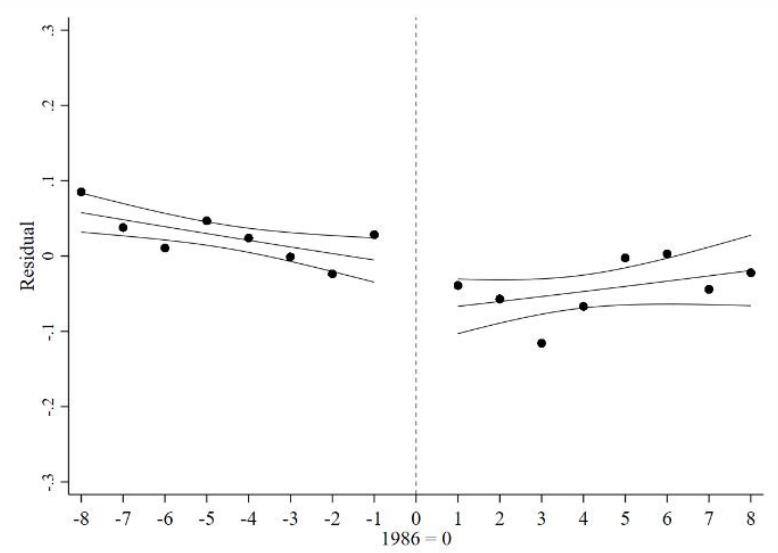

Figure 15: Proportion of Ever Married Women by Birth Cohort who Declare that Spouse's Education is not Important

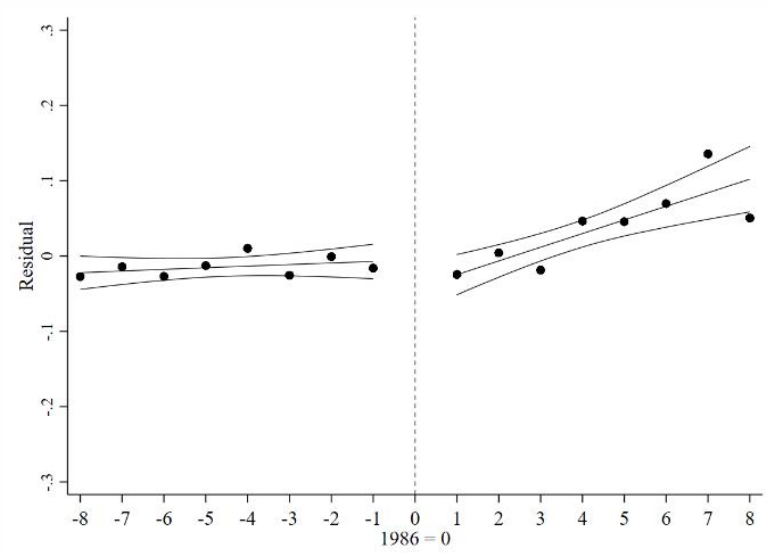

Figure 14: Proportion of Ever Married Women by Birth Cohort who Declare that it is OK to Marry a Blood Relative

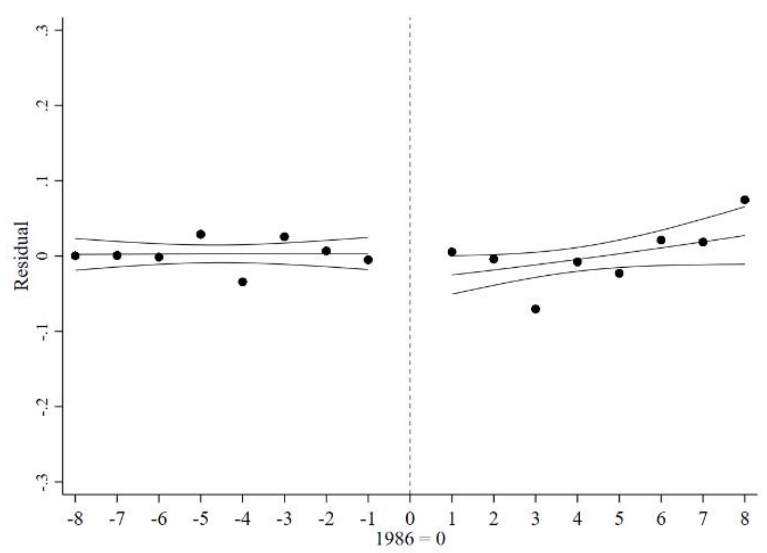

Figure 16: Proportion of Ever Married Women who States Spouse's Religious Sect is Important

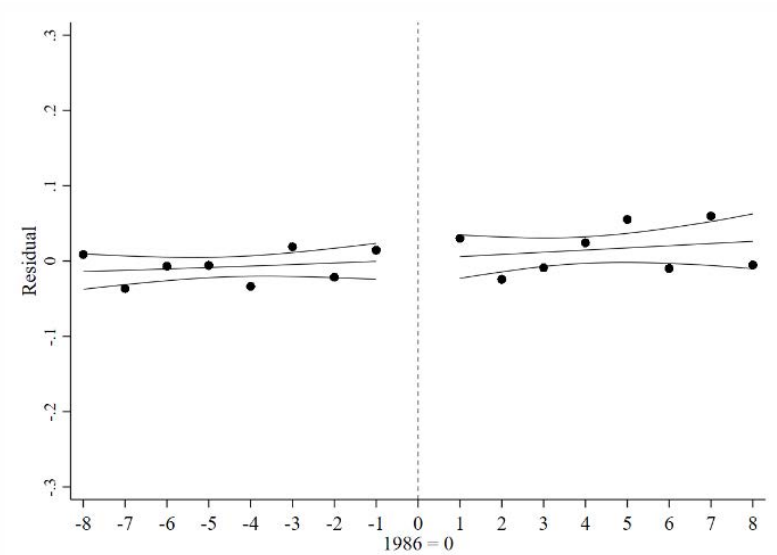


Figure 17: Proportion of Ever Married Women who States It is Important to have Similar Political Views with the

Spouse

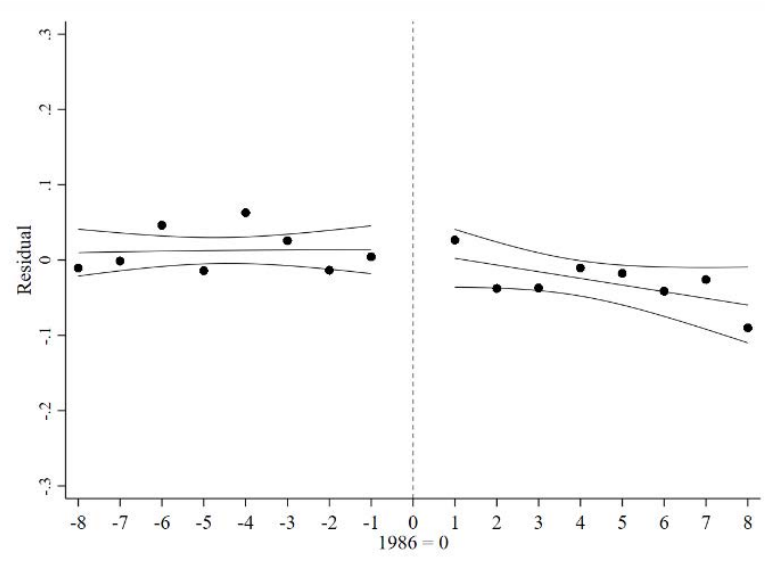

Figure 18: Proportion of Women and 4-year older Men Married to a First Cousin by Birth Cohort

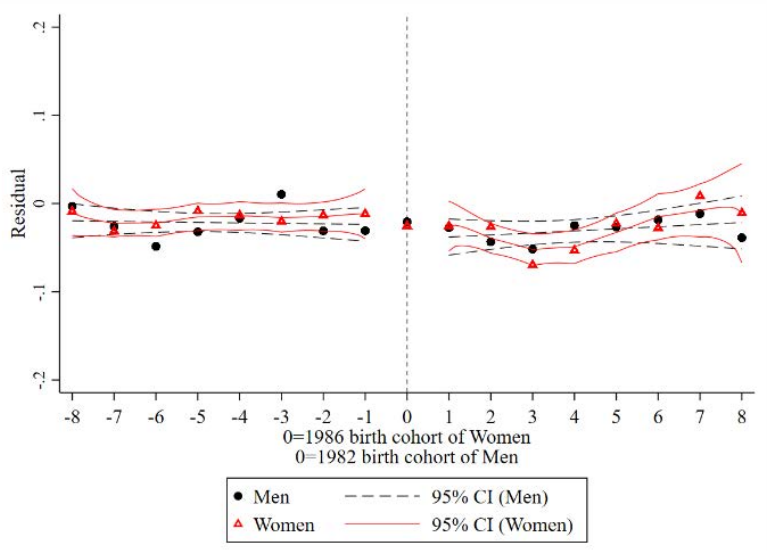

Figure 19: Proportion of Women and 4-year older Men Married to a Blood Relative by Birth Cohort

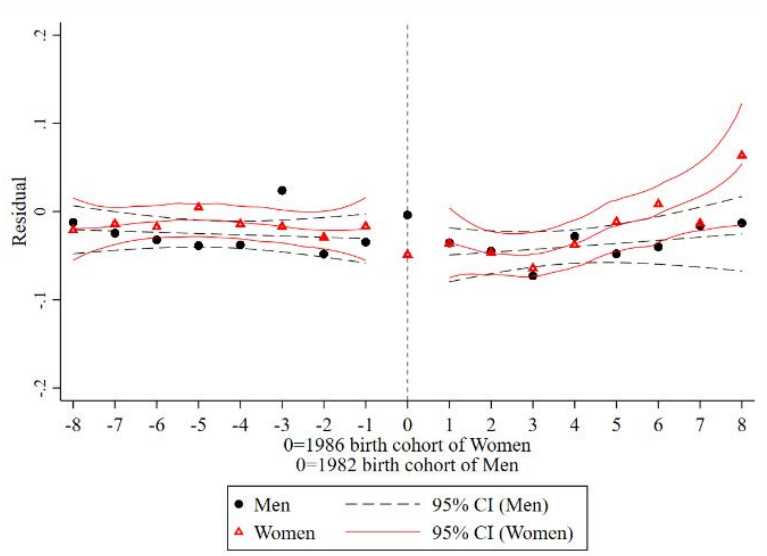


Table 1: Descriptive Statistics by Exposure to the Education Reform

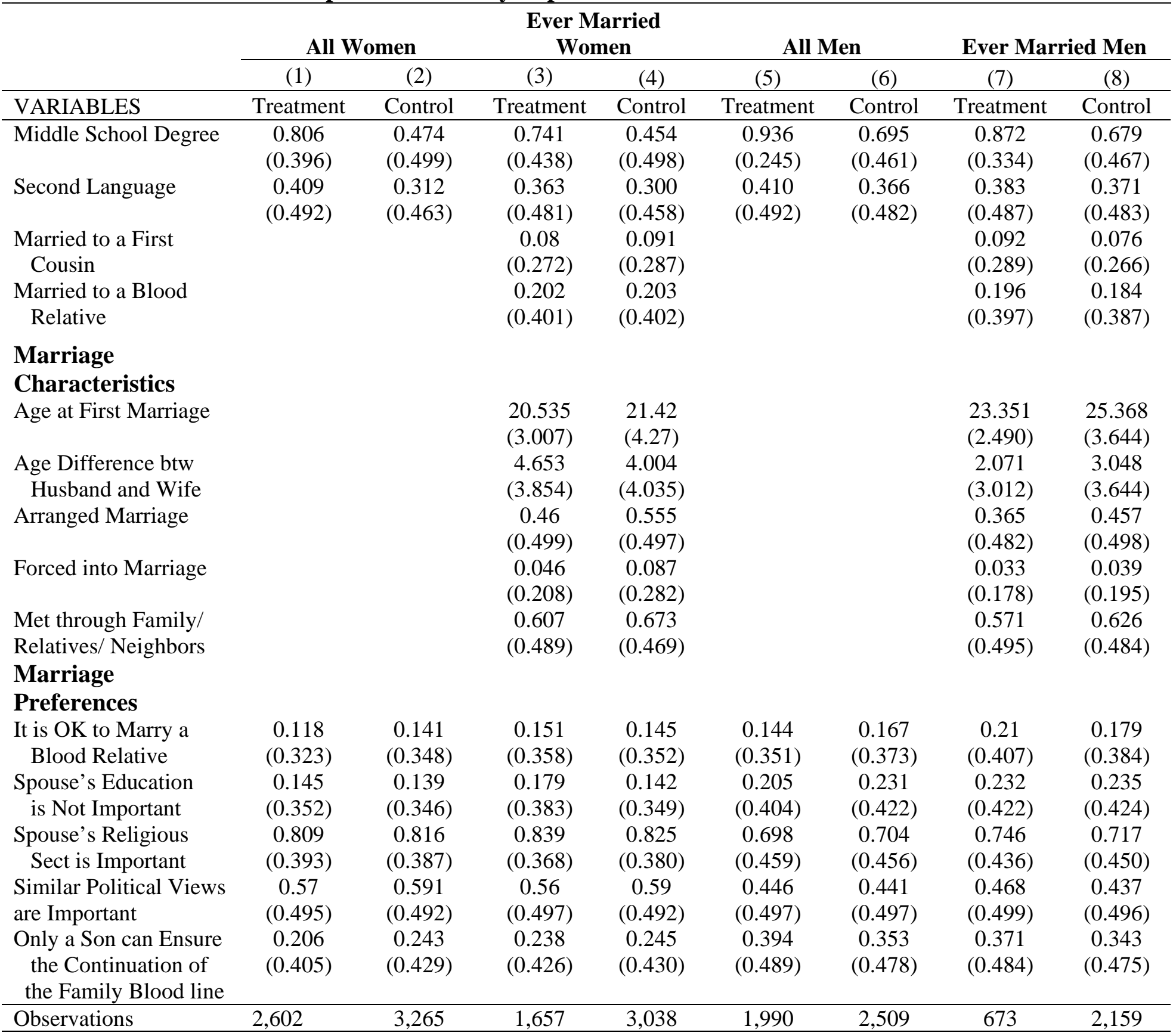

The data are from the 2016 Turkish Family Structure Survey. The treatment group consists of those who are born between 1987-1994. The control group consists of those who are born between 1978-1985. 1986 cohort is excluded as it is uncertain the extent to which this cohort is exposed to the reform. 
Table 2: The Effect of Exposure to the Education Reform on Educational Outcomes

\begin{tabular}{lcccccc}
\hline & $(1)$ & $(2)$ & $(3)$ & $(4)$ & $(5)$ & $(6)$ \\
\cline { 2 - 7 } & \multicolumn{3}{c}{ All Women } & \multicolumn{4}{c}{ Ever Married Women } \\
\cline { 2 - 7 } VARIABLES & Middle & High & & Middle & High & \\
\hline Reform & School & School & College & School & School & College \\
& $0.139^{* * *}$ & $0.043^{*}$ & 0.031 & $0.138^{* * *}$ & $0.071^{* * *}$ & 0.024 \\
& $(0.027)$ & $(0.023)$ & $(0.026)$ & $(0.030)$ & $(0.025)$ & $(0.026)$ \\
& {$[0.0140]$} & {$[0.0826]$} & {$[0.409]$} & {$[0.0170]$} & {$[0.0434]$} & {$[0.164]$} \\
\hline Observations & 5,867 & 5,867 & 5,867 & 4,695 & 4,695 & 4,695 \\
\hline \multirow{3}{*}{ VARIABLES } & All Men & \multicolumn{4}{c}{ Ever Married Men } \\
\hline Reform & School & School & College & Middle & High & \\
& $0.128^{* * *}$ & $0.086^{* * *}$ & 0.037 & $0.143^{* * *}$ & $0.138^{* * *}$ & 0.029 \\
& $(0.024)$ & $(0.031)$ & $(0.031)$ & $(0.033)$ & $(0.039)$ & $(0.036)$ \\
& {$[0.0010]$} & {$[0.0066]$} & {$[0.132]$} & {$[0.0014]$} & {$[0.0140]$} & {$[0.0706]$} \\
\hline Observations & 4,499 & 4,499 & 4,499 & 2,832 & 2,832 & 2,832 \\
\hline
\end{tabular}

The reform variable is equal to one if the respondent was born between 1987 and 1994 and equal to zero if the respondent was born between 1978 and 1985. The 1986 cohort is excluded from the sample as exposure to the reform is unclear for this cohort. The entries in parentheses are standard errors of the estimated coefficients, clustered by childhood regionby-birth cohort; * $\mathrm{p}<0.1 * * \mathrm{p}<0.05 * * * \mathrm{p}<0.01$. P-values related to bootstrapped standard errors, clustered by birth cohort level, are given in brackets. All regressions control for trend in the outcome variable separately for treatment and control groups, region of current residence and region of childhood fixed effects, an indicator if the person grew up in a village, and the interaction between the latter two variables, an indicator if the person speaks a second language, and the interaction of second language with region of residence fixed effects. See the text for details. 
Table 3: The Effect of Exposure to the Education Reform on Marriage Characteristics

\begin{tabular}{|c|c|c|c|c|c|c|c|}
\hline & \multicolumn{7}{|c|}{ Panel A: Ever Married Women } \\
\hline VARIABLES & $\begin{array}{c}\text { Married to } \\
\text { a First } \\
\text { Cousin }\end{array}$ & $\begin{array}{l}\text { Married to } \\
\text { a Blood } \\
\text { Relative }\end{array}$ & $\begin{array}{c}\text { Age at } \\
\text { First } \\
\text { Marriage }\end{array}$ & $\begin{array}{c}\text { Age } \\
\text { Difference }\end{array}$ & $\begin{array}{l}\text { Arranged } \\
\text { Marriage }\end{array}$ & $\begin{array}{c}\text { Forced } \\
\text { into } \\
\text { Marriage }\end{array}$ & $\begin{array}{c}\text { Met } \\
\text { through } \\
\text { Family/ } \\
\text { Relatives/ } \\
\text { Neighbors }\end{array}$ \\
\hline Reform & $\begin{array}{c}-0.036 * * \\
(0.017) \\
\{0.047\} \\
{[0.024]} \\
\end{array}$ & $\begin{array}{c}-0.056 * * \\
(0.024) \\
\{0.047\} \\
{[0.002]} \\
\end{array}$ & $\begin{array}{l}0.460 * \\
(0.235) \\
\{0.086\} \\
{[0.066]} \\
\end{array}$ & $\begin{array}{l}-0.439 * \\
(0.242) \\
\{0.088\} \\
{[0.124]}\end{array}$ & $\begin{array}{c}-0.072 * * \\
(0.031) \\
\{0.086\} \\
{[0.107]}\end{array}$ & $\begin{array}{c}-0.020 \\
(0.016) \\
\{0.210\} \\
{[0.0282]}\end{array}$ & $\begin{array}{c}-0.060 * * \\
(0.029 \\
\{0.086\} \\
{[0.134]}\end{array}$ \\
\hline Observations & 4,695 & 4,6 & 4,695 & 4,695 & 4,341 & & 4,695 \\
\hline VARIABLES & $\begin{array}{c}\text { Married to } \\
\text { a First } \\
\text { Cousin }\end{array}$ & $\begin{array}{l}\text { Married to } \\
\text { a Blood } \\
\text { Relative }\end{array}$ & $\begin{array}{c}\text { Age at } \\
\text { First } \\
\text { Marriage }\end{array}$ & $\begin{array}{c}\text { Age } \\
\text { Difference }\end{array}$ & $\begin{array}{l}\text { Arranged } \\
\text { Marriage }\end{array}$ & $\begin{array}{l}\text { Forced } \\
\text { into } \\
\text { Marriage }\end{array}$ & $\begin{array}{c}\text { Met } \\
\text { through } \\
\text { Family/ } \\
\text { Relatives/ } \\
\text { Neighbors }\end{array}$ \\
\hline Reform & $\begin{array}{c}0.013 \\
(0.022) \\
\{0.927\} \\
{[0.393]} \\
\end{array}$ & $\begin{array}{c}0.003 \\
(0.034) \\
\{0.927\} \\
{[0.863]}\end{array}$ & $\begin{array}{l}-0.343 \\
(0.214) \\
\{0.547\} \\
{[0.309]}\end{array}$ & $\begin{array}{c}0.073 \\
(0.264) \\
\{0.848\} \\
{[0.883]}\end{array}$ & $\begin{array}{c}0.029 \\
(0.040) \\
\{0.848\} \\
{[0.217]}\end{array}$ & $\begin{array}{c}0.003 \\
(0.014) \\
\{0.848\} \\
{[0.871]}\end{array}$ & $\begin{array}{c}-0.012 \\
(0.045) \\
\{0.848\} \\
{[0.805]}\end{array}$ \\
\hline Observations & 2,823 & 2,823 & 2,823 & 2,823 & 2,645 & 2,645 & 2,823 \\
\hline \multicolumn{8}{|c|}{$\begin{array}{l}\text { The Reform variable is equal to one if the respondent was born between } 1987 \text { and } 1994 \text { and equal to zero if the } \\
\text { respondent was born between } 1978 \text { and } 1985 \text {. The } 1986 \text { cohort is excluded from the sample as exposure to the } \\
\text { reform is unclear for this cohort. The entries in (parentheses) are standard errors of the estimated coefficients, } \\
\text { clustered by childhood region-by-birth cohort; } * \mathrm{p}<0.1 * * \mathrm{p}<0.05 * * * \mathrm{p}<0.01 \text {. P-values, adjusted for multiple } \\
\text { hypothesis testing, are displayed in \{curly brackets\}. P-values, related to bootstrapped standard errors clustered } \\
\text { by birth cohort, are given in [square brackets]. All regressions control for trend in the outcome variable } \\
\text { separately for treatment and control groups, region of current residence and region of childhood fixed effects, } \\
\text { an indicator if the person grew up in a village, and the interaction between the latter two variables, an indicator } \\
\text { if the person speaks a second language, and the interaction of second language with region of residence fixed } \\
\text { effects. See the text for details. }\end{array}$} \\
\hline
\end{tabular}


Table 4: The Effect of Exposure to the Education Reform on Marriage Preferences

\begin{tabular}{|c|c|c|c|c|}
\hline & $(1)$ & $(2)$ & (3) & (4) \\
\hline & \multicolumn{4}{|c|}{ Panel A: Ever Married Women } \\
\hline VARIABLES & $\begin{array}{c}\text { It is OK to } \\
\text { Marry a Blood } \\
\text { Relative }\end{array}$ & $\begin{array}{c}\text { Spouse's } \\
\text { Education is } \\
\text { Not Important }\end{array}$ & $\begin{array}{c}\text { Spouse's } \\
\text { Religious Sect } \\
\text { is Important }\end{array}$ & $\begin{array}{c}\text { Similar } \\
\text { Political } \\
\text { Views are } \\
\text { Important }\end{array}$ \\
\hline Reform & $\begin{array}{l}-0.038 * \\
(0.022) \\
\{0.087\} \\
{[0.210]} \\
\end{array}$ & $\begin{array}{l}-0.039 * \\
(0.021) \\
\{0.192\} \\
{[0.111]} \\
\end{array}$ & $\begin{array}{c}0.002 \\
(0.023) \\
\{0.924\} \\
{[0.949]} \\
\end{array}$ & $\begin{array}{l}-0.003 \\
(0.030) \\
\{0.924\} \\
{[0.921]} \\
\end{array}$ \\
\hline Observations & 4,695 & 4,695 & 4,695 & 4,695 \\
\hline VARIABLES & $\begin{array}{c}\text { It is OK to } \\
\text { Marry a Blood } \\
\text { Relative }\end{array}$ & $\begin{array}{c}\text { Spouse's } \\
\text { Education is } \\
\text { Not Important }\end{array}$ & $\begin{array}{c}\text { Spouse's } \\
\text { Religious Sect } \\
\text { is Important }\end{array}$ & $\begin{array}{c}\text { Similar } \\
\text { Political } \\
\text { Views are } \\
\text { Important }\end{array}$ \\
\hline Reform & $\begin{array}{l}-0.032 * \\
(0.019) \\
\{0.097\} \\
{[0.209]}\end{array}$ & $\begin{array}{l}-0.011 \\
(0.019) \\
\{0.553\} \\
{[0.465]}\end{array}$ & $\begin{array}{l}-0.013 \\
(0.021) \\
\{0.553\} \\
{[0.669]}\end{array}$ & $\begin{array}{l}-0.016 \\
(0.027) \\
\{0.553\} \\
{[0.481]}\end{array}$ \\
\hline Observations & 5,867 & 5,867 & 5,867 & 5,867 \\
\hline
\end{tabular}

The Reform variable is equal to one if the respondent was born between 1987 and 1994 and equal to zero if the respondent was born between 1978 and 1985. The 1986 cohort is excluded from the sample as exposure to the reform is unclear for this cohort. The entries in (parentheses) are standard errors of the estimated coefficients, clustered by childhood regionby-birth cohort; * $\mathrm{p}<0.1 * * \mathrm{p}<0.05 * * * \mathrm{p}<0.01$. P-values, adjusted for multiple hypothesis testing, are displayed in \{curly brackets\}. P-values, related to bootstrapped standard errors clustered by birth cohort, are given in [square brackets]. All regressions control for trend in the outcome variable separately for treatment and control groups, region of current residence and region of childhood fixed effects, an indicator if the person grew up in a village, and the interaction between the latter two variables, an indicator if the person speaks a second language, and the interaction of second language with region of residence fixed effects. See the text for details. 
Table 5: Sensitivity of Results to Omission of Control Variables

\begin{tabular}{|c|c|c|c|}
\hline & $(1)$ & $(2)$ & (3) \\
\hline & $\begin{array}{c}\text { Omission of } \\
\text { Second Language }\end{array}$ & $\begin{array}{l}\text { Omission of Second } \\
\text { Language \& Current } \\
\text { Region of Residence }\end{array}$ & $\begin{array}{l}\text { Omission of All } \\
\text { Control Variables }\end{array}$ \\
\hline & \multicolumn{3}{|c|}{ Panel A: Married to a Cousin } \\
\hline Reform & $\begin{array}{c}-0.036 * * \\
(0.017) \\
0.0278 \\
\end{array}$ & $\begin{array}{c}-0.037 * * \\
(0.017) \\
{[0.0226]} \\
\end{array}$ & $\begin{array}{c}-0.046 * * \\
(0.022) \\
{[0.0168]}\end{array}$ \\
\hline Observations & 4,695 & 4,695 & 4,695 \\
\hline Reform & $\begin{array}{c}-0.056 * * \\
(0.024) \\
0.00160\end{array}$ & $\begin{array}{c}\text { Married to a Blood } \\
-0.057^{* *} \\
(0.024) \\
{[0.00280]}\end{array}$ & $\begin{array}{c}-0.067 * * \\
(0.033) \\
{[0.00480]}\end{array}$ \\
\hline Observations & 4,695 & 4,695 & 4,695 \\
\hline Reform & $\begin{array}{c}0.466^{* *} \\
(0.234) \\
0.0726\end{array}$ & $\begin{array}{c}\text { Panel C: Marriage Ag } \\
0.439 * \\
(0.232) \\
{[0.0776]}\end{array}$ & $\begin{array}{l}0.545 * \\
(0.304) \\
{[0.108]}\end{array}$ \\
\hline Observations & 4,695 & 4,695 & 4,695 \\
\hline Reform & $\begin{array}{l}\text { Panel D: Pa } \\
-0.420^{*} \\
(0.246) \\
0.148 \\
\end{array}$ & $\begin{array}{c}\text { : Age Difference btw I } \\
-0.414^{*} \\
(0.243) \\
{[0.143]} \\
\end{array}$ & $\begin{array}{r}\text { nd and Wife } \\
-0.402 \\
(0.266) \\
{[0.124]} \\
\end{array}$ \\
\hline Observations & 4,695 & $\begin{array}{r}4,695 \\
\end{array}$ & 4,695 \\
\hline Reform & $\begin{array}{c}-0.069 * * \\
(0.031) \\
0.123 \\
\end{array}$ & $\begin{array}{c}\text { lel E: Arranged Marr } \\
-0.068^{* *} \\
(0.031) \\
{[0.135]} \\
\end{array}$ & $\begin{array}{l}-0.080 * \\
(0.048) \\
{[0.183]}\end{array}$ \\
\hline Observations & 4,341 & 4,341 & 4,341 \\
\hline Reform & $\begin{array}{l}-0.019 \\
(0.016) \\
0.0300 \\
\end{array}$ & $\begin{array}{c}\text { el F: Forced into Mar } \\
-0.017 \\
(0.016) \\
{[0.0546]} \\
\end{array}$ & $\begin{array}{c}-0.023 \\
(0.017) \\
{[0.0130]}\end{array}$ \\
\hline Observations & 4,341 & 4,341 & 4,341 \\
\hline Reform & $\begin{array}{c}\text { Panel G: } \\
-0.059 * * \\
(0.030) \\
0.153 \\
\end{array}$ & $\begin{array}{c}\text { through Family/Relat } \\
-0.059^{* *} \\
(0.030) \\
{[0.128]}\end{array}$ & $\begin{array}{c}\text { eighbors } \\
-0.074^{*} \\
(0.041) \\
{[0.0488]}\end{array}$ \\
\hline Observations & 4,695 & 4,695 & 4,695 \\
\hline Reform & $\begin{array}{l}\text { Panel } \\
-0.037^{*} \\
(0.022) \\
0.232 \\
\end{array}$ & $\begin{array}{c}\text { is OK to Marry a Blc } \\
-0.038^{*} \\
(0.022) \\
{[0.211]}\end{array}$ & $\begin{array}{c}\text { lative } \\
-0.051 \\
(0.033) \\
{[0.0202]}\end{array}$ \\
\hline Observations & 4,695 & 4,695 & 4,695 \\
\hline & \multicolumn{3}{|c|}{ Panel I: Spouse's Education is Not Important } \\
\hline Reform & $\begin{array}{c}-0.042 * * \\
(0.021) \\
0.0804 \\
\end{array}$ & $\begin{array}{c}-0.044^{* *} \\
(0.021) \\
{[0.0712]}\end{array}$ & $\begin{array}{c}-0.038 * \\
(0.022) \\
{[0.0618]}\end{array}$ \\
\hline Observations & 4,695 & 4,695 & 4,695 \\
\hline
\end{tabular}


Table 6: The Effect of Exposure to the Education Reform on Composite Outcomes

\begin{tabular}{lcccccc}
\hline & $(1)$ & $(2)$ & $(3)$ & $(4)$ & $(5)$ & $(6)$ \\
\cline { 2 - 6 } & $\begin{array}{l}\text { PC1 with } \\
\text { Control } \\
\text { Variables }\end{array}$ & $\begin{array}{c}\text { PC1 without } \\
\text { Control } \\
\text { Variables }\end{array}$ & $\begin{array}{c}\text { PC2 with } \\
\text { Control } \\
\text { Variables }\end{array}$ & $\begin{array}{c}\text { PC2 without } \\
\text { Control } \\
\text { Variables }\end{array}$ & $\begin{array}{c}\text { PC3 with } \\
\text { Control } \\
\text { Variables }\end{array}$ & $\begin{array}{c}\text { PC3 without } \\
\text { Control } \\
\text { Variables }\end{array}$ \\
\hline Reform & $-0.318^{* * *}$ & $-0.374^{* * *}$ & 0.018 & 0.010 & $-0.155^{* *}$ & $-0.181^{* *}$ \\
& $(0.087)$ & $(0.142)$ & $(0.065)$ & $(0.070)$ & $(0.065)$ & $(0.078)$ \\
& {$[0.00200]$} & {$[0.00620]$} & {$[0.847]$} & {$[0.669]$} & {$[0.00460]$} & {$[0.00380]$} \\
\hline Observations & 4,341 & 4,341 & 4,695 & 4,695 & 4,695 & 4,695 \\
\hline Note: PC1 is constructed by using Married a Cousin, Married a Blood Relative, Arranged Marriage, Forced into \\
Marriage and Met through Family/Relatives/Neighbors variables. PC2 is constructed by using It is OK to Marry \\
a Blood Relative, Spouse's Education is not Important, Spouse's Religious Sect is Important, Similar Political \\
Views are Important. PC3 is constructed by using It is OK to Marry a Blood Relative and Spouse's Education \\
is not Important.
\end{tabular}

Table 7: The Reason Why Consanguineous Marriage is Acceptable

\begin{tabular}{|c|c|c|c|c|c|c|}
\hline $\begin{array}{l}\text { The reason given by } \\
\text { the respondent }\end{array}$ & $\begin{array}{c}\text { All } \\
\text { Women } \\
(1) \\
\end{array}$ & $\begin{array}{c}\text { Ever } \\
\text { Married } \\
\text { Women } \\
(2) \\
\end{array}$ & $\begin{array}{l}\text { All Men } \\
\text { (3) }\end{array}$ & $\begin{array}{c}\text { Ever } \\
\text { Married } \\
\text { Men } \\
(4) \\
\end{array}$ & $\begin{array}{l}\text { Women in } \\
\text { Cousin } \\
\text { Marriage } \\
(5) \\
\end{array}$ & $\begin{array}{c}\text { Men in } \\
\text { Cousin } \\
\text { Marriage } \\
(6) \\
\end{array}$ \\
\hline Not to divide up the wealth & 0.39 & 0.44 & 1.13 & 1.33 & 0.91 & 1.33 \\
\hline $\begin{array}{l}\text { To preserve the roots of the } \\
\text { family }\end{array}$ & 47.72 & 47.97 & 48.16 & 49.24 & 45.66 & 47.02 \\
\hline $\begin{array}{l}\text { Because husband and wife ge } \\
\text { along better if they are blood } \\
\text { relatives }\end{array}$ & 29.73 & 29.28 & 20.26 & 19.89 & 30.59 & 17.22 \\
\hline $\begin{array}{l}\text { Because the elders of the fam } \\
\text { get more respect in blood } \\
\text { marriages }\end{array}$ & 9.26 & 9.28 & 10.34 & 9.85 & 10.50 & 13.25 \\
\hline $\begin{array}{l}\text { To preserve customs and } \\
\text { traditions }\end{array}$ & 10.30 & 10.44 & 15.16 & 14.58 & 10.50 & 17.22 \\
\hline Other reasons & 2.61 & 2.61 & 4.96 & 5.11 & 1.83 & 3.97 \\
\hline
\end{tabular}

The samples in each column correspond to the regression samples reported in the Tables.

The percentages in each column add up to 100 . 
Table 8: The Effect of Exposure to the Education Reform on the Propensity to Agree with the Statement that "Only a Son can Ensure the Continuation of the Family Blood line"

\begin{tabular}{|c|c|c|c|c|c|}
\hline & (1) & $(2)$ & (3) & (4) & (5) \\
\hline & \multicolumn{5}{|c|}{ Bandwidth } \\
\hline & 10 & 9 & 8 & 7 & 6 \\
\hline & \multicolumn{5}{|c|}{ Panel A: Ever Married Women } \\
\hline Reform & $\begin{array}{c}-0.048 * * \\
(0.024) \\
{[0.053]}\end{array}$ & $\begin{array}{c}-0.053 * * \\
(0.025) \\
{[0.054]}\end{array}$ & $\begin{array}{c}-0.068 * * \\
(0.027) \\
{[0.015]}\end{array}$ & $\begin{array}{c}-0.071^{* *} \\
(0.029) \\
{[0.043]}\end{array}$ & $\begin{array}{c}-0.072 * * \\
(0.031) \\
{[0.031]}\end{array}$ \\
\hline \multirow[t]{2}{*}{ Observations } & 5,589 & 5,148 & 4,695 & 4,188 & 3,661 \\
\hline & \multicolumn{5}{|c|}{ Panel B: All Women } \\
\hline Reform & $\begin{array}{l}-0.038 * \\
(0.021) \\
{[0.097]} \\
\end{array}$ & $\begin{array}{l}-0.032 \\
(0.022) \\
{[0.127]} \\
\end{array}$ & $\begin{array}{c}-0.041^{*} \\
(0.024) \\
{[0.079]}\end{array}$ & $\begin{array}{c}-0.051^{* *} \\
(0.026) \\
{[0.093]} \\
\end{array}$ & $\begin{array}{c}-0.052 * \\
(0.028) \\
{[0.075]}\end{array}$ \\
\hline \multirow[t]{2}{*}{ Observations } & 7,201 & 6,506 & 5,867 & 5,134 & 4,398 \\
\hline & \multicolumn{5}{|c|}{ Panel C: Ever Married Men } \\
\hline Reform & $\begin{array}{c}0.028 \\
(0.040) \\
{[0.347]} \\
\end{array}$ & $\begin{array}{c}0.014 \\
(0.041) \\
{[0.701]} \\
\end{array}$ & $\begin{array}{c}0.007 \\
(0.043) \\
{[0.859]} \\
\end{array}$ & $\begin{array}{c}0.014 \\
(0.044) \\
{[0.734]} \\
\end{array}$ & $\begin{array}{l}-0.020 \\
(0.046) \\
{[0.685]}\end{array}$ \\
\hline \multirow[t]{2}{*}{ Observations } & 3,417 & 3,141 & 2,832 & 2,491 & 2,173 \\
\hline & \multicolumn{5}{|c|}{ Panel D: All Men } \\
\hline Reform & $\begin{array}{l}-0.027 \\
(0.028) \\
{[0.286]}\end{array}$ & $\begin{array}{l}-0.028 \\
(0.028) \\
{[0.282]}\end{array}$ & $\begin{array}{c}-0.043 \\
(0.030) \\
{[0.109]}\end{array}$ & $\begin{array}{l}-0.036 \\
(0.033) \\
{[0.148]}\end{array}$ & $\begin{array}{l}-0.043 \\
(0.037) \\
{[0.379]}\end{array}$ \\
\hline Observations & 5,516 & 5,013 & 4,499 & 3,910 & 3,342 \\
\hline \multicolumn{6}{|c|}{$\begin{array}{l}\text { The Reform variable is equal to one if the respondent was born between } 1987 \text { and } 1994 \text { and equal to zero if } \\
\text { the respondent was born between } 1978 \text { and } 1985 \text {. The } 1986 \text { cohort is excluded from the sample as exposure } \\
\text { to the reform is unclear for this cohort. The entries in (parentheses) are standard errors of the estimated } \\
\text { coefficients, clustered by childhood region-by-birth cohort; }{ }^{*} \mathrm{p}<0.1 * * \mathrm{p}<0.05^{* * *} \mathrm{p}<0.01 \text {. P-values, related } \\
\text { to bootstrapped standard errors clustered by birth cohort, are given in [square brackets]. All regressions } \\
\text { control for trend in the outcome variable separately for treatment and control groups, region of current } \\
\text { residence and region of childhood fixed effects, an indicator if the person grew up in a village, and the } \\
\text { interaction between the latter two variables, an indicator if the person speaks a second language, and the } \\
\text { interaction of second language with region of residence fixed effects. }\end{array}$} \\
\hline
\end{tabular}




\section{References}

Abu-Rabia, Salim, and Lateefeh Maroun. 2005. "The Effect of Consanguineous Marriage on Reading Disability in the Arab Community." Dyslexia 11 (1): 1-21.

Akbari, Mahsa, Duman Bahrami-Rad, and Erik O. Kimbrough. 2019. "Kinship, Fractionalization and Corruption." Journal of Economic Behavior and Organization. 166: 493-528.

Akyol, Pelin, Murat G. Kirdar. 2020. "Does Education Really Cause Domestic Violence? Replication and Reappraisal of "For Better or Worse? Education and Prevalence of Domestic violence in Turkey." IZA Discussion Paper No: 14001.

Al-Sekait, Mohammed Abdulaziz. 1989. "Maternal Influences on Birth Weight." Journal of the Royal Society of Health. 109(2): 69-70.

Almond, Douglas, Lena Edlund, and Mårten Palme. 2009. "Chernobyl's Subclinical Legacy: Prenatal Exposure to Radioactive Fallout and School Outcomes in Sweden." Quarterly Journal of Economics 124 (4): 1729-1772.

Altindag, Duha and Naci Mocan. 2014. "Education, Cognition, Health Knowledge and Health Behavior." European Journal of Health Economics. 15: 265-279.

Ambrus, Attila, Erica Field, and Maximo Torero. 2010. "Muslim Family Law, Prenuptial Agreements, and the Emergence of Dowry in Bangladesh." Quarterly Journal of Economics 125 (3): 1349-1397.

Ashraf, Nava, Natalie Bau, Nathan Nunn, and Alessandra Voena. 2020. "Bride Price and Female Education." Journal of Political Economy 128 (2): 591-641.

Asker, Erdal, 2020. "The Impact of Women's Education on the Prevalence of Consanguineous Marriage: The Case of Turkey." Unpublished manuscript, University of Connecticut.

Aydemir, Abdurrahman, Murat G. Kirdar, and Huzeyfe Torun 2020. "The Effect of Education on Geographic Mobility: Incidence, Timing, and Type of Migration." Working Paper.

Aydemir, Abdurrahman, and Murat G. Kirdar, 2017. "Low Wage Returns to Schooling in a Developing Country: Evidence from a Major Policy Reform in Turkey." Oxford Bulletin of Economics and Statistics. 79(6): 1046-1086.

Bahrami-Rad, Duman. 2019. Keeping It in the Family: Female Inheritance, Inmarriage, and the Status of Women. Working Paper.

Battistin, Erich, Agar Brugiavini, Enrico Rettore, and Guglielmo Weber. 2009. "The Retirement Consumption Puzzle: Evidence from a Regression Discontinuity Approach." American Economic Review 99 (5): 2209-2226.

Becker, Gary S., and Casey B. Mulligan. 1997. "The Endogenous Determination of Time Preference." The Quarterly Journal of Economics 112 (3): 729-758. 
Becker, Sascha O., Markus Nagler, and Ludger Woessmann. 2017. "Education and Religious Participation: City-level Evidence from Germany’s Secularization Period 1890-1930." Journal of Economic Growth 22 (3): 273-311.

Bellad. M., S. Goudar, S. Edlavitch, N. Mahantshetti, V. Naik, J. Hemingway-Foday, M. Gupta, H. Nalina, R. D Erman, and B Kodkany. 2012. "Consanguinity, Prematurity, Birth Weight, and Pregnancy Loss: A Prospective Cohort Study at Four Primary Health Center Areas of Karnataka, India." Journal of Perinatology 32: 431-437.

Bener, Abdulbari, and Rafat Hussain. 2006. "Consanguineous Unions and Child Health in the State of Qatar." Paediatric and Perinatal Epidemiology 20 (5): 372-378.

Benjamini, Yoav, and Daniel Yekutieli. 2001. "The Control of the False Discovery Rate in Multiple Testing Under Dependency." Annals of statistics 1165-1188.

Bernheim, B. Douglas, and Sergei Severinov. 2003. "Bequests as Signals: An Explanation for the Equal Division Puzzle." Journal of Political Economy 111 (4): 733-764.

Bharadwaj, Prashant, Petter Lundborg, and Dan Olof Rooth. 2018. "Birth Weight in the Long run." Journal of Human Resources 53 (1): 189-231.

Bittles, Alan H. 1998. "Empirical Estimates of the Global Prevalence of Consanguineous Marriage in Contemporary Societies."

Bittles, Alan H. 2003. "Consanguineous Marriage and Childhood Health." Developmental Medicine \& Child Neurology 45 (8): 571-576.

Bittles, Alan H., and Michael L. Black. 2010. "Consanguinity, Human Evolution, and Complex Diseases." Proceedings of the National Academy of Sciences of the United States of America 107: 1779-1786.

Botticini, Maristella, and Aloysius Siow. 2003. "Why Dowries?" American Economic Review. Vol. 93. no. 4. 9. 1385-1398.

Cannonier, Colin, and Naci Mocan. 2018. "The Impact of Education on Women's Preferences for Gender Equality: Evidence from Sierra Leone." Journal of Demographic Economics 84 (1): 3-40.

Card, David. 2001. "Estimating the Return to Schooling: Progress on some Persistent Econometric Problems." Econometrica 69 (5): 1127-1160.

Card, David. 1999. The Causal Effect of Education on Earnings. Vol. 3 PART, in Handbook of Labor Economics, by David Card, 1801-1863.

Cavaille, Charlotte, and John Marshall. 2019. "Education and Anti-immigration Attitudes: Evidence from Compulsory Schooling reforms Across Western Europe." American Political Science 113 (1): 254-263. 
Cesur, Resul, and Naci Mocan. 2013. "Does Secular Education Impact Religiosity, Electoral Participation and the Propensity to Vote for Islamic Parties? Evidence from an Education Reform in a Muslim Country." NBER Working Paper No. 19769.

Cesur, Resul, and Naci Mocan. 2018. "Education, Religion, and Voter Preference in a Muslim Country." Journal of Population Economics 31 (1).

Charafeddine, Lama, Farah Ammous, Loulou Kobeissi, Timothy De Ver Dye, Maroun Matar, Marie-Claude Faddous Khalife, and Khalid Yunis. 2012. "In-hospital Neonatal Mortality and the Role of Consanguinity." Paediatric and Perinatal Epidemiology 26 (5): 398-407.

Chay, Kenneth Y., and Michael Greenstone. 2003. "The Impact of Air Pollution on Infant Mortality: Evidence from Geographic Variation in Pollution Shocks Induced by a Recession." The Quarterly Journal of Economics 118 (3): 1121-1167.

Chou, Shin-Yi, Jin-Tan Liu, Michael Grossman, and Ted Joyce. 2010. "Parental Education and Child Health: Evidence from a Natural Experiment in Taiwan." American Economic Journal: Applied Economics 2 (1): 33-61.

Chu, C. Y. Cyrus. 1991. "Primogeniture." Journal of Political Economy 99 (1): 78-99.

Coneus, Katja, and C. Katharina Spiess. 2012. "The Intergenerational Transmission of Health in Early Childhood - Evidence from the German Socio-Economic Panel Study." Economics and Human Biology 10 (1): 89-97.

Cunha, Flavio, and James J. Heckman. 2008. "Formulating, Identifying and Estimating the Technology of Cognitive and Noncognitive Skill Formation." Journal of Human Resources 43 (4): 738-782.

Currie, Janet. 2009. "Healthy, Wealthy, and Wise: Socioeconomic Status, Poor Health in Childhood, and Human Capital Development." Journal of Economic Literature 47 (1): 87122.

Currie, Janet, and Matthew Neidell. 2005. "Air Pollution and Infant Health: What Can We Learn from California's Recent Experience?" The Quarterly Journal of Economics 120 (3): 10031030.

Currie, Janet, and Reed Walker. 2011. "Traffic Congestion and Infant Health: Evidence from EZPass." American Economic Journal: Applied Economics 3 (1): 65-90.

Currie, Janet, Lucas Davis, Michael Greenstone, and Walker Reed. 2015. "Environmental Health Risks and Housing Values: Evidence from 1,600 Toxic Plant Openings and Closings." American Economic Review 105 (2): 678-709.

Dee, Thomas S. 2004. "Are There Civic Returns to Education?" Journal of Public Economics. 88 (9-10): 1697-1720. 
De La Croix, David, Matthias Doepke, and Joel Mokyr, 2018. "Clans, Guilds, and Markets:

Apprenticeship Institutions and Growth in Preindustrial Economy," Quarterly Journal of Economics, 133(1): 1-70.

Diebolt, Claude, and Faustine Perrin. 2013. "From Stagnation to Sustained Growth: The Role of Female Empowerment." American Economic Review 103 (3): 545-549.

Dinçer, Mehmet Alper, Neeraj Kaushal, and Michael Grossman. 2014. "Women's Education: Harbinger of Another Spring? Evidence from a Natural Experiment in Turkey." World Development 64: 243-258.

Do, Quy Toan, Sriya Iyer, and Shareen Joshi. 2013. "The Economics of Consanguineous Marriages." Review of Economics and Statistics 95 (3): 904-918.

Dohmen, Thomas, Armin Falk, David Huffman, and Uwe Sunde. 2010. "Are Risk Aversion and Impatience Related to Cognitive Ability?" American Economic Review 100 (3): 12381260.

Dorsten, Linda Eberst, Lawrence Hotchkiss, and Terri M. King. 1999. "The effect of Inbreeding on Early Childhood Mortality: Twelve Generations of an Amish Settlement." Demography 36 (2): 263-271.

Dow, Gregory K., Clyde G. Reed, and Simon Woodcock. 2016. "The Economics of Exogamous Marriage in Small-scale Societies." Economic Inquiry 54 (4): 1805-1823.

Duflo, Esther. 2012. "Women Empowerment and Economic Development." Journal of Economic Literature 50 (4): 1051-1079.

Dulger, Ilhan. 2004. "Turkey: Rapid Coverage for Compulsory Education-the 1997 Basic Education Program." In Scaling Up Poverty Reduction: A Global Learning Process and Conference. Shanghai. 25-27.

Dursun, Bahadır, Resul Cesur, and Naci Mocan. 2018. "The Impact of Education on Health Outcomes and Behaviors in a Middle-Income, Low-Education Country." Economics and Human Biology 31: 94-114.

Dursun, Bahadir, Resul Cesur and Inas Kelly, 2017. "The value of Mandating Maternal Education in a Developing Country." National Bureau of Economic Research Working Paper, No: 23492.

Dursun, Bahadir, and Resul Cesur. 2016. "Transforming Lives: The Impact of Compulsory Schooling on Hope and Happiness." Journal of Population Economics 29 (3): 911-956.

Eapen, Valsamma, Lihadh Al-Gazali, S. Bin-Othman, and T. Pramathan. 1998. "Learning Disorders in School-going Children-Detection and Diagnosis." Journal of Tropical Pediatrics 44 (4): 192-193.

Edlund, Lena. 2018. "Cousin Marriage Is Not Choice: Muslim Marriage and Underdevelopment." AER Papers and Proceedings 108: 353-57. 
Edlund, Lena. 1999. "Son Preference, Sex Ratios, and Marriage Patterns." Journal of Political Economy 107 (6 PART 1): 1275-1304.

Erkin, Gulten, Sibel Unsal Delialioglu, Sumru Ozel, Canan Culha, and Hulya Sirzai. 2008. "Risk Factors and Clinical Profiles in Turkish Children with Cerebral Palsy: Analysis of 625 Cases." International Journal of Rehabilitation Research 31 (1): 89-91.

Fenske, James. 2015. "African Polygamy: Past and Present." Journal of Development Economics 117: 58-73.

Fernández, Raquel. 2003. "Household Formation, Inequality, and the Macroeconomy." Journal of the European Economic Association 1 (2-3): 683-697.

Fernandez, Raquel, and Richard Rogerson. 2001. "Sorting and Long-Run Inequality." The Quarterly Journal of Economics 116 (4): 1305-1341.

Fernell, Elisabeth. 1998. "Aetiological Factors and Prevalence of Severe Mental Retardation in Children in a Swedish Municipality: the Possible Role of Consanguinity." Developmental Medicine \& Child Neurology 40 (9): 608-611.

Fort, Margherita, Nicole Schneeweis, and Rudolf Winter-Ebmer. 2016. "Is Education Always Reducing Fertility? Evidence from Compulsory Schooling Reforms." The Economic Journal 126 (595): 1823-1855.

Friedman, Willa, Michael Kremer, Edward Miguel, and Rebecca Thornton. 2016. "Education as Liberation?" Economica 83 (329): 1-30.

Ghosh Arkadev, Sam Hwang, and Munir Squires, 2020, "Economic Consequences of Kinship: Evidence from U.S. Bans on Cousin Marriage," Unpublished manuscript, University of British Columbia.

Glaeser, Edward L., and Bruce I. Sacerdote. 2008. "Education and Religion." Journal of Human Capital 2 (2): 188-215.

Goody, Jack. 1983. The Development of the Family and Marriage in Europe. Cambridge University Press.

Gould, Eric D., Omer Moav, and Avi Simhon. 2008. "The Mystery of Monogamy." American Economic Review 98 (1): 333-357.

Greenstone, Michael, and Rema Hanna. 2014. "Environmental Regulations, Air and Water Pollution, and Infant Mortality in India." American Economic Review 104 (10): 3038-3072.

Greif, Avner, and Guido Tabellini, 2017." The Clana nd the Corporartion: Sustaining Cooperation in China dn Europe," Journal of Comparative Economics, 45: 1-35.

Greif, Avner, 2006." Family Structure, Institutions, and Growth: The origins and Implications of Western Corporations," American Economic Review Papers and Proceedings, 96(2): 308312 
Grépin, Karen A., and Prashant Bharadwaj. 2015. "Maternal Education and Child Mortality in Zimbabwe." Journal of Health Economics 44: 97-117.

Grossman, Michael. 2008. "The Relationship between Health and Schooling." Eastern Economic Journal. 34: 281-292

Grossman, Michael. 2006. "Education and Nonmarket Outcomes." In Handbook of the Economics of Education, by Michael Grossman, 577-633. Amsterdam: Elsevier.

Grossman, Michael and Theodore Joyce. 1990. "Unobservables, Pregnancy Resolutions, and Birth Weight Production Functions in New York City." Journal of Political Economy. 98(5): 983-1007.

Grossman, Michael. 1972. "On the Concept of Health Capital and the Demand for Health." Journal of Political Economy 80 (2): 223-255.

Gulesci, Selim, Erik Meyersson and Sifia Trommlerova, 2020. "The Effect of Compulsory Schooling Expansion on Mother's Attitudes Toward Domestic Violence in Turkey." World Bank Economic Review, 34(2): 464-484.

Gün, Feyza and Gülsün Atanur Başkan. 2014. "new Education System in Turkey (4+4+4): A Critical Look," Procedia-Social and Behavioral Sciences, 131: 229-235.

Hamamy, Hanan. 2012. "Consanguineous Marriages Preconception Consultation in Primary Health Care Settings." Journal of Community Genetics 3 (3): 185-192.

Hamamy, Hanan, Stylianos E. Antonarakis, Luigi Luca Cavalli-Sforza, Samia Temtamy, Giovanni Romeo, Leo P.Ten Kate, Robin L. Bennett, et al. 2011. "Consanguineous Marriages, Pearls and Perils: Geneva International Consanguinity Workshop Report." Genetics in Medicine. 841-847.

Hanushek, Eric A., and Ludger Woessmann. 2020. "Education, Knowledge Capital, and Economic Growth." In The Economics of Education, by Eric A. Hanushek and Ludger Woessmann, 171-182. Elsevier.

Harlap, S., K. Kleinhaus, M. Perrin, R. Calderon-Margalit, O. Paltiel, L. Deutsch, O. Manor, E. Tiram, R. Yanetz, and Y. Friedlander. 2008. "Condanguinity and Birth Defects in the Jerusalem Pernatal Study Cohort." 66(3): 180-189.

Harrison, Glenn W., Morten I. Lau, and E. Elisabet Rutström. 2007. "Estimating Risk Attitudes in Denmark: A Field Experiment." Scandinavian Journal of Economics 109 (2): 341-368.

Heckman, James J. 2006. "Skill Formation and the Economics of Investing in Disadvantaged Children." Science 312 (5782): 1900-1902.

Hjalmarsson, Randi, Helena Holmlund, and Matthew J. Lindquist. 2015. "The Effect of Education on Criminal Convictions and Incarceration: Causal Evidence from Micro-data." The Economic Journal 125 (587): 1290-1326. 
Hungerman, Daniel, 2014. "The Effect of Education on Religion: Evidence from Compulsory Schooling Laws," Journal of Economic Behavior and Organization, 104: 52-63.

Hussain, R., A.H. Bittles, and S. Sullivan. 2001. "Consanguinity and Early Mortality in the Muslim Populations of India and Pakistan." American Journal of Human Biology. 13: 777-787.

Imbens, Guido, and Karthik Kalyanaraman. 2012. "Optimal Bandwidth Choice for the Regression Discontinuity Estimator." The Review of Economic Studies 79 (3): 933-959.

Jaber, Lutfi, G.J. Halpern, and M. Shohat. 1998. "The Impact of Consanguinity Worldwide." Public Health Genomics. 1(1): 12-17

Jaber, Lutfi, Paul Merlob, Reuben Gabriel, and Mordechi Shohat. 1997. "Effects of Consanguineous Marriage on Reproductive Outcome in an Arab Community in Israel." Journal of Medical Genetics. 34(12): 1000-1002.

Jensen, Robert and Emily Oster. 2009. "The Power of TV: cable Televesion and Women's Status in India. Quarterly Journal of Economics. 124(3): 1057-1094.

Johow, Johannes, Kai P. Willführ, and Eckart Voland. 2019. "High Consanguinity Promotes Intergenerational Wealth Concentration in Socioeconomically Privileged Krummhörn Families of the 18th and 19th Centuries." Evolution and Human Behavior 40 (2): 204213.

Kaplan, Sena, Gül Pinar, Bekir Kaplan, and Filiz Aslantekin. 2016."The Prevalence of Consanguineous Marriages and Affecting Factors in Turkey: A National Survey." Journal of Biological Science. 48(5): 616-630.

Keats, Anthony. 2018. "Women's Schooling, Fertility, and Child Health Outcomes: Evidence from Uganda's Free Primary Education Program." Journal of Development Economics 135: 142159.

Erten, Bilge and Pinar Keskin. 2020. "Breaking the Cycle? Education and the Intergenerational Transmission of Violence." Review of Economics and Statistics. 102(2): 252-268.

Khalid, Yunis, Mumtaz Ghina, Bitar Fadi, Chamseddine Fadi, Kassar May, Rashkidi Joseph, Ghaith Makhoul, and Tamim Hala. 2006. "Consanguineous Marriage and Congenital Heart Defects: A Case-control Study in the Neonatal Period." American Journal of Medical Genetics, Part A 140 (14): 1524-1530.

Kırdar, Murat G., Meltem Dayığlu, and İsmet Koç. 2018. "The Effects of Compulsory Schooling Laws on Teenage Marriage and Births in Turkey." Journal of Human Capital 12 (4): 640668.

Kırdar, Murat G., Meltem Dayığlu, and İsmet Koç. 2015. "Does Longer Compulsory Education Equalize Schooling by Gender and Rural/Urban Residence? " The World Bank Economic Review 30(3): 549-579. 
Koc, Ismet and Mehmel Ali Eryurt, 2017. "The Causal relationship between consanguineous Marriages and Infant Mortality in Turkey." Journal of Biosocial Science 49: 536-555.

Kottelenberg, Michael J., and Steven F. Lehrer. 2017. "Targeted or Universal Coverage? Assessing Heterogeneity in the Effects of Universal Child Care." Journal of Labor Economics 35 (3): 609-653.

Kuper, Adam. 2002. "Incest, Cousin Marriage, and the Origin of the Human Sciences in Nineteenth-century England." Past \& present 174: 158-183.

La Ferrara, Eliana. 2007. "Descent Rules and Strategic Transfers. Evidence from Matrilineal Groups in Ghana." Journal of Development Economics 83 (2): 280-301.

Lleras-Muney, Adriana. 2005. "The Relationship Between Education and Adult Mortality in the United States." Review of Economic Studies 72 (1): 189-221.

Machin, Stephen, Olivier Marie, and Sunčica Vujić. 2011. "The Crime Reducing Effect of Education." The Economic Journal 121 (552): 463-484.

Magnus, P. K. Berg, and T. Bjerkedal. 1985. "Association of Parental Consanguinity with Decreased Birth Weight and Increased rate of Death and Congenital Malformations." Clinical Genetics. 28(4): 335-342.

Makate, Marshall, and Clifton Makate. 2016. "The Causal Effect of Increased Primary Schooling on Child Mortality in Malawi: Universal Primary Education as a Natural Experiment." Social Science \& Medicine 168: 72-83.

Meghir, Costas, and Steven Rivkin. 2011. "Econometric Methods for Research in Education." Handbook of the Economics of Education 3: 1-87.

Mete, Cem, Laurent Bossavie, John Giles, and Harold Alderman. 2020. "Is Consanguinity an Impediment to Child Development?" Population Studies 1-21.

Milligan, Kevin, Enrico Moretti, and Philip Oreopoulos. 2004. "Does Education Improve Citizenship? Evidence from the United States and the United Kingdom." Journal of Public Economics 88 (9-10): 1667-1695.

Ministry of National Education (MONE). 2001. "Formal Education Statistics." Ankara.

Mobarak, Ahmed Mushfiq, Randall Kuhn, and Christina Peters. 2013. "Consanguinity and Other Marriage Market Effects of a Wealth Shock in Bangladesh." Demography 50 (5): 18451871.

Mocan, Leyla. 2014. "The Impact of Education on Wages: Analysis of an Education Reform in Turkey." Koc University-TUSIAD Economic Research Forum Working Paper No: 1424.

Mocan, Naci, and Luiza Pogorelova. 2017. "Compulsory Schooling Laws and Formation of Beliefs: Education, Religion and Superstition." Journal of Economic Behavior \& Organization 142: 509-539. 
Modell, Bernadette, and Aamra Darr. 2002. "Genetic Counselling and Customary Consanguineous Marriage." Nature Reviews Genetics 3 (3): 225-229.

Mumtaz, Ghina, Hala Tamim, Mona Kanaan, Marwan Khawaja, Mustafa Khogali, Gerard Wakim, and Khalid A. Yunis. 2007. "Effect of Consanguinity on Birth Weight for Gestational Age in a Developing Country." American Journal of Epidemiology 165 (7): 742-752.

Naderi, Shahrokh. 1979. "Congenital Abnormalities in Newborns of Consanguineous and Nonconsanguineous Parents." Obstetrics and Gynecology 53 (2): 195-199.

Newson, Roger B. 2010. "Frequentist q-values for Multiple-test Procedures." Stata Journal 10 (4): 568-584.

Oniya, Olubunmi, Karen Neves, Badreldeen Ahmed, and Justin C. Konje. 2019. "A Review of the Reproductive Consequences of Consanguinity." European Journal of Obstetrics and Gynecology and Reproductive Biology 232: 87-96.

Oreopoulos, Philip. 2007. "Do Dropouts Drop out too Soon? Wealth, Health and Happiness from Compulsory Schooling." Journal of Public Economics 91 (11-12): 2213-2229.

Osili, Una Okonkwo, and Bridget Terry Long. 2008. "Does Female Schooling Reduce Fertility? Evidence from Nigeria." Journal of Development Economics 87 (1): 57-75.

Pedersen, J. 2002. "The Influence of Consanguineous Marriage on Infant and Child Mortality among Palestinians in the West Bank and Gaza, Jordan, Lebanon and Syria." Public Health Genomics. 5: 178-181.

Perez-Arce, Francisco. 2017. "The Effect of Education on Time Preferences." Economics of Education Review 56: 52-64.

Romeo, Giovanni, and Alan H. Bittles. 2014. "Consanguinity in the Contemporary World." Human Heredity. Vol. 77. no. 1-4. 6-9.

Rosenzweig, Mark R, and T Paul Schultz. 1982. "The Behavior of Mothers as Inputs to Child Health: the Determinants of Birth Weight, Gestation, and Rate of Fetal Growth." In Economic aspects of health, by Mark R Rosenzweig and T Paul Schultz, 53-92. University of Chicago Press.

Sabean, David Warren, Simon Teuscher, and Jon Mathieu. 2007. Kinship in Europe: Approaches to Long-term Development (1300-1900). Berghahn Books.

Sanders, Nicholas J. 2012. "What doesn't Kill You Makes You Weaker: Prenatal Pollution Exposure and Educational Outcomes." Journal of Human Resources 47 (3): 826-850.

Schulz, Jonathan F., Duman Bahrami-Rad, Jonathan P. Beauchamp, and Joseph Henrich, 2019. "The Church, Intensive Kinship, and Global Psychological Variation," Science, 366 (707):1-12

Schulz, Jonathan F. 2020." Kin Networks and Institutional Development." Unpublished manuscript, George Mason University. 
Sexton, Mary, and Richard Hebel. "A Clinical Trial of Change in Maternal Smoking and Its Effect on Birth Weight." Journal of the American Medical Association 251(7): 911915.

Simes, R. John. 1986. "An Improved Bonferroni Procedure for Multiple Tests of Significance." Biometrika 73 (3): 751-754.

Sinha, Gyan, Peter Corry, D. Subesinghe, J. Wild, and Malcolm I. Levene. 1997. "Prevalence and Type of Cerebral Palsy in a British Ethnic Community: The Role of Consanguinity." Developmental Medicine \& Child Neurology 39 (4): 259-262.

Stoltenberg, Camilla, P. Magnus, A.Skrondal, and R. T. Lie. 1999a. "Consanguinity and Reoccurrence Risk of Stillbirth and Infant Death." American Journal of Public Health 89(4): 517-523.

Stoltenberg, Camilla, P. Magnus, A.Skrondal, and R. T. Lie. 1999b. "Consanguinity and Reoccurrence Risk of Birth Defects: A Population-based Study." American Journal of Medical Genetics. 82(5): 423-428.

Stoltenberg, Camilla, Per Magnus, Rolv Terje Lie, Anne Kjersti Daltveit,, and Lorents M. Irgens. 1998. "Influence of Consanguinity and Maternal Education on Risk of Stillbirth and Infant Death in Norway, 1967-1993." American Journal of Epidemiology. 148(5): 452459.

Tadmouri, Ghazi, Pratibha Nair, Tasneem Obeid, Mahmoud Tal Ali, Najib Al Khaja, and Hanan Hamamy. 2009. "Consanguinity and Reproductive Health among Arabs." Reproductive Health. 6(17): 1-9.

Torun, Huzeyfe. 2018. "Compulsory Schooling and Early Labor Market Outcomes in a MiddleIncome Country." Journal of Labor Research 39 (3): 277-305.

Tunçbilek, Ergül, and İsmet Koç. 1994. "Consanguineous Marriage in Turkey and its Impact on Fertility and Mortality." Annals of Human Genetics 58 (4): 321-329.

World Bank. 2005. "Turkey-Education Sector Study: Sustainable Pathways to an Effective, Equitable, and Efficient Education System for Preschool Through Secondary School Education." 


\section{$\underline{\text { APPENDIX }}$}

\section{Health Risks of Consanguineous Marriage}

It has been shown that the probability of prematurity and prenatal mortality is higher for the newborns of consanguineous parents (Naderi1979). For example, in-hospital neonatal mortality is more than twice as likely in infants whose parents are first cousins in comparison to parents who are not blood-related (Charafeddine et al. 2012). Similarly, Jaber et al. (1997) report that the neonatal mortality rate is almost twice as high among first cousin marriages, and Magnus et al. (1985) find that neonatal mortality among the offspring of consanguineous parents is about 2.5 times higher than infants born to genetically unrelated parents. The same pattern holds for postneonatal, infant and under-5 mortality rates for first cousin marriages (Hussain et al, 2001, Hotchkiss and King 1999). Pederson (2002) finds an increase in infant mortality of 15 additional deaths per 1,000 live births among the progeny of first cousins. ${ }^{57}$

Holding constant a vector of family and pregnancy attributes, babies born to consanguineous parents are lighter than those of unrelated parents. The difference ranges from two-to-three percent (Mumtaz et al. 2007; Magnus et al.1985) to six percent (Al-Sekait 1989). The odds of being low birth weight ( $<2.5 \mathrm{~kg}$ at birth) is more than four times higher for the offspring of consanguineous parents (Bellad et al. 2012) ${ }^{58}$

\footnotetext{
${ }^{57}$ Additional evidence is provided by Stoltenberg et al. (1999a) who report that the risk of early death (stillbirth plus infant death) is twice as high for the offspring of first cousins. Similarly, Stoltenberg et al. (1998) find the risk of infant death twice as high in children with consanguineous parents. Jaber et al. (1997) report that the infant mortality rate is almost five times higher among consanguineous couples in comparison to infants of couples who are genetically unrelated.

Environmental pollution too leads to infant mortality with non-trivial but modest impact in comparison to the impact of consanguinity. For example, Currie and Neidell (2005) find that a one-unit reduction in carbon monoxide (CO) concentration in the air would prevent 34 deaths per 100,000 live births. In the sample they analyze the mean value of CO is $2 \mathrm{ppm}$, which is also the average ambient CO level in the U.S. (https://www.epa.gov/air-trends/corabon-monoxide-trends). Thus, a one-unit reduction of CO would reflect a 50\% decrease from a low baseline (the EPA standard is not to exceed the CO level of 9 ppm more than once a year). Chay and Greenstone (2005) analyze the impact of total suspended particulate (TSP) concentration on infant mortality rate and report an elasticity of 0.35 , which translates into 5-8 fewer infant deaths per 100,000 live births for a one-unit reduction in TSP (average TSP=64)

${ }^{58}$ Smoking is the most important risk factor of low birth weight (Almond et al. 2005, Grossman and Joyce 1990, Sexton and Hebel 1984). Smoking during pregnancy lowers birth weight up to six percent, which indicates that consanguinity has about the same impact on birthweight as smoking.
} 
Dursun, Cesur and Kelly (2017) leverage the same Turkish education reform used in this paper and employ two large data sets that include information on birth outcomes. Using exposure to the reform as an instrument for mother's education the authors show that mother's education has a significant impact on both child mortality and on birth weight and prematurity. They also demonstrate significant reduced form effects of the reform. Although their paper is unrelated to consanguinity, that the reform had a significant impact on birth outcomes is consistent with the hypothesis that part of the effect may be driven by a switch away from consanguineous marriages.

Medical literature has established that the mutation of recessive genes, inherited from a common ancestor, increases the likelihood of serious recessive disorders in the offspring. ${ }^{59}$ As a result, there is also a long list of congenital anomalies and disorders which are prevalent in the progeny of consanguineous marriages (Oniya et al. 2019; Harlap et al. 2008; Bittles 2003; Naderi 1979). ${ }^{60}$ Mete et al. (2020) adjust for potential endogeneity of consanguineous marriage and show that these unions cause lower cognition, lower height-for-weight in the offspring and that these children are more likely to be stunted. Learning and reading disorders are more prevalent among children of consanguineous marriages (Eapen et al. 1998; Abu-Rabia and Maroun 2005). In short, a large body of medical evidence underlines that consanguineous marriage constitutes a substantial risk factor for the offspring and that it is a public health concern.

\footnotetext{
${ }^{59}$ The probability of homozygosity, the receipt of identical alleles of a given gene from each parent, is higher for recessive genes for the offspring in case of consanguineous marriages.

60 These disorders range from hearing loss to blindness, from childhood glaucoma to a number of neurodegenerative conditions. Consanguinity also increases the risk of congenital heart defects and of cerebral palsy in newborns (Erkin et al. 2008; Khalid et al. 2006; Sinha et al. 1997), and severe mental retardation (Bener and Hussain 2006; Fernell 1998). Birth defects and congenital malformations rate is more than twice as high among the offspring of first cousins (Tadmouri et al. 2009; Stoltenberg et al. 1999b; Jaber et al. 1998; Magnus et al. 1985).
} 
Figure A.1: Proportion of Individuals with Second Language
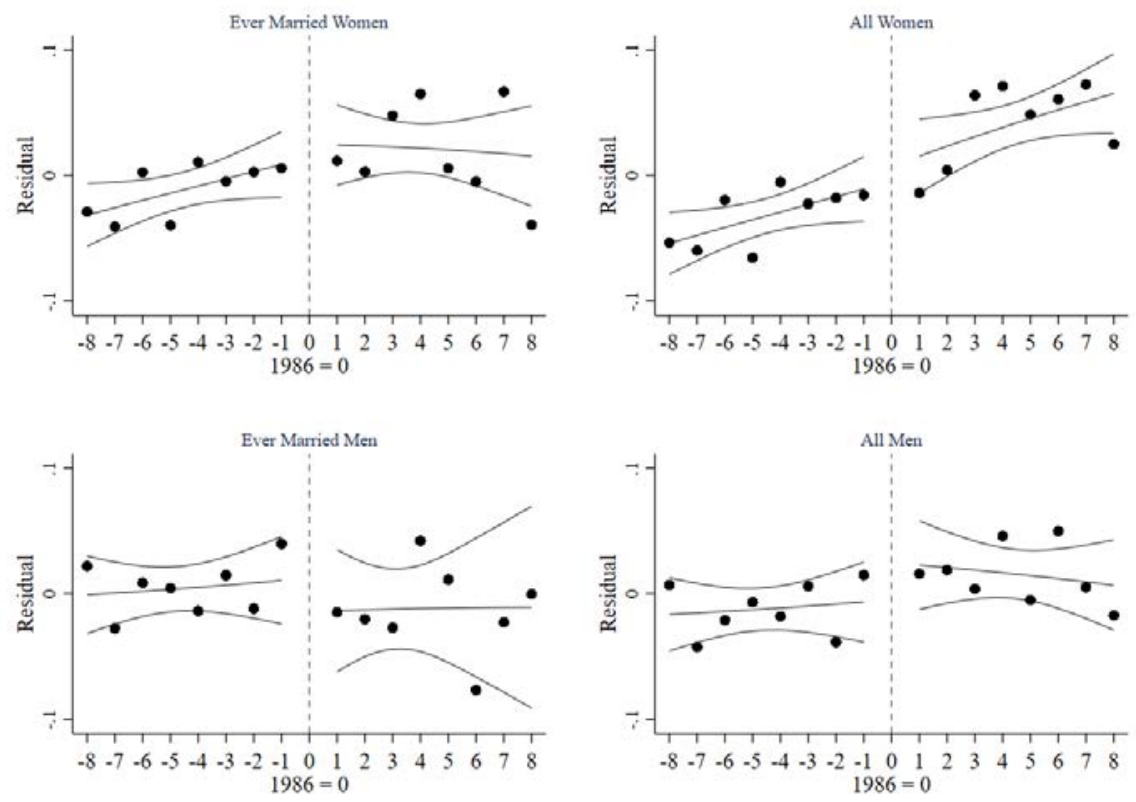

Figure A.2: Marriage Characteristics of Men by Birth Cohort
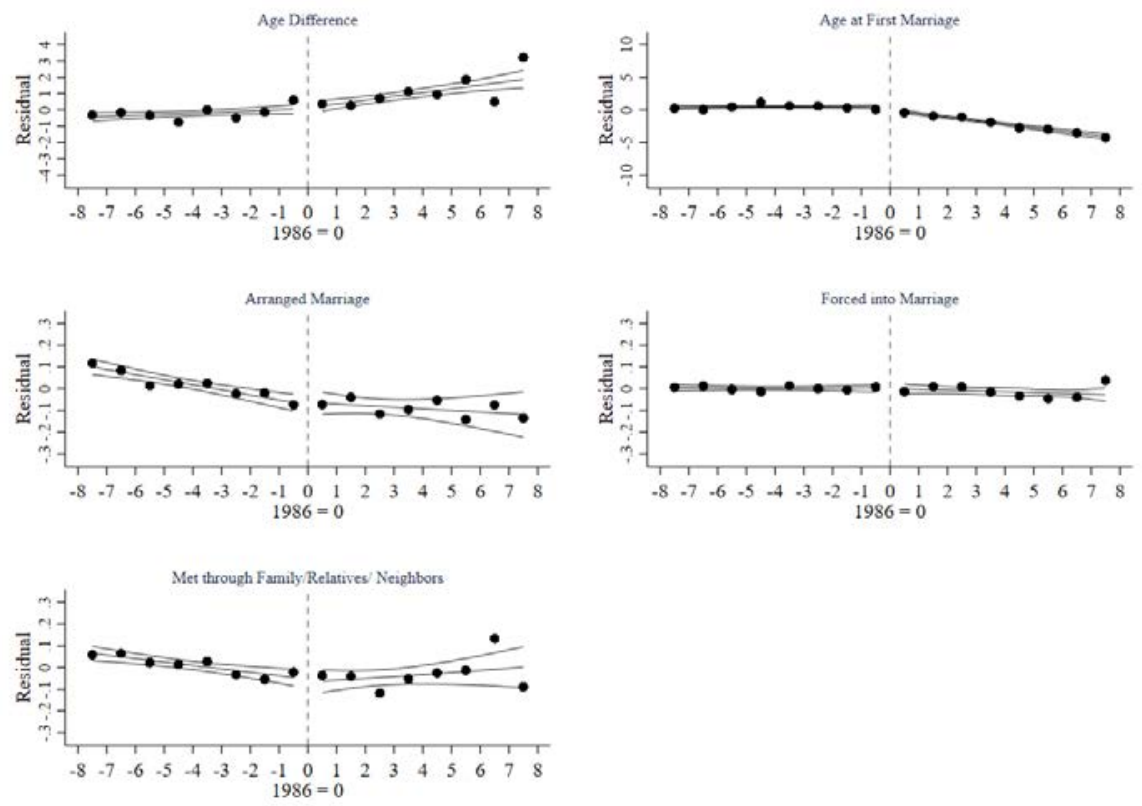
Figure A.3: Marriage Preferences of All Women by Birth Cohort
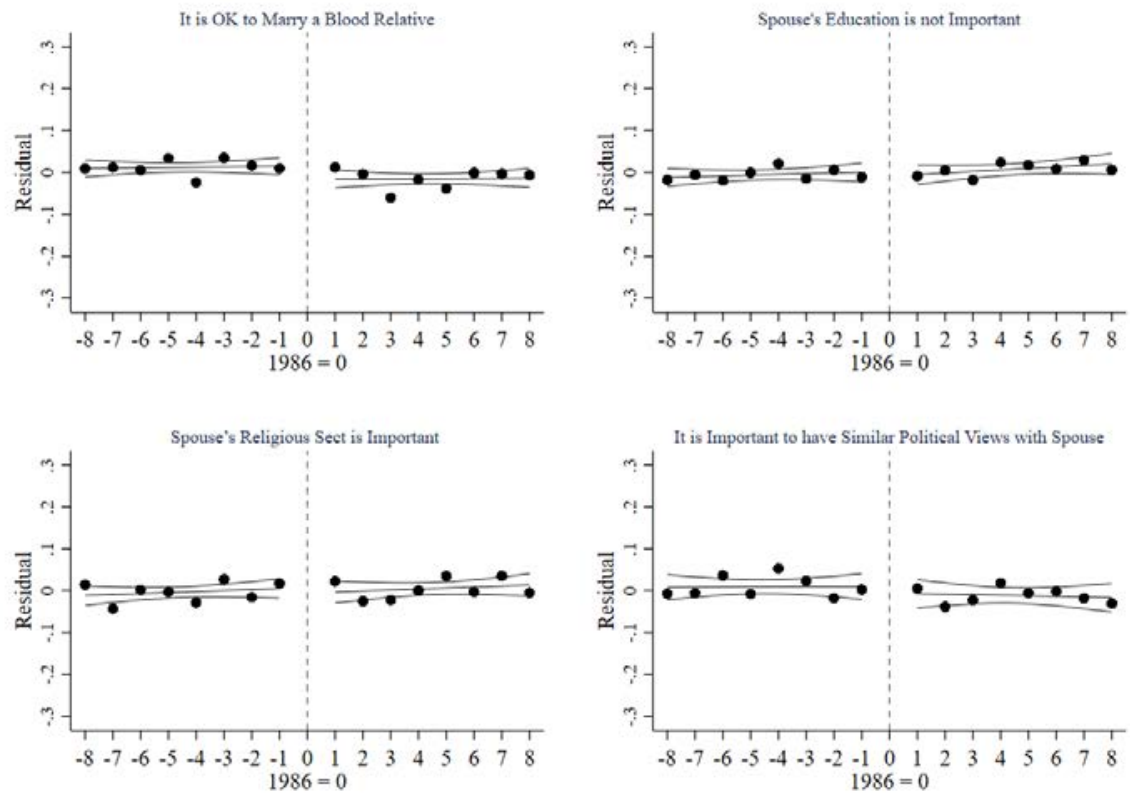

Figure A.4: Proportion of Ever Married Women and Men who Agree with the Statement that "Only a Son can Ensure the Continuation of the Family Blood line"
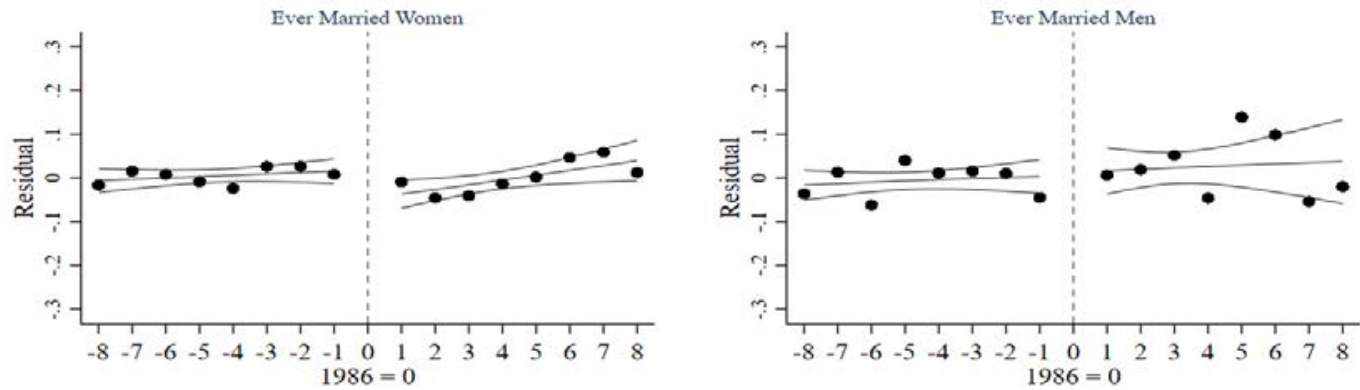
Table A.1: The Effect of Exposure to the Education Reform on Marriage Preferences for Men

\begin{tabular}{|c|c|c|c|c|}
\hline & $(1)$ & $(2)$ & (3) & (4) \\
\hline & \multicolumn{4}{|c|}{ Panel A: Ever Married Men } \\
\hline VARIABLES & $\begin{array}{l}\text { It is OK to Marry } \\
\text { a Blood Relative }\end{array}$ & $\begin{array}{c}\text { Spouse's } \\
\text { Education is Not } \\
\text { Important }\end{array}$ & $\begin{array}{c}\text { Spouse's } \\
\text { Religious Sect } \\
\text { is Important }\end{array}$ & $\begin{array}{c}\text { Similar } \\
\text { Political Views } \\
\text { are Important }\end{array}$ \\
\hline Reform & $\begin{array}{c}0.007 \\
(0.031) \\
{[0.751]}\end{array}$ & $\begin{array}{c}-0.020 \\
(0.036) \\
{[0.535]}\end{array}$ & $\begin{array}{c}0.004 \\
(0.039) \\
{[0.875]}\end{array}$ & $\begin{array}{c}0.004 \\
(0.042) \\
{[0.948]}\end{array}$ \\
\hline \multirow[t]{2}{*}{ Observations } & 2,832 & 2,832 & 2,832 & 2,832 \\
\hline & \multicolumn{4}{|c|}{ Panel B: All Men } \\
\hline VARIABLES & $\begin{array}{l}\text { It is OK to Marry } \\
\text { a Blood Relative }\end{array}$ & $\begin{array}{c}\text { Spouse's } \\
\text { Education is Not } \\
\text { Important }\end{array}$ & $\begin{array}{c}\text { Spouse's } \\
\text { Religious Sect } \\
\text { is Important } \\
\end{array}$ & $\begin{array}{c}\text { Similar } \\
\text { Political Views } \\
\text { are Important } \\
\end{array}$ \\
\hline Reform & $\begin{array}{c}0.000 \\
(0.022) \\
{[0.995]}\end{array}$ & $\begin{array}{l}-0.023 \\
(0.028) \\
{[0.392]}\end{array}$ & $\begin{array}{l}-0.001 \\
(0.030) \\
{[0.952]}\end{array}$ & $\begin{array}{c}0.009 \\
(0.031) \\
{[0.865]} \\
\end{array}$ \\
\hline Observations & 4,499 & 4,499 & 4,499 & 4,499 \\
\hline \multicolumn{5}{|c|}{$\begin{array}{l}\text { The Reform variable is equal to one if the respondent was born between } 1987 \text { and } 1994 \text { and equal to zero if } \\
\text { the respondent was born between } 1978 \text { and } 1985 \text {. The } 1986 \text { cohort is excluded from the sample as exposure } \\
\text { to the reform is unclear for this cohort. The entries in (parentheses) are standard errors of the estimated } \\
\text { coefficients, clustered by childhood region-by-birth cohort; }{ }^{*} p<0.1 * * p<0.05 * * * p<0.01 \text {. P-values, related } \\
\text { to bootstrapped standard errors clustered by birth cohort, are given in [square brackets]. All regressions } \\
\text { control for trend in the outcome variable separately for treatment and control groups, region of current } \\
\text { residence and region of childhood fixed effects, an indicator if the person grew up in a village, and the } \\
\text { interaction between the latter two variables, an indicator if the person speaks a second language, and the } \\
\text { interaction of second language with region of residence fixed effects. See the text for details. }\end{array}$} \\
\hline
\end{tabular}


Table A.2: Results with the Inclusion of the 1986 Cohort

\begin{tabular}{|c|c|c|c|c|c|c|c|}
\hline & (1) & (2) & (3) & (4) & (5) & (6) & (7) \\
\hline \multicolumn{8}{|c|}{ Panel A: Reform=0.5 if Birth cohort=1986 } \\
\hline VARIABLES & $\begin{array}{c}\text { Married to } \\
\text { a Cousin }\end{array}$ & $\begin{array}{c}\text { Married to } \\
\text { a Blood } \\
\text { Relative }\end{array}$ & $\begin{array}{c}\text { Age at } \\
\text { First } \\
\text { Marriage }\end{array}$ & $\begin{array}{c}\text { Age } \\
\text { Difference }\end{array}$ & $\begin{array}{l}\text { Arranged } \\
\text { Marriage }\end{array}$ & $\begin{array}{c}\text { Forced } \\
\text { into } \\
\text { Marriage }\end{array}$ & $\begin{array}{c}\text { Met } \\
\text { through } \\
\text { Family/ } \\
\text { Relatives/ } \\
\text { Neighbors }\end{array}$ \\
\hline Reform & $\begin{array}{c}-0.036^{* *} \\
(0.017) \\
0.0166\end{array}$ & $\begin{array}{c}-0.055^{* *} \\
(0.023) \\
0.00180\end{array}$ & $\begin{array}{c}-0.037 * \\
(0.022) \\
0.195\end{array}$ & $\begin{array}{c}0.469 * \\
(0.239) \\
0.0594\end{array}$ & $\begin{array}{c}-0.433^{*} \\
(0.240) \\
0.138\end{array}$ & $\begin{array}{c}-0.074^{* *} \\
(0.031) \\
0.0756\end{array}$ & $\begin{array}{c}-0.023 \\
(0.016) \\
0.0572\end{array}$ \\
\hline Observations & 5,012 & 5,012 & 5,012 & 5,012 & 5,012 & 4,635 & 4,635 \\
\hline VARIABLES & $\begin{array}{l}\text { Married to } \\
\text { a Blood } \\
\text { Relative is } \\
\text { OK }\end{array}$ & $\begin{array}{l}\text { Spouse's } \\
\text { Education } \\
\text { is Not } \\
\text { Important }\end{array}$ & $\begin{array}{l}\text { Spouse's } \\
\text { Sect is } \\
\text { Important }\end{array}$ & $\begin{array}{c}\text { Similar } \\
\text { Political } \\
\text { Views are } \\
\text { Important }\end{array}$ & & & \\
\hline Reform & $\begin{array}{c}-0.054^{*} \\
(0.029) \\
0.151\end{array}$ & $\begin{array}{c}-0.035 * \\
(0.021) \\
0.148\end{array}$ & $\begin{array}{c}0.000 \\
(0.022) \\
0.994 \\
\end{array}$ & $\begin{array}{c}-0.001 \\
(0.029) \\
0.966 \\
\end{array}$ & & & \\
\hline Observations & 5,012 & 5,012 & 5,012 & 5,012 & & & \\
\hline \multicolumn{8}{|c|}{ Panel B: Reform=1 if Birth Cohort=1986 } \\
\hline VARIABLES & $\begin{array}{c}\text { Married to } \\
\text { a Cousin }\end{array}$ & $\begin{array}{c}\text { Married to } \\
\text { a Blood } \\
\text { Relative } \\
\end{array}$ & $\begin{array}{c}\text { Age at } \\
\text { First } \\
\text { Marriage }\end{array}$ & $\begin{array}{c}\text { Age } \\
\text { Difference }\end{array}$ & $\begin{array}{l}\text { Arranged } \\
\text { Marriage }\end{array}$ & $\begin{array}{c}\text { Forced } \\
\text { into } \\
\text { Marriage } \\
\end{array}$ & $\begin{array}{c}\text { Met } \\
\text { through } \\
\text { Family/ } \\
\text { Relatives/ } \\
\text { Neighbors }\end{array}$ \\
\hline Reform & $\begin{array}{c}-0.026^{*} \\
(0.014) \\
{[0.0460]}\end{array}$ & $\begin{array}{c}-0.043^{* *} \\
(0.019) \\
{[0.00120]}\end{array}$ & $\begin{array}{c}0.383 * \\
(0.215) \\
{[0.0624]}\end{array}$ & $\begin{array}{c}-0.366^{*} \\
(0.210) \\
{[0.192]}\end{array}$ & $\begin{array}{c}-0.069 * * * \\
(0.027) \\
{[0.0250]}\end{array}$ & $\begin{array}{c}-0.029 * * \\
(0.014) \\
{[0.0308]}\end{array}$ & $\begin{array}{l}-0.030 \\
(0.024) \\
{[0.506]}\end{array}$ \\
\hline Observations & 5,012 & 5,012 & 5,012 & 5,012 & 4,635 & 4,635 & 5,012 \\
\hline VARIABLES & $\begin{array}{l}\text { Married to } \\
\text { a Blood } \\
\text { Relative is } \\
\text { OK }\end{array}$ & $\begin{array}{l}\text { Spouse's } \\
\text { Education } \\
\text { is Not } \\
\text { Important }\end{array}$ & $\begin{array}{l}\text { Spouse's } \\
\text { Sect is } \\
\text { Important }\end{array}$ & $\begin{array}{c}\text { Similar } \\
\text { Political } \\
\text { Views are } \\
\text { Important }\end{array}$ & & & \\
\hline Reform & $\begin{array}{l}-0.025 \\
(0.019) \\
{[0.183]}\end{array}$ & $\begin{array}{l}-0.018 \\
(0.019) \\
{[0.381]} \\
\end{array}$ & $\begin{array}{l}-0.003 \\
(0.017) \\
{[0.891]} \\
\end{array}$ & $\begin{array}{c}0.007 \\
(0.024) \\
{[0.753]}\end{array}$ & & & \\
\hline Observations & 5,012 & 5,012 & 5,012 & 5,012 & & & \\
\hline
\end{tabular}


Table A.3: The Effect of Exposure to the Education Reform on Marriage Characteristics and Marital Preferences for Ever Married Women

\begin{tabular}{|c|c|c|c|c|}
\hline \multirow{6}{*}{ Reform } & \multicolumn{4}{|c|}{ Bandwidth } \\
\hline & 10 & 9 & 7 & 6 \\
\hline & \multicolumn{4}{|c|}{ Panel A: Married to a Cousin } \\
\hline & $-0.032 * *$ & $-0.033 * *$ & $-0.040 * *$ & -0.025 \\
\hline & $(0.015)$ & $(0.016)$ & $(0.018)$ & $(0.020)$ \\
\hline & {$[0.036]$} & [0.016] & [0.026] & [0.152] \\
\hline Observations & 5,589 & 5,148 & 4,188 & 3,661 \\
\hline \multirow{4}{*}{ Reform } & \multicolumn{4}{|c|}{ Panel B: Married to a Blood Relative } \\
\hline & $-0.048 * *$ & $-0.051 * *$ & $-0.042 *$ & -0.040 \\
\hline & $(0.021)$ & $(0.022)$ & $(0.025)$ & $(0.026)$ \\
\hline & [0.007] & {$[0.001]$} & [0.023] & {$[0.107]$} \\
\hline Observations & 5,589 & 5,148 & 4,188 & 3,661 \\
\hline \multirow{4}{*}{ Reform } & \multicolumn{4}{|c|}{ Panel C: Marriage Age } \\
\hline & $0.372 *$ & $0.429 *$ & $0.472^{*}$ & $0.472 *$ \\
\hline & $(0.208)$ & $(0.222)$ & $(0.253)$ & $(0.268)$ \\
\hline & [0.142] & [0.069] & [0.063] & {$[0.162]$} \\
\hline Observations & 5,589 & 5,148 & 4,188 & 3,661 \\
\hline \multirow{4}{*}{ Reform } & \multicolumn{4}{|c|}{ Panel D: Age Difference btw Husband and Wife } \\
\hline & -0.339 & $-0.465 * *$ & $-0.458 *$ & $-0.537 * *$ \\
\hline & $(0.218)$ & $(0.229)$ & $(0.257)$ & $(0.267)$ \\
\hline & [0.190] & {$[0.0814]$} & [0.122] & {$[0.111]$} \\
\hline Observations & 5,589 & 5,148 & 4,188 & 3,661 \\
\hline \multirow{4}{*}{ Reform } & \multicolumn{4}{|c|}{ Panel E: Arranged Marriage } \\
\hline & $-0.080 * * *$ & $-0.081 * * *$ & $-0.091 * * *$ & $-0.100 * * *$ \\
\hline & $(0.028)$ & $(0.030)$ & $(0.033)$ & $(0.035)$ \\
\hline & [0.037] & [0.040] & [0.026] & [0.032] \\
\hline Observations & 5,158 & 4,757 & 3,879 & 3,398 \\
\hline \multirow{4}{*}{ Reform } & \multicolumn{4}{|c|}{ Panel F: Forced into Marriage } \\
\hline & $-0.024 *$ & -0.023 & -0.018 & -0.022 \\
\hline & $(0.014)$ & $(0.015)$ & $(0.017)$ & $(0.018)$ \\
\hline & [0.024] & [0.008] & [0.017] & {$[0.012]$} \\
\hline Observations & 5,158 & 4,757 & 3,879 & 3,398 \\
\hline \multirow{4}{*}{ Reform } & \multicolumn{4}{|c|}{ Panel G: Met through Family/Relatives/ Neighbors } \\
\hline & $-0.053 * *$ & $-0.059 * *$ & $-0.070 * *$ & $-0.084 * *$ \\
\hline & $(0.027)$ & $(0.028)$ & $(0.032)$ & $(0.034)$ \\
\hline & {$[0.126]$} & [0.097] & {$[0.080]$} & {$[0.125]$} \\
\hline Observations & 5,589 & 5,148 & 4,188 & 3,661 \\
\hline \multirow{4}{*}{ Reform } & \multicolumn{4}{|c|}{ Panel H: It is OK to Marry a Blood Relative } \\
\hline & -0.030 & $-0.042 * *$ & -0.026 & -0.018 \\
\hline & $(0.019)$ & $(0.021)$ & $(0.023)$ & $(0.026)$ \\
\hline & [0.312] & {$[0.126]$} & [0.304] & {$[0.480]$} \\
\hline Observations & 5,589 & 5,148 & 4,188 & 3,661 \\
\hline \multirow{4}{*}{ Reform } & \multicolumn{4}{|c|}{ Panel I: Spouse's Education is Not Important } \\
\hline & -0.022 & -0.029 & $-0.050 * *$ & $-0.041^{*}$ \\
\hline & $(0.019)$ & $(0.020)$ & $(0.023)$ & $(0.024)$ \\
\hline & [0.326] & [0.146] & [0.019] & {$[0.037]$} \\
\hline Observations & 5,589 & 5,148 & 4,188 & 3,661 \\
\hline
\end{tabular}

See Notes to Table A.1. 
Table A.4: Results with Asymmetric Bandwidths (Control Group Bandwidth=8)

\begin{tabular}{|c|c|c|c|}
\hline & \multicolumn{3}{|c|}{ Treatment Group Bandwidth } \\
\hline & 8 & 7 & 6 \\
\hline \multirow{4}{*}{ Reform } & \multicolumn{3}{|c|}{ Panel A: Married to a Cousin } \\
\hline & $-0.036 * *$ & $-0.037 * *$ & -0.025 \\
\hline & $(0.017)$ & $(0.018)$ & $(0.019)$ \\
\hline & {$[0.0240]$} & {$[0.0334]$} & {$[0.0794]$} \\
\hline Observations & 4,695 & 4,576 & 4,437 \\
\hline \multirow{4}{*}{ Reform } & \multicolumn{3}{|c|}{ Panel B: Married to a Blood Relative } \\
\hline & $-0.056 * *$ & $-0.047 * *$ & $-0.048^{*}$ \\
\hline & $(0.024)$ & $(0.024)$ & $(0.026)$ \\
\hline & {$[0.00220]$} & {$[0.0124]$} & [0.0252] \\
\hline Observations & 4,695 & 4,576 & 4,437 \\
\hline \multirow{4}{*}{ Reform } & \multicolumn{3}{|c|}{ Panel C: Marriage Age } \\
\hline & $0.460 *$ & 0.401 & 0.343 \\
\hline & $(0.235)$ & $(0.244)$ & $(0.252)$ \\
\hline & {$[0.0656]$} & [0.127] & [0.236] \\
\hline Observations & 4,695 & 4,576 & 4,437 \\
\hline \multirow{4}{*}{ Reform } & \multicolumn{3}{|c|}{ Panel D: Age Difference btw Husband and Wife } \\
\hline & $-0.439 *$ & -0.404 & $-0.450^{*}$ \\
\hline & $(0.242)$ & $(0.252)$ & $(0.257)$ \\
\hline & {$[0.124]$} & {$[0.160]$} & [0.133] \\
\hline Observations & 4,695 & 4,576 & 4,437 \\
\hline \multirow{4}{*}{ Reform } & \multicolumn{3}{|c|}{ Panel E: Arranged Marriage } \\
\hline & $-0.072 * *$ & $-0.095 * * *$ & $-0.105^{* * *}$ \\
\hline & $(0.031)$ & $(0.032)$ & $(0.034)$ \\
\hline & [0.107] & {$[0.0152]$} & {$[0.0118]$} \\
\hline Observations & 4,341 & 4,239 & 4,119 \\
\hline \multirow{4}{*}{ Reform } & \multicolumn{3}{|c|}{ Panel F: Forced into Marriage } \\
\hline & -0.020 & -0.024 & -0.024 \\
\hline & $(0.016)$ & $(0.016)$ & $(0.017)$ \\
\hline & [0.0282] & {$[0.0112]$} & {$[0.0200]$} \\
\hline Observations & 4,341 & 4,239 & 4,119 \\
\hline \multirow{4}{*}{ Reform } & \multicolumn{3}{|c|}{ Panel G: Met through Family/Relatives/ Neighbors } \\
\hline & $-0.060 * *$ & $-0.060 *$ & $-0.067 * *$ \\
\hline & $(0.029)$ & $(0.031)$ & $(0.033)$ \\
\hline & [0.134] & [0.142] & {$[0.143]$} \\
\hline Observations & 4,695 & 4,576 & 4,437 \\
\hline \multirow{4}{*}{ Reform } & \multicolumn{3}{|c|}{ Panel H: It is OK to Marry a Blood Relative } \\
\hline & $-0.038 *$ & -0.027 & -0.019 \\
\hline & $(0.022)$ & $(0.022)$ & $(0.024)$ \\
\hline & {$[0.210]$} & [0.298] & {$[0.473]$} \\
\hline Observations & 4,695 & 4,576 & 4,437 \\
\hline \multirow{4}{*}{ Reform } & \multicolumn{3}{|c|}{ Panel I: Spouse's Education is Not Important } \\
\hline & $-0.039 *$ & $-0.053 * *$ & $-0.041^{*}$ \\
\hline & $(0.021)$ & $(0.021)$ & $(0.022)$ \\
\hline & {$[0.111]$} & {$[0.0126]$} & {$[0.0230]$} \\
\hline Observations & 4,695 & 4,576 & 4,437 \\
\hline
\end{tabular}


Table A.5:

The Effect of Exposure to the Education Reform on Women's Propensity for Consanguineous Marriage by Region and by Urban vs. Rural Residence

\begin{tabular}{|c|c|c|c|c|c|c|}
\hline & (1) & $(2)$ & (3) & (4) & (5) & (6) \\
\hline & \multicolumn{6}{|c|}{ Current Region of Residence } \\
\hline \multirow{6}{*}{$\begin{array}{l}\text { VARIABLES } \\
\text { Reform }\end{array}$} & \multicolumn{3}{|c|}{ Eastern Turkey } & \multicolumn{3}{|c|}{ Western Turkey } \\
\hline & $\begin{array}{l}\text { Middle } \\
\text { School } \\
\end{array}$ & $\begin{array}{c}\text { Married to } \\
\text { a Cousin }\end{array}$ & $\begin{array}{l}\text { Married to } \\
\text { a Blood } \\
\text { Relative } \\
\end{array}$ & $\begin{array}{l}\text { Middle } \\
\text { School } \\
\end{array}$ & $\begin{array}{c}\text { Married to } \\
\text { a Cousin }\end{array}$ & $\begin{array}{c}\text { Married to } \\
\text { a Blood } \\
\text { Relative }\end{array}$ \\
\hline & $0.125^{* *}$ & $-0.054^{*}$ & $-0.123 * * *$ & $0.156 * * *$ & -0.029 & -0.022 \\
\hline & $(0.050)$ & $(0.031)$ & $(0.040)$ & $(0.037)$ & $(0.020)$ & $(0.027)$ \\
\hline & & $\{0.085\}$ & $\{0.007\}$ & & $\{0.428\}$ & $\{0.63\}$ \\
\hline & [0.009] & [0.281] & [0.015] & [0.022] & [0.263] & {$[0.542]$} \\
\hline Mean of Dep. Var. & 0.464 & 0.124 & 0.28 & 0.610 & 0.065 & 0.156 \\
\hline Observations & 1,759 & 1,759 & 1,759 & 2,936 & 2,936 & 2,936 \\
\hline \multirow{7}{*}{$\begin{array}{l}\text { VARIABLES } \\
\text { Reform }\end{array}$} & \multicolumn{6}{|c|}{ Childhood Region } \\
\hline & \multicolumn{3}{|c|}{ Eastern Turkey } & \multicolumn{3}{|c|}{ Western Turkey } \\
\hline & \multicolumn{2}{|r|}{$\begin{array}{c}\text { Married to } \\
\text { a Cousin }\end{array}$} & $\begin{array}{c}\text { Married to } \\
\text { a Blood } \\
\text { Relative }\end{array}$ & \multicolumn{2}{|r|}{$\begin{array}{l}\text { Married to } \\
\text { a Cousin }\end{array}$} & $\begin{array}{c}\text { Married to } \\
\text { a Blood } \\
\text { Relative } \\
\end{array}$ \\
\hline & $0.107^{* *}$ & $-0.066^{* *}$ & $-0.135 * * *$ & \multirow{3}{*}{$\begin{array}{l}0.176^{*+* * *} \\
(0.038)\end{array}$} & \multirow{3}{*}{$\begin{array}{l}-0.018 \\
(0.020) \\
\{0.921\}\end{array}$} & \multirow{4}{*}{$\begin{array}{c}0.003 \\
(0.027) \\
\{0.921\} \\
{[0.935]}\end{array}$} \\
\hline & \multirow[t]{2}{*}{$(0.050)$} & $(0.029)$ & $(0.039)$ & & & \\
\hline & & $\{0.033\}$ & $\{0.002\}$ & & & \\
\hline & [0.012] & {$[0.074]$} & [0.001] & {$[0.018]$} & {$[0.486]$} & \\
\hline \multirow{3}{*}{$\begin{array}{l}\text { Mean of Dep. } \\
\text { Observations }\end{array}$} & & 0.131 & 0.291 & 0.654 & 0.051 & 0.13 \\
\hline & 2,113 & 2,113 & 2,113 & 2,582 & 2,582 & \multirow[t]{2}{*}{2,582} \\
\hline & \multirow{2}{*}{\multicolumn{3}{|c|}{ Grew up in a Village }} & lence in $\mathrm{C}$ & dhood & \\
\hline \multirow{6}{*}{$\begin{array}{l}\text { VARIABLES } \\
\text { Reform }\end{array}$} & & & & \multicolumn{3}{|c|}{ Grew up in a Town or City } \\
\hline & $\begin{array}{l}\text { Middle } \\
\text { School }\end{array}$ & $\begin{array}{l}\text { Married to } \\
\text { a Cousin }\end{array}$ & $\begin{array}{l}\text { Married to } \\
\text { a Blood } \\
\text { Relative }\end{array}$ & $\begin{array}{l}\text { Middle } \\
\text { School }\end{array}$ & $\begin{array}{l}\text { Married to } \\
\text { a Cousin }\end{array}$ & $\begin{array}{l}\text { Married to } \\
\text { a Blood } \\
\text { Relative }\end{array}$ \\
\hline & $0.215^{* * *}$ & $-0.069 *$ & $-0.101 * *$ & $0.120 * * *$ & -0.024 & -0.038 \\
\hline & $(0.056)$ & $(0.038)$ & $(0.051)$ & $(0.032)$ & (0.019) & $(0.028)$ \\
\hline & & $\{0.107\}$ & $\{0.107\}$ & & $\{0.206\}$ & $\{0.206\}$ \\
\hline & {$[0.006]$} & {$[0.027]$} & {$[0.023]$} & {$[0.034]$} & {$[0.160]$} & {$[0.0304]$} \\
\hline Mean of Dep. Var. & 0.325 & 0.125 & 0.28 & 0.660 & 0.0696 & 0.167 \\
\hline Observations & 1,474 & 1,474 & 1,474 & 3,221 & 3,221 & 3,221 \\
\hline
\end{tabular}

The Reform variable is equal to one if the respondent was born between 1987 and 1994 and equal to zero if the respondent was born between 1978 and 1985. The 1986 cohort is excluded from the sample as exposure to the reform is unclear for this cohort. The entries in (parentheses) are standard errors of the estimated coefficients, clustered by childhood region-by-birth cohort; * $\mathrm{p}<0.1{ }^{* *} \mathrm{p}<0.05^{* * *} \mathrm{p}<0.01$. Pvalues, adjusted for multiple hypothesis testing, are displayed in \{curly brackets\}. P-values, related to bootstrapped standard errors clustered by birth cohort, are given in [square brackets]. All regressions control for trend in the outcome variable separately for treatment and control groups, region of current residence and region of childhood fixed effects, an indicator if the person grew up in a village, and the interaction between the latter two variables, an indicator if the person speaks a second language, and the interaction of second language with region of residence fixed effects. See the text for details. 
Table A.6: The Effect of Exposure to the Education Reform on the Propensity to be in a Consanguineous Marriage by the Consanguineous Marriage Rate in 1993

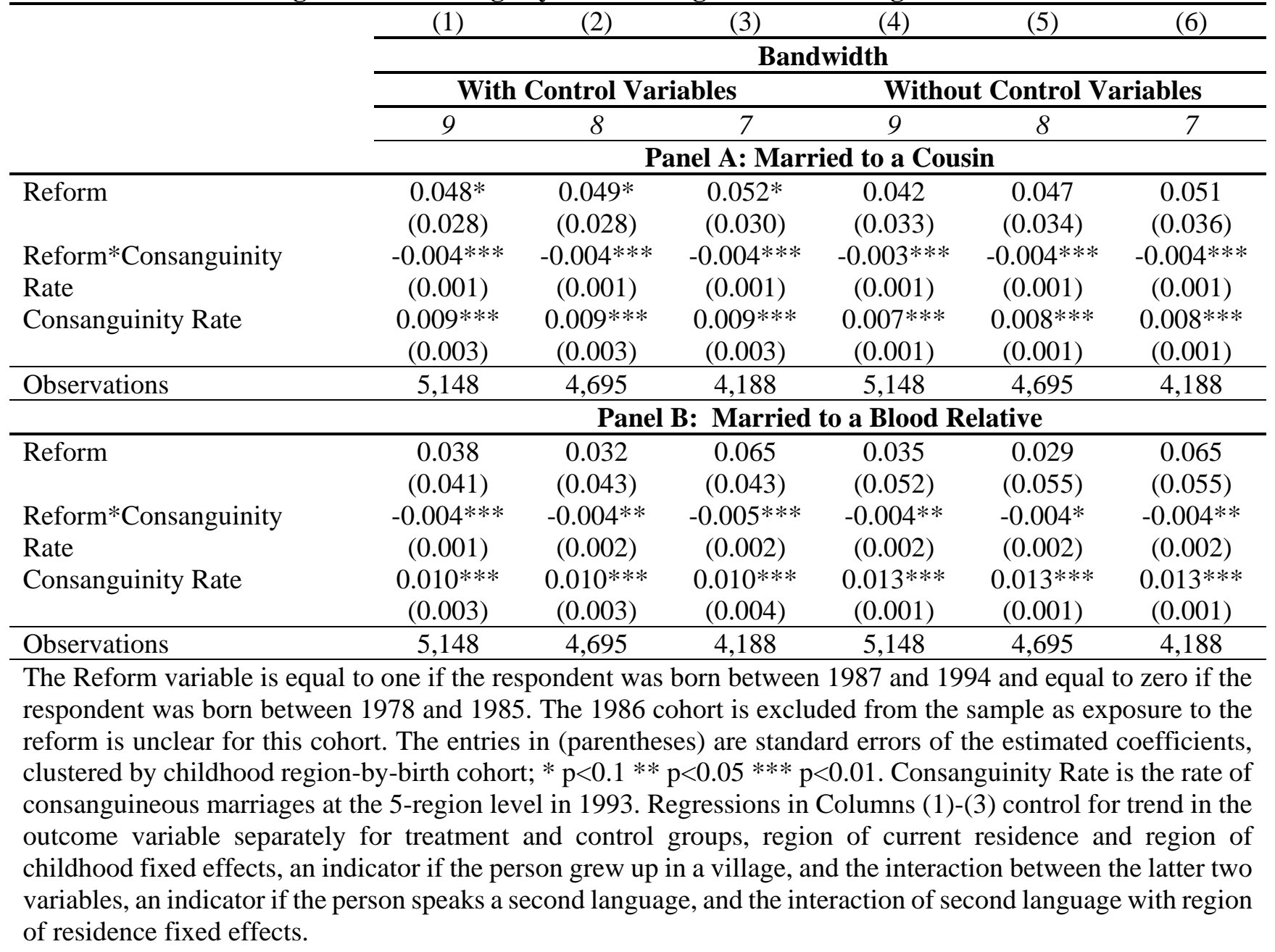


Table A.7: The Effect of Exposure to the Education Reform on the Propensity to Agree with the Statement that "It is Important to have a Religious Spouse"

\begin{tabular}{|c|c|c|c|}
\hline & $(1)$ & $(2)$ & (3) \\
\hline & \multicolumn{3}{|c|}{ Bandwidth } \\
\hline & 9 & 8 & 7 \\
\hline & \multicolumn{3}{|c|}{ Panel A: Ever Married Women } \\
\hline Reform & $\begin{array}{c}-0.003 \\
(0.015) \\
{[0.918]}\end{array}$ & $\begin{array}{c}0.003 \\
(0.016) \\
{[0.943]}\end{array}$ & $\begin{array}{l}-0.003 \\
(0.017) \\
{[0.940]} \\
\end{array}$ \\
\hline Observations & 5,148 & 4,695 & 4,188 \\
\hline \multirow[b]{2}{*}{ Reform } & \multicolumn{3}{|c|}{ Panel B: All Women } \\
\hline & $\begin{array}{c}-0.006 \\
(0.015) \\
{[0.786]}\end{array}$ & $\begin{array}{c}-0.007 \\
(0.016) \\
{[0.785]}\end{array}$ & $\begin{array}{l}-0.013 \\
(0.017) \\
{[0.704]} \\
\end{array}$ \\
\hline Observations & 6,506 & 5,867 & 5,134 \\
\hline \multirow[b]{2}{*}{ Reform } & \multicolumn{3}{|c|}{ Panel C: Ever Married Men } \\
\hline & $\begin{array}{c}0.001 \\
(0.026) \\
{[0.930]}\end{array}$ & $\begin{array}{c}0.005 \\
(0.027) \\
{[0.775]}\end{array}$ & $\begin{array}{c}0.009 \\
(0.028) \\
{[0.578]} \\
\end{array}$ \\
\hline Observations & 3,141 & 2,832 & 2,491 \\
\hline \multirow[b]{2}{*}{ Reform } & \multicolumn{3}{|c|}{ Panel D: All Men } \\
\hline & $\begin{array}{c}-0.006 \\
(0.023) \\
{[0.624]}\end{array}$ & $\begin{array}{c}-0.009 \\
(0.025) \\
{[0.552]}\end{array}$ & $\begin{array}{c}0.001 \\
(0.027) \\
{[0.938]} \\
\end{array}$ \\
\hline Observations & 5,013 & 4,499 & 3,910 \\
\hline
\end{tabular}

See Notes to Table A.1. 
Table A.8: The Effect of Exposure to the Education Reform on being from the Same Childhood Region

\begin{tabular}{|c|c|c|c|c|c|c|}
\hline & (1) & $(2)$ & (3) & (4) & (5) & (6) \\
\hline & \multicolumn{6}{|c|}{ Bandwidth } \\
\hline & 9 & 8 & 7 & 9 & 8 & 7 \\
\hline & \multicolumn{3}{|c|}{ With Control Variables } & \multicolumn{3}{|c|}{ Without Control Variables } \\
\hline & \multicolumn{6}{|c|}{ Panel A: Partners are from the same childhood province } \\
\hline \multirow[t]{3}{*}{ Reform } & 0.000 & -0.002 & -0.001 & -0.005 & -0.009 & -0.011 \\
\hline & $(0.030)$ & $(0.032)$ & $(0.034)$ & $(0.034)$ & $(0.036)$ & $(0.038)$ \\
\hline & [0.990] & [0.951] & [0.962] & [0.712] & {$[0.556]$} & {$[0.507]$} \\
\hline \multirow[t]{2}{*}{ Observations } & 4,733 & 4,331 & 3,874 & 4,733 & 4,331 & 3,874 \\
\hline & \multicolumn{6}{|c|}{$\begin{array}{l}\text { Panel B: Partners are from the same childhood province and the same } \\
\text { type of childhood settlement }\end{array}$} \\
\hline \multirow[t]{3}{*}{ Reform } & -0.006 & 0.016 & 0.034 & -0.007 & 0.011 & 0.028 \\
\hline & $(0.028)$ & $(0.030)$ & $(0.032)$ & $(0.032)$ & $(0.034)$ & $(0.036)$ \\
\hline & [0.842] & [0.497] & [0.0844] & [0.664] & [0.783] & {$[0.220]$} \\
\hline Observations & 4,733 & 4,331 & 3,874 & 4,733 & 4,331 & 3,874 \\
\hline
\end{tabular}

The sample includes women whose partners live in the same household. The Reform variable is equal to one if the respondent was born between 1987 and 1994 and equal to zero if the respondent was born between 1978 and 1985. The 1986 cohort is excluded from the sample as exposure to the reform is unclear for this cohort. The entries in (parentheses) are standard errors of the estimated coefficients, clustered by childhood region-by-birth cohort; ${ }^{*} \mathrm{p}<0.1 * * \mathrm{p}<0.05$ $* * * \mathrm{p}<0.01$. P-values, related to bootstrapped standard errors clustered by birth cohort, are given in [square brackets]. All regressions control for trend in the outcome variable separately for treatment and control groups, region of current residence and region of childhood fixed effects, an indicator if the person grew up in a village, and the interaction between the latter two variables, an indicator if the person speaks a second language, and the interaction of second language with region of residence fixed effects. 